University of Louisville

ThinkIR: The University of Louisville's Institutional Repository

Electronic Theses and Dissertations

$12-2008$

\title{
Quantifying the costs and benefits of product variety on key performance measures-a simulation study.
}

Trivikram H. Rao

University of Louisville

Follow this and additional works at: https://ir.library.louisville.edu/etd

\section{Recommended Citation}

Rao, Trivikram H., "Quantifying the costs and benefits of product variety on key performance measures-a simulation study." (2008). Electronic Theses and Dissertations. Paper 1180.

https://doi.org/10.18297/etd/1180

This Master's Thesis is brought to you for free and open access by ThinkIR: The University of Louisville's Institutional Repository. It has been accepted for inclusion in Electronic Theses and Dissertations by an authorized administrator of ThinkIR: The University of Louisville's Institutional Repository. This title appears here courtesy of the author, who has retained all other copyrights. For more information, please contact thinkir@louisville.edu. 


\title{
QUANTIFYING THE COSTS AND BENEFITS OF PRODUCT VARIETY ON KEY PERFORMANCE MEASURES-A SIMULATION STUDY
}

\author{
By
}

\section{TRIVIKRAM H RAO}

B.E., SDM College of Engineering and Technology, 2006

\author{
A Thesis \\ Submitted to the Faculty of the \\ Graduate School of the University of Louisville \\ In Partial Fulfillment of the Requirements \\ For the Degree of \\ Master of Science \\ Department of Industrial Engineering \\ University of Louisville \\ Louisville, KY \\ December 2008
}


QUANTIFYING THE COSTS AND BENEFITS OF PRODUCT VARIETY ON

KEY PERFORMANCE MEASURES-A SIMULATION STUDY

By

TRIVIKRAM H RAO

B.E., SDM College of Engineering and Technology, 2006

Thesis approved on

December 02, 2008

By the following thesis committee

Dr. Sunderesh S. Heragu, Thesis Director

Department of Industrial Engineering

Dr. Gerald Evans, Co-Advisor, Department of Industrial Engineering

Dr. Adel S. Elmaghraby, External Advisor

Computer Engineering and Computer Science department 


\section{ACKNOWLEDGEMENTS}

I would like to thank my advisors Dr. Sunderesh S. Heragu and Dr. Gerald Evans for all their time, guidance and patience. Their continuous encouragement and understanding was a key factor in the completion of this thesis. Also, I would like to thank my external advisor Dr. Adel S. Elmaghraby for his comments and assistance. I express my thanks to Emcien Corporation, for funding this project. Last but not the least, I would like to thank my family and friends, faculty and staff at the Department of Industrial Engineering for their constant support during the completion of this thesis. 


\title{
ABSTRACT
}

\section{QUANTIFYING THE COSTS AND BENEFITS OF PRODUCT VARIETY ON KEY PERFORMANCE MEASURES-A SIMULATION STUDY}

\author{
TRIVIKRAM H RAO \\ December 02, 2008
}

In today's market customers are increasingly demanding a greater number of options in the products they purchase. Offering products in greater variety helps industries cater to a wider range of customers. However, at the same time, this product proliferation is creating new problems for manufacturers. The effect of an increase in the variants of a product on the supply chain and production operations is largely unknown. Understanding this affect along with the benefits of increased product variety on the company's market share would greatly assist industries in making a return on investment analysis.

In this thesis, we develop a simulation model of the production operations of a typical manufacturing company, and study the effect of changing product variety on these operations. This is done by determining the variation in the key performance indicators (KPIs) such as product cycle time, work-in-process (WIP) 
and resource utilization when changes are made to the variety of the products manufactured.

This thesis consists of three simulation models representing three different scenarios in a manufacturing environment. The models built using the simulation software-ARENA, compare the three production strategies employed to cater to the current variety and when new variety is added to the current mix. The first model represents the current manufacturing design. The model parameters and outputs were compared with the real manufacturing setting to make sure it is consistent. The second model represents a scenario where changes and additions are made to the initial design, to meet the production requirements of the new product mix. No changes are made to accommodate the takt time requirements of the customer. In the third simulation model design changes are made so as to meet takt time requirements and thus satisfy the required throughput rules. The three models are then compared to see which one performs the best in terms of meeting customer requirements and KPIs. Based on the results we believe that changing product variety can have a significant impact on an industry's manufacturing operations and significant investments might be required to mitigate these effects. 


\section{TABLE OF CONTENTS}

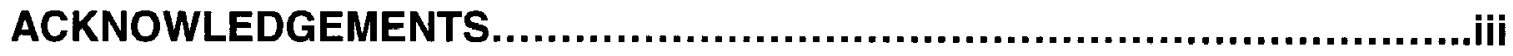

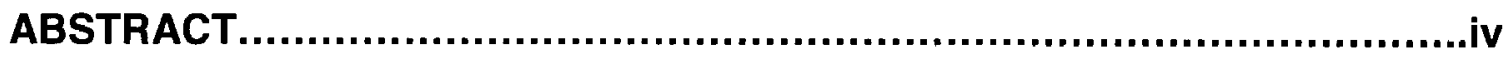

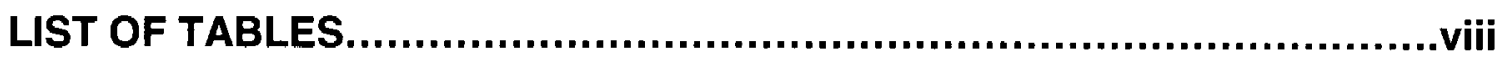

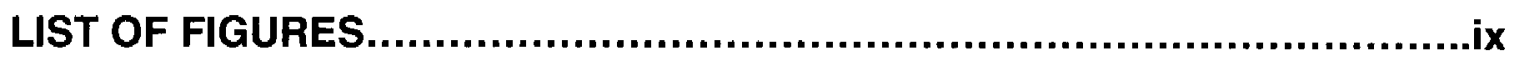

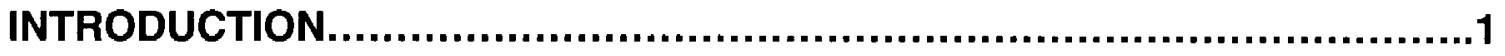

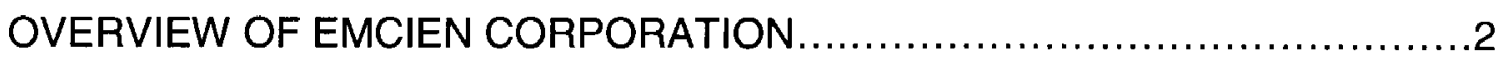

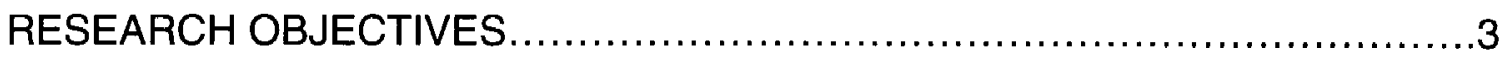

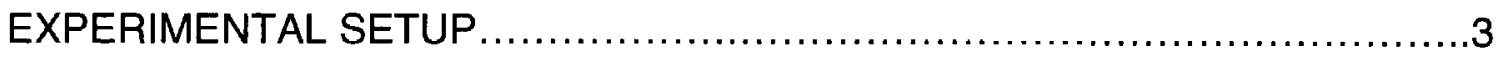

LITERATURE REVIEW.............................................................8

FINDINGS FROM LITERATURE REVIEW ................................... 16

OPERATIONS MODEL I..........................................................18

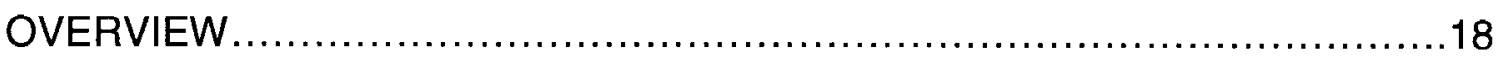

MODELING ASSUMPTIONS ................................................. 18

MODEL CONSTRUCTION AND APPROACH...............................19

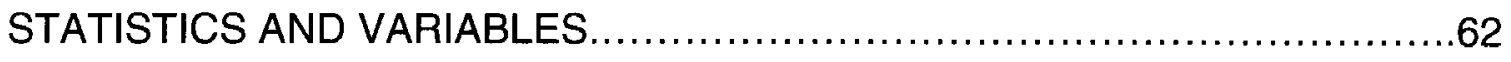

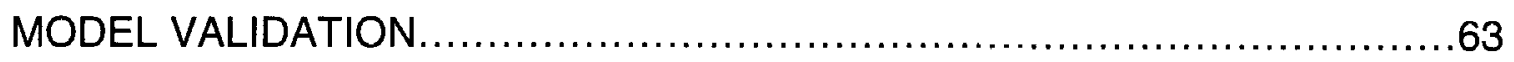

OPERATIONS MODEL II..........................................................66

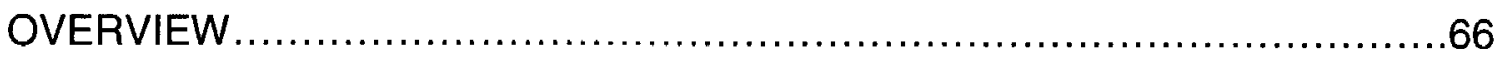

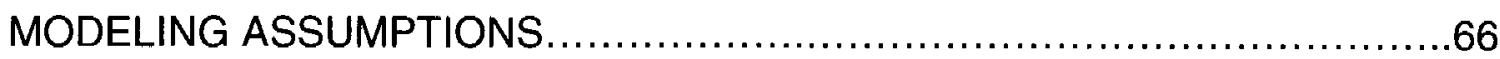




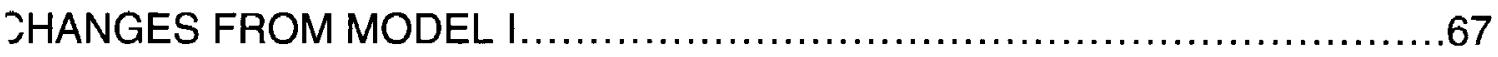

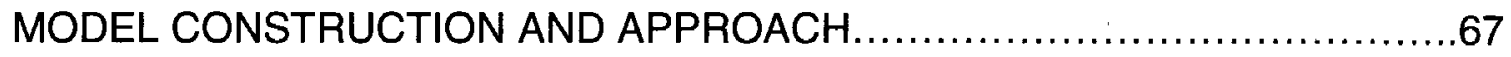

OPERATIONS MODEL III..............................................................79

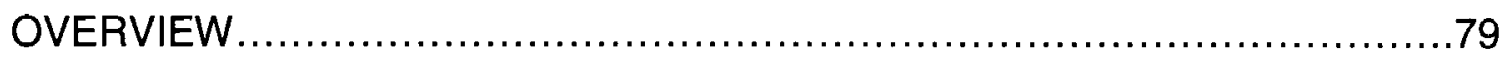

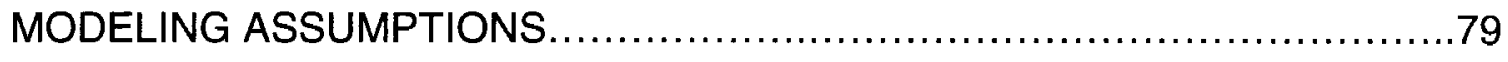

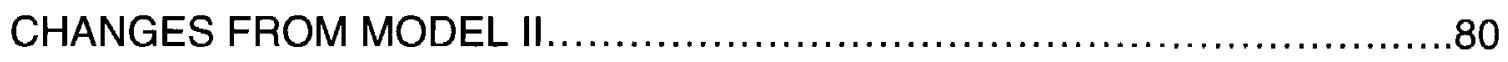

MODEL CONSTRUCTION AND APPROACH.................................80

DETERMINATION OF WARM UP PERIOD .................................... 84

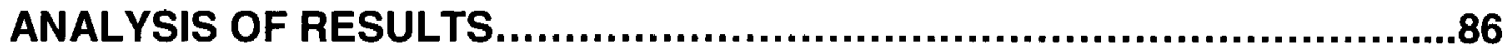

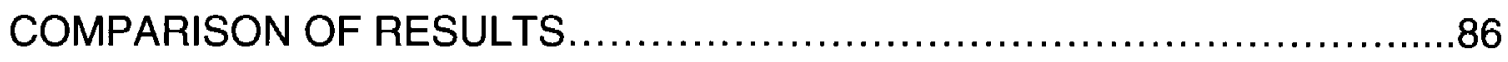

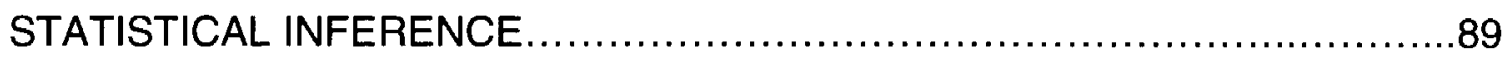

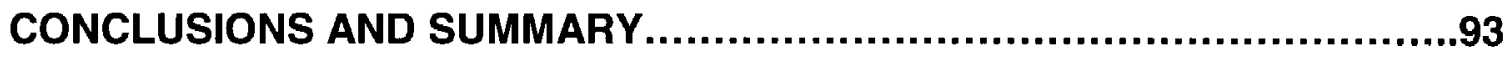

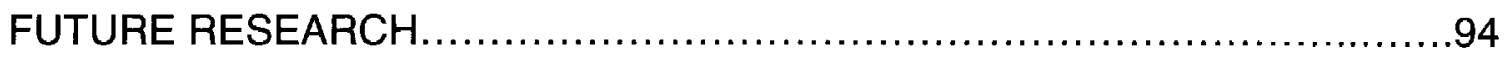

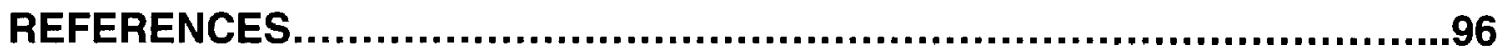

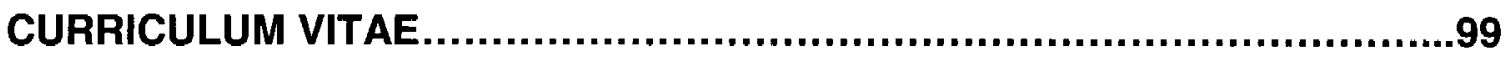




\section{LIST OF TABLES}

1. Downtime Data for Model 1 Resources................................61

2. Manufacturing Line: Monthly Production Data............................63

3. Model 1: Equipment Utilization Data...................................64

4. Manufacturing Line: Monthly Utilization Data...........................64

5. Model 1: First Piece Yield Data..........................................65

6. Manufacturing Line: First Piece Yield Data..............................65

7. Model 2: Downtime Data................................................

8. Model 3: Downtime Data.............................................. 84

9. Average Output Data for Entities........................................

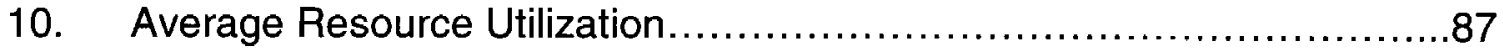

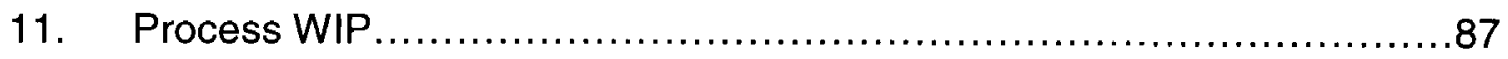

12. Average Operation Total Times.........................................88

13. Average Time Allocation for Manufactured Entities.......................88

14. Average Spare Tires in Inventory During Process.......................89

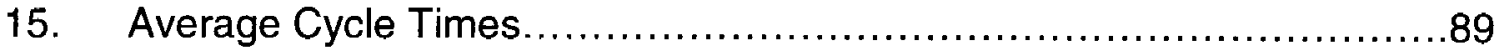




\section{LIST OF FIGURES}

1. Process Flow Description.....................................................

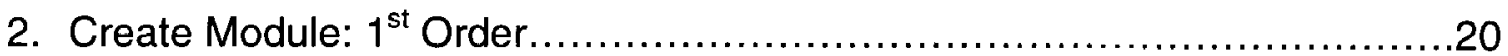

3. ReadWrite Module: Read Order Data....................................20

4. File Module: Assembly Orders1 ........................................21

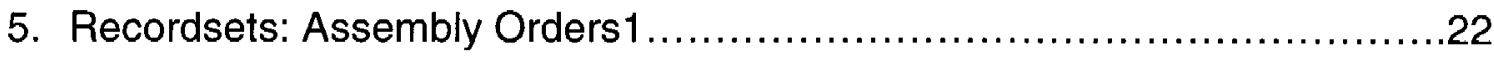

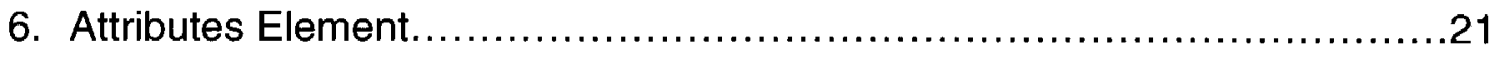

7. Assign Module: Assign Assembly Characteristics.........................22

8. Record Module: Record Orders Processed .................................22

9. Dispose Module: Order Manufactured...................................23

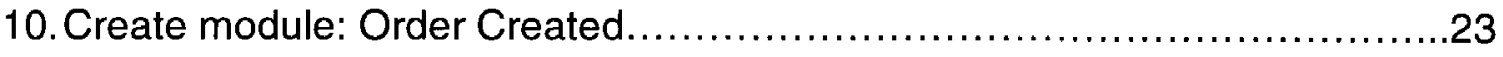

11. Hold Module: Hold Order......................................................24

12. Remove module: Place Next Order.......................................24

13. Assign Module: Update Manufactured Quantity .............................25

14. Order Generation Submodel..............................................25

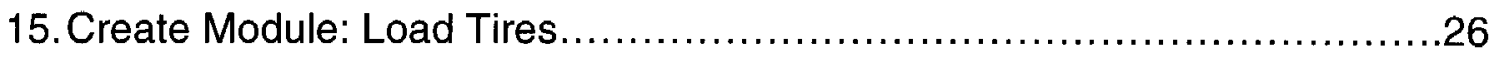

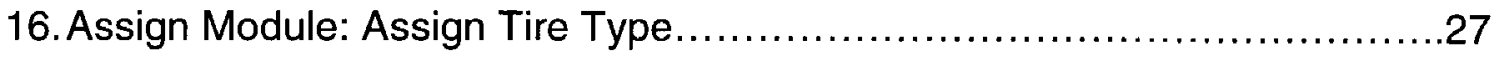

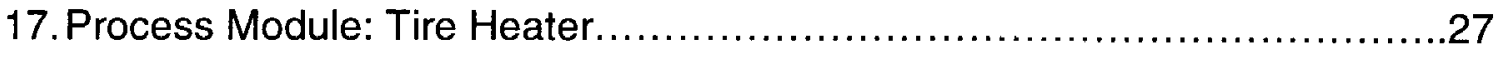

18. Process Module: Tire Soaper..............................................28 
19. Process Flow Chart of Tire Line Operations Submodel.........................28

20. Create Module: Load Wheel..............................................29

21. Assign Module: Assign Tire Type........................................30

22. Decide Module: Road or Spare Wheel...................................30

23. Process Module: Load Stem.................................................31

24.Process Module: Load TPM................................................32

25. Process Module: TPM Scan and Torque..................................32

26. Process Module: Wheel Orient.............................................33

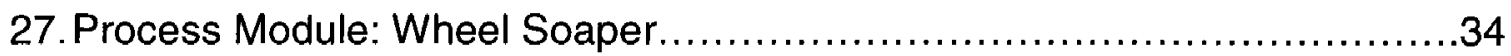

28. Wheel Line Operations Submodel........................................

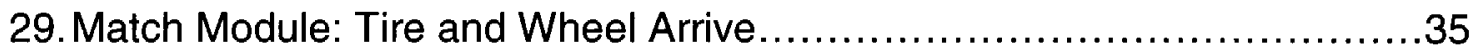

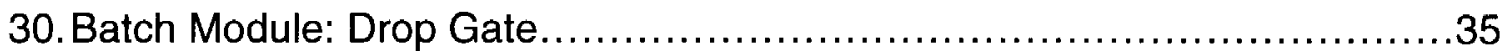

31.Process Module: Mount Tire on Wheel........................................36

32. Process Module: Match Mark High Point with Low Point......................36

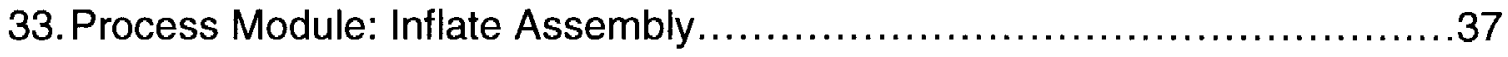

34. Assembly and Inflation Submodel.......................................37

35. Decide Module: Road or Spare Assembly ..................................38

36. Decide module: Spare Assembly Good ......................................39

37. Decide Module: Check Spare Manufactured Quantity........................39

38. Record Module: Record Spare Assemblies Manufactured..................40

39. Record Module: Average Spare Tires in Inventory ..........................40

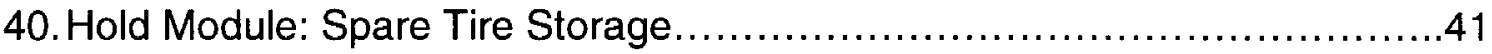

41. Record Module: Record Spare Assemblies Sent for Rework...............41 
42. Record Module: Record Spare Assemblies Scrapped.

43. Dispose Module: Spare Assembly Scrapped...............................42

44. Spare Assembly operations Submodel...................................42

45. Process Module: Load Simulator........................................43

46. Decide Module: Transfer Assembly for RFV Testing......................44

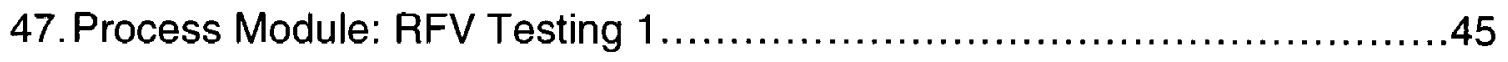

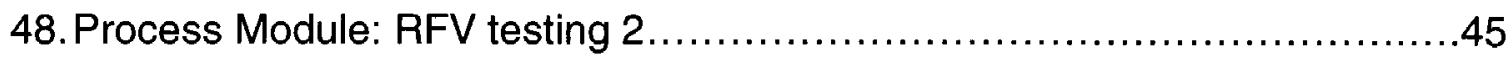

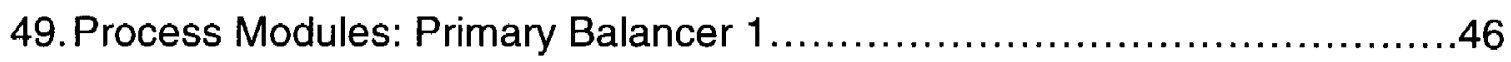

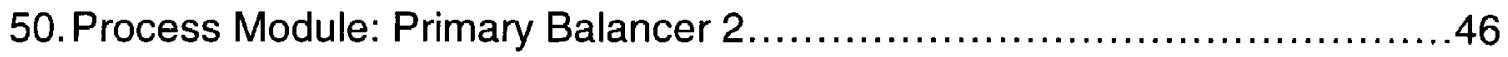

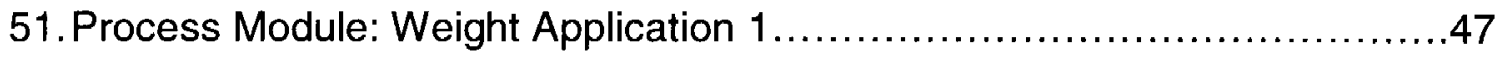

52. Process Modules: Weight Application $2 \ldots \ldots \ldots \ldots \ldots \ldots \ldots \ldots \ldots \ldots \ldots \ldots . \ldots \ldots$

53.Process Module: Audit Balancer........................................48

54. Process Modules: TPM Retorque and ID...............................49

55.Decide module: Road Assembly Good ....................................49

56. Assign Module: Count Number of Assemblies Manufactured...............50

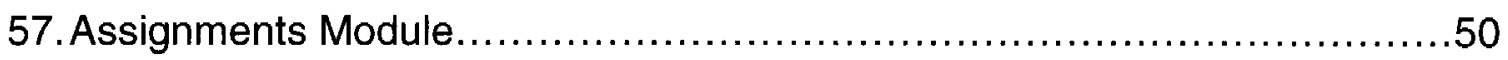

58. Record Module: Record Road Assemblies Manufactured...................51

59. Decide Module: Check Manufactured Quantity ...........................51

60. Record Module: Record Road Assemblies Sent for Rework.................52

61. Record Module: Record Road Assemblies Scrapped ........................52

62. Dispose Module: Assembly Scrapped ...................................52

63. Road Assembly Inspection Process Submodel.............................53

64. Separate Module: Split Assembly Into Tire and Wheel.....................54 
65. Batch Module: Road Tire Set..............................................55

66. Scan Block: Check Availability of Spare Tire ...............................55

67. Remove Module: Pick Up Spare Tire .....................................56

68. Match Module: SpareTire matched with Road Tires......................56

69. Batch Module: 4 Road Tires and 1 Spare Tire............................. 57

70. Process Module: Full Set and Stock......................................57

71.Process Module: Film Application .........................................58

72. Record Module: Count Total Assemblies Manufactured.......................58

73. Dispose Module: To Stacker............................................59

74. Final Sets and Storage Submodel.......................................59

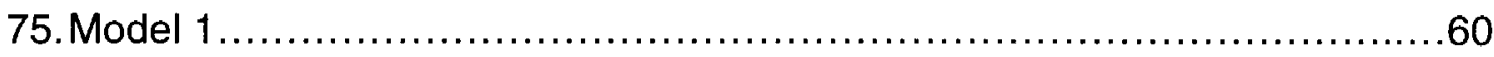

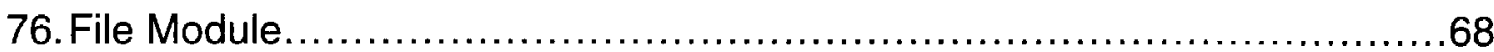

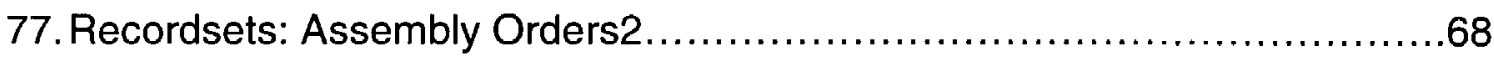

78. Decide Module: Check if 16 to 18 inch order...........................69

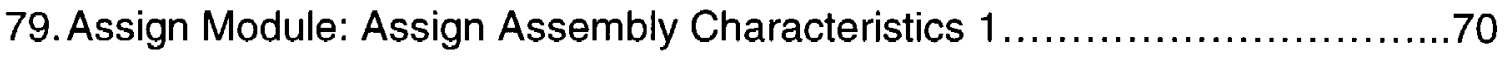

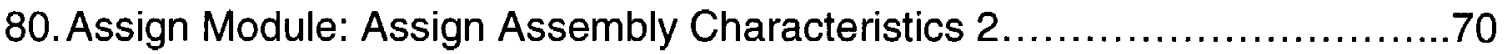

81. Order Generation Submodel...............................................

82. Decide Module: Check if 16 to 18 inch Tire................................72

83.Process Module: 16 to 18 inch Tire Soaper..................................72

84.Process Module: 19 to 20 inch Tire Soaper...............................73

85. Tire Line Operations Submodel.........................................73

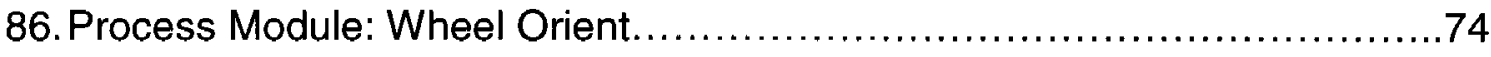

87. Process Module: Mount Tire on Wheel.......................................75 
88. Decide Module: Check if 16 to 18 inch Tire...............................75

89. Process Module: Inflate 16 to 18 inch Assembly..........................76

90.Process Module: Inflate 19 to 20 inch Assembly.............................77

91. Assembly and Inflation Submodel..........................................77

92. File Module: Read Order Data.............................................8

93. Assign Module: Assign Assembly Characteristics $1 \ldots \ldots \ldots \ldots \ldots \ldots \ldots \ldots \ldots 1$

94. Assign Module: Assign Assembly Characteristics $2 \ldots \ldots \ldots \ldots \ldots \ldots \ldots \ldots \ldots 1$

95. Road Assembly Inspection Process Submodel.............................83

96. Total Average Utilization for all 3 models ....................................85 


\section{CHAPTER I \\ INTRODUCTION}

With the globalization of consumer markets customers are receiving a wide array of choices for each product and each service they desire. Monopolies have almost ceased to exist, and industries can no longer take refuge in an environment where customers have to acquire products or services only from them. As a result of this competition between companies, customers are now able to choose from among many options. Companies are trying to compete with each other and thus survive in the market. One of the strategies they are adopting to achieve this is providing more and more options in every product to the customer. At the same time though, this increasing variety in the products is leading to what is known as product complexity. Every time a new variant is added to an existing product mix it impacts the entire facility. It makes an enormous impact on factors such as the production methods used, resource requirements and supply chain management. Much research is being conducted in various industries to determine the factors that lead to product complexity and on how these complications impact the production and supply chain operations of manufacturers and service providers. Various approaches that can be used to address product complexity in different scenarios are also being explored. 
In this research we have considered the scenario in a real time assembly company, which recently added new variants to the range of products it manufactures for its customer with full-fledged production to begin in a few months time. As a result of the introduction of this new variety to the existing mix, the company is planning to make many equipment and process changes to accommodate this new product, thus resulting in significant investments. Hence, the central idea of this research is to analyze the effects that changes to the existing variety can have on operational parameters such as production cycle times, resource utilization, WIP Inventory.

\section{OVERVIEW OF EMCIEN CORPORATION}

Emcien Inc. is an analytics software company that helps discrete manufacturing companies improve their profit margins by managing their product mix across their entire supply chain. Emcien provides unique on-demand solutions to product managers enabling them to monitor product configurations and feature mix options' popularity. Emcien breaks down the sales data of a company at the product option level, to establish the company's high and low demand configurations and the association between features that affect its profit margins.

With Emcien capturing the impact of product configuration on sales and market share, if the company could simultaneously evaluate the impact a change in the product variety would have on their production and supply chain 
operations, this would enable them to make a return on investment (ROI) analysis for the investments necessitated by the change in product mix.

\section{RESEARCH OBJECTIVES}

This Thesis develops and compares three simulation models representing different manufacturing scenarios. The first model corresponds to the current setting of the company and the other two models represent two different scenarios where design and equipment changes are made to the current set-up to accommodate new variety in the process which the company plans to add to its production line.

These three models are evaluated to determine under which conditions the assembly setting would perform better. This is achieved by comparing the KPIs for each process.

This method of comparison although used for assembly operations in this case, can be extended to different manufacturing and service industries by making required changes to operation parameters and KPls assessed.

\section{EXPERIMENTAL SETUP}

In order to ensure the reliability of the models created, the current setting was studied and data was collected on:

- $\quad$ Existing product variety and the new variants.

- Assembly process performance measures such as operation cycle times, downtimes, scrap rate, rework rate. 
- Changes due to introduction of new variant such as equipment changes and process modifications.

The data collected was analyzed and distributions were fit to processing times for all operations. The company gets tires, wheels and other required parts from external suppliers and assembles them in its plant, sequences them in the order the customer (automobile manufacturing company) requires and delivers it to them in a JIT method. The firm has already applied several lean principles such as JIT manufacturing, one-piece flow, pull system of ordering, zero set up times and modularization

The entire assembly process is depicted in the Process Flow Diagram in Figure 1. The operations performed on the assembly line are:

Order Generation (Not shown in Figure 1): The command to produce the next ordered configuration is generated in this step.

Tire Loading: The tires received from the suppliers are loaded on to the conveyers.

Tire Heater: Here the tire is heated to around $70-75^{\circ} \mathrm{F}$ to increase its elasticity and make the mounting process easier.

Tire Soap Application: Soap, a mixture of water and lubricant, is applied to the tire surface that comes in contact with the wheel. This is done to make the mounting process easier and avoid damage to the tire and wheel while mounting. Wheel Loading: The wheels received from the suppliers are loaded on to the conveyers. 


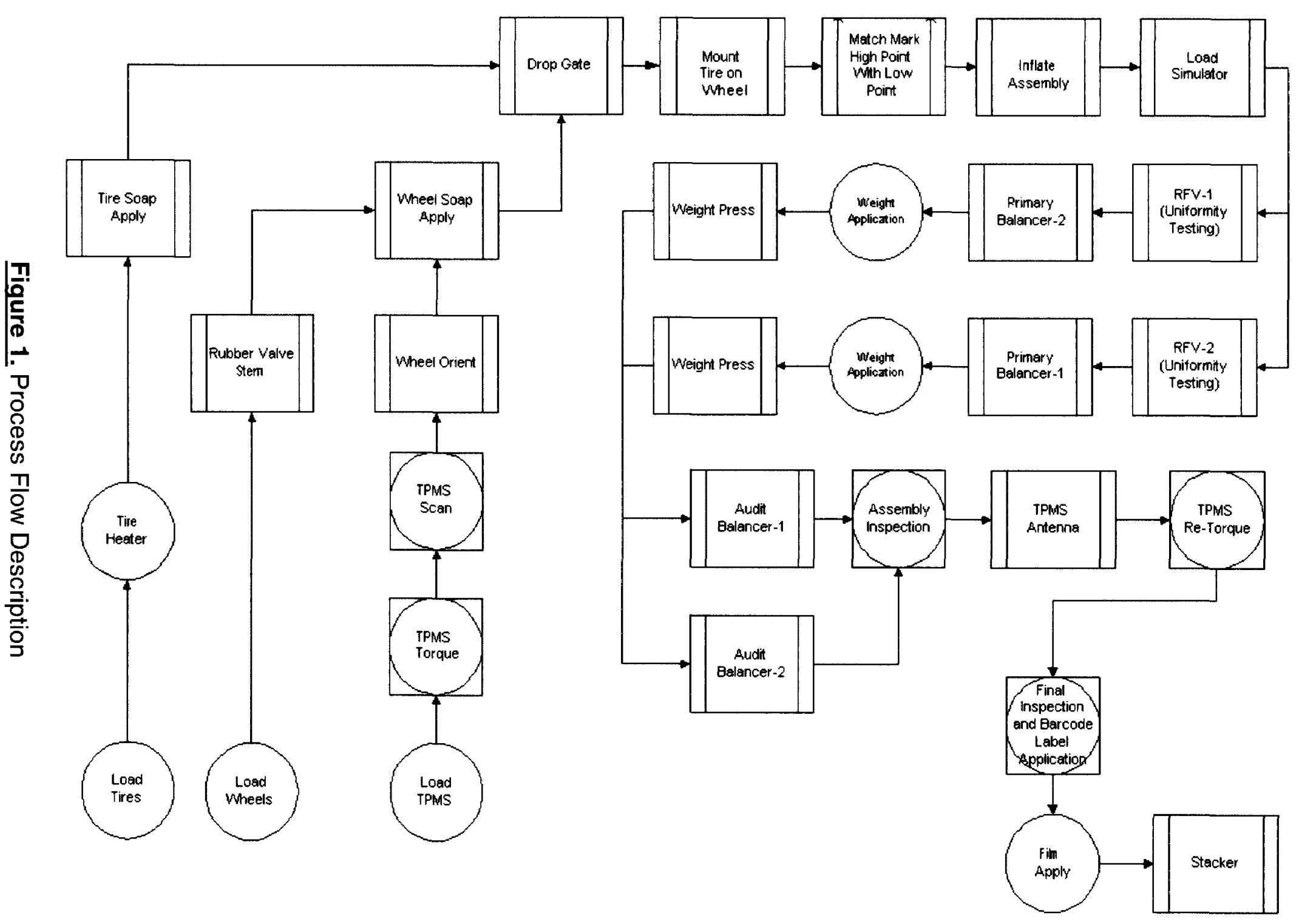


TPM/Rubber Stem Application: Here depending on if the tire is a road or spare tire, a tire pressure monitor (TPM) or rubber stem is loaded on to the wheel.

TPMS Torque: The TPMs are torqued to fit into the wheel properly.

Wheel Soap Application: Soap is applied to the wheel surfaces in a station before the drop gate.

Drop Gate: It is at this stage that the tire comes in contact with the wheel for the first time. Here the tire is placed on the wheel.

Mounting: In this operation the tire is mounted on the wheel

Matching: The high point of the tire is matched with the low point of the wheel and vice versa. This is done to minimize geometry variations within the assembly due to irregularities in the tire and wheel shape.

Inflation: Here the tire is inflated with air to the required pressure.

Spare Tire Operation (Not shown in Figure 1): Spare tire is sent to the spare tire inventory.

Load Simulator: The assembly is tested for uniformity of shape by simulating road conditions.

RFV (Radial Force variation) Testing: The assembly is tested for force variations in the radial direction due to irregularities in shape and air pressure in the assembly. There are two such units in the production line.

Primary Balancer: At this stage the assembly is tested for load exerted by the rotating assembly due to irregularities in weight of the tires and wheels. There are two Primary Balancers in the production line. 
Weight Application: Weights are applied on the wheel to correct the imbalance in load detected at the primary balancers. There are two Load application centers in the assembly line.

Audit balancers: The assemblies are again tested for imbalance after weight application.

Assembly Inspection and TPMS Re-torque: The assembly is checked for any irregularities and the TPM is re-torqued to account for any changes that might have occurred during assembly and testing.

Full Set and Barcode Application: Here the assembly is inspected once again and a barcode generated after scanning the TPM id is applied on the assembly for assembly identification.

Film Apply and Stacking: A plastic film is applied on one side of the assembly to prevent moisture from entering into the assembly. Finally the assemblies are stacked in sets of five (four road tires and one spare tire) and sent to the gantry from where they are sent to the customer.

Processing times for each of these operations were tabulated and distributions were fit to the data. 


\section{CHAPTER II}

\section{LITERATURE REVIEW}

In this chapter, we review past research on product complexity, its causes and effects. Also the various approaches researchers suggest and companies have taken to overcome Product Complexity issues are studied. We also note how simulation has been used as a tool in the past to analyze the impact product proliferation has on manufacturing related activities.

Randall and Ulrich (2001) define product variety as, "the number of different versions of a product offered by a firm at a single point in time." In other words, the greater the product variety, the larger is the number of options that are made available to the customer within a specific product.

Appelqvist (2005) gives a similar definition of product variety. Citing from a paper by Ulrich (1995) he defines product variety as the diversity of products that an operations system provides to the market place. He then makes it more specific by providing the classification of product variety as external product variety, internal product variety and technical product variety and then quoting their definitions from different researchers. External variety, as defined by Fisher and Ittner (1999), is the range of choice offered to customers and can be estimated by multiplying all possible features offered. Appelqvist (2005) gives Pil and Holweg's (2004) description of internal variety as the range of different variants that are handled in each production step. Technical variety, per Fujimoto 
et al. (2003), refers to the diverse design methodologies and manufacturing processes necessary to achieve product variety.

Product complexity is the overall complicatedness involved in the manufacture of a product or stipulation of a service. This product complexity results in the proliferation of products, parts and suppliers and multiplying of processes executed in the course of production of end goods (Garg et al, 1999).

Zhang et al (2003) define product complexity based on some common properties of complex systems identified by Simon (1962) namely hierarchy, interaction, and embedded coordination.

Child et al (1991) mention that high degrees of customizations, implementation of total quality control procedures and development of high powered information systems all end up creating highly complex businesses. They discuss some circumstances that can lead to complexity such as broader product lines, addition of multiple departments to the existing business system causing unbalanced hikes in product prices and structural factors such as multilayered decision making levels.

Child et al (1991) also observe that only around 20 percent of a typical company's products make up almost 80 percent of its sales and even though many companies attribute up to 30 percent of their costs to product variety, these investments result in an overall increase of only 3 percent in sales. They also identify some of the symptoms for identifying complexity in the system and classify them as physical and organizational symptoms. 
Sivadasan et al (2000) describe the ways in which increasing product variety translates into information complexity issues by investigating the various methods of information transfer among organizations. The authors suggest that customers transfer their complexity to suppliers by: making alterations to existing orders, varying initially ordered quantities, changing previous priorities, revoking orders, and revising specifications. Suppliers principally export complexity to clients through the transportation of material via inconsistent delivery quantities or lead times and end products with low quality.

Fisher et al (1999) conduct a series of experiments using data from a plant's production operations. The empirical analysis implied that product mix variability amplifies overhead hours, rework, inventory and the excess labor capacity assigned to workstations to provide slack against variability. From their analyses the authors conclude that option variability has a significantly greater negative impact on labor productivity than the average number of options.

Kekre and Srinivasan (1990) conducted research on the pros and cons of having high product variety over a sample of 1400 business units by examining the impact of 'product line breadth' on the various facets of marketing and production such as market share, manufacturing costs and profitability.

MacDuffie et al (1996) test the effect of product variety on plant performance measures such as labor productivity and consumer perceived product quality by considering four measures of product complexity namely model mix complexity, parts complexity, option content and option variability. They conclude that most of the product complexity measures do not have a 
negative impact on labor productivity or quality. They observed that there is a persistent and statistically significant negative effect of parts complexity on productivity and that lean production methods give plants the capability to handle the product variety more effectively.

Harrington (2006) states that, excessive complexity causes a "logistics double whammy"'. She suggests that process complexity results directly from the number of steps and inputs required to complete a process, which lets defects to creep into the supply chain.

Srinivasan and Swaminathan (1997) explain the various challenges faced by the computer manufacturing industries in areas such as planning and operations management due to increase in product variety. They describe the concept of a feature-based product line and the issues related to its operations such as forecasting, product transition, upgrading products, parts planning, final assembly and interplant coordination. They say that such issues make the production process more complex and thus increase operational expenses. Increase in product variety makes each product development project very complex, thereby aggravating the difficulty in estimating the resulting product content and time of volume production. They also list other factors impacted by increasing product variety such as pricing assessments, marketing and production synchronization, choosing of the right modular designs and quantity, position of components and final assembly plants and distribution centers.

Child et al (1991) advocate that to optimize the product variety offered, modularizing the product design, and simplification and standardization of the 
procedures and components used can be employed. This leads to higher quality, lower costs, and improved capacity utilization.

Srinivasan et al (1997) suggest that, to overcome the difficulties in maintaining a feature-based product Line, such as the uncertainty in demand, quick response to demand etc manufacturers are integrating functional constraints while designing the end product, delaying product differentiation during assembly, incorporating information sharing in the organization and across the supply chain, clustering products into product families or are exploiting similarities in components and manufacturing processes and using decision support tools for forecasting and parts planning. Using quantitative models and analyzing the process as stochastic, one can tackle difficulties in estimation of product content and production volumes. The authors direct the reader's attention to Dietrich et al's (1995) suggestion that parts planning problems can be assuaged by formulating them as linear programs for deterministic demands and Srinivasan et al's (1992) proposal to use stochastic programs with heuristic solutions for stochastic demands.

Fisher et al (1995) give a good general description of some of the approaches to handle product variety and manufacturing flexibility by studying the correlation of plant productivity with the measures of variety in the product mix. They studied the aspects of variety challenges, technical capabilities and organizational capabilities of the companies adapting different strategies such as mass production, craft production and lean production. The authors conclude by suggesting that product complimentarity can help attain throughput gains. They 
strongly support parts sharing across product classes and investing in flexible production systems. They advise that organizational flexibility can lead to better utilization of human resources and mitigate the need for in-process buffers. Also companies need a market strategy to successfully minimize "market defects", i.e. product varieties that customers do not want.

Yano and Rachamadugu (1991) try to address sequencing problems for jobs involving several combinations of product options on a paced assembly line (jobs arriving at the workstation at equal intervals of predetermined duration) so as to minimize the total work overload. The authors state that the integrity of a predetermined input sequence is difficult to maintain in practical situations because defects in some processes necessitate rework.

Pil and Holweg (2004) discuss the relation between internal variety (variety involved in creating the product) and external variety (variety offered to the customer) and the various strategies adopted in production-to-forecast and production-to-order environments to alleviate the undesired effects of increasing variety. The authors analyzed strategies such as mutable support structures, modularization, option bundling and late configuration adopted by manufacturers to alleviate the negative effects of variety.

Jina et al (1997) compare the features of high variety low volume (HVLV) systems with lean manufacturing companies. They give suggestions to tackle issues such as turbulence in schedule, product mix, volume and design, and management of manufacturing system with examples from various industries. 
Lee and Tang (1997) give a detailed explanation of three approaches to solve product complexity problems by redesigning the end user commodities or manufacturing procedures so as to delay the differentiation point so that the WIP inventory does not get entrusted to a particular finished product until later stages of the process. The three approaches described are: standardization, modularization of design and reorganizing the process structure.

Novak and Eppinger (2001) exhibit the relation between product complexity and vertical integration of production using empirical data from automobile manufacturing firms.

Randall and Ulrich (2001) analyze the association between product variety and supply chain makeup and the impact of corresponding product variety with supply chain structure on firm performance. They say that two types of costs are induced by variety: production costs and market mediation costs. Corresponding to these two types of costs they classify variety as production dominant variety and mediation dominant variety.

Loveland, Monkman and Morrice (2007) explain a new production scheduling algorithm adopted by Dell Inc. to overcome the problem of degradation in production rates in a manufacturing center designed to support its "assemble-to-order" business model. This helped limit the increase in the number of set-ups and thus avoided degradation of production rates by an anticipated $20 \%$ due to the doubling of production variety and a projected increase in 
demand by $13 \%$. It also helped accomplish an effective production volume increase of over $35 \%$.

Danese and Romano (2005) describe how they developed and implemented a method of using planning bills and modularization of products to tackle high product variety and recurrent product alterations for Finn-Power Italia from Scandinavia.

Tynjala and Eloranta (2007) analyze the effect of product variation and demand distributions over the demand supply network. The 5 DSN Analysis methods they mention are: optimization, analytic hierarchy processes, control theory, discrete event simulation and petri net. From their analysis, they suggest that the fewer the variants in a product, the more constructive it is for final assembly.

Swaminathan and Nitsch (2007) in their paper refer to the role of the location of sequencing point of components in the manufacturing environment in catering to product variety. The authors define and describe the four ways a sequencing point can be positioned in the manufacturing facility depending on the product variety and structure and the lead time constraints and discuss the advantages, disadvantages and the various limitations posed on these sequencing points such as space feasibility, cycle time feasibility, selection feasibility and lead-time constraints. The authors conclude that we might be able to use discrete event simulation and analytical modeling to come up with a model to optimize the location of the sequencing point. 
Yee (2002) demonstrates the use of simulation to build an order-todelivery (OTD) model. The important factors influencing the supply chain complexity are the number of merchandizing models and optional parts. He tests the effect of varying these on parameters such as customer wait time, conditions mismatch, and operational parts usage.

Mahendrawathi et al (2006) use a simulation model of the supply chain system of a multi-national company to analyze the effect of increasing product variety on supply chain performance. From their analysis they determined that an increase in product variety has a detrimental impact on flow times and inventory for systems with high lead times and demand uncertainty resulting in poor supply chain performance.

\section{FINDINGS FROM LITERATURE REVIEW}

It is evident from the review of existing literature that changing product variety has been an area of focus for a considerable period of time. Various approaches have been tried to analyze the impact of increasing product variety on industry performance with special focus on the supply chain and information complexity. Child et al (1991) and Sivadasan et al (2000) explain how changing product mix impacts the business as a whole and by the addition of more processes and departments and increased information handling makes it more complex. Fisher et al (1999), Kekre and Srinivasan (1990) and Mac Duffie et al (1996) analyze the effect of product variety on Production Performance 
measures such as productivity, rework rate, manufacturing costs and product quality.

Fisher et al (1995) suggests several lean and other strategies most manufacturing companies can adopt to mitigate product variety effects. Fisher et al (1995) concentrate mainly on production strategies while Harrington (2006), Srinivasan et al (1997) and Swaminathan and Nitsch (2007) examine how product complexity issues can be assuaged in the supply chain.

A number of methods such as discrete time models (Lee and Tang (1997)), mathematical programming (Yano and Rachamadugu (1991)), scheduling algorithms (Loveland et al (2007)) and planning bills (Danese and Romano (2005)) have been used to establish and solve production issues due to product variety. Also, computer simulation is widely used to evaluate supply chain complexity and the influence of product mix variation on it (Yee (2002) and Mahendrawathi et al (2006)).

Simulation has not been used extensively to investigate the impact of changing product variety on production operations. Use of simulation models in determining this effect will help companies analyze the impact of adding or eliminating variants to a production line. 


\section{CHAPTER III OPERATIONS MODEL I}

\section{OVERVIEW}

Model 1 represents the current manufacturing scenario in the plant. The simulation model is built in Arena as a discrete-event, stochastic model. In the current setting the plant manufactures 32 different types of tire wheel assemblies. The 32 variations are combinations of different types of 16 and 17 inch tires and wheels with varying parameters such as material composition, design, etc. The plant runs for 20 hours a day and five days a week. The simulation is run for 10 replications and each replication length equal to 200 days.

\section{MODELING ASSUMPTIONS}

The following assumptions are made in the simulation model

- Order schedule is not subject to change

- No set up times for different varieties

- The same type of spare tire is used for all assembly sets

- Spare tire storage has unlimited capacity

- All spare tires use rubber stems and all road tires use TPMs

- Processing times are the same for 16 and 17 inch tires

- Cumulative scrap/rework rate is used for assemblies for all operations 
- Infinite supply of tires, wheels and other parts is assumed

- Equipment downtime due to maintenance has been ignored

- Infinite queue lengths are allowed at all processes. In reality, queue lengths are finite resulting in downtimes due to line stoppages when queue holding capacity is reached. These have been ignored

- Transfer times between stations have been ignored

- The order of processing is first-in-first-out (FIFO)

\section{MODEL CONSTRUCTION AND APPROACH}

Features from the basic and advanced process modules and the blocks module are used. The following sections describe the construction of Model 1.

\section{ORDER GENERATION SUBMODEL}

The orders for Road and Spare Assemblies are created in this Submodel.

Create Module: $1^{\text {st }}$ Order

The " $1{ }^{\text {st }}$ Order" Create module generates the first order to start the process. This module creates only one entity and then stops. This module was created only to supplement the actual order generating Create module- "Order Created" (explained later) so that the condition in the Hold module-"Hold Order" (explained later) can be accommodated. 


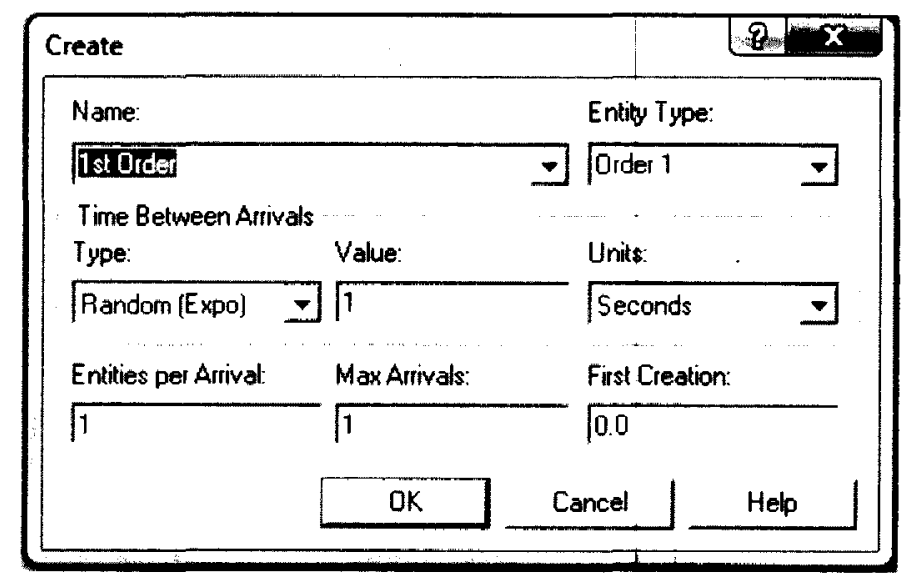

Figure 2. Create Module: $1^{\text {st }}$ Order

ReadWrite Module: Read Order Data

The details of the order are read from an excel file by the ReadWrite module. The parameters read are Order Number, Assembly Type, Order Quantity, Tire Type and Wheel Type.

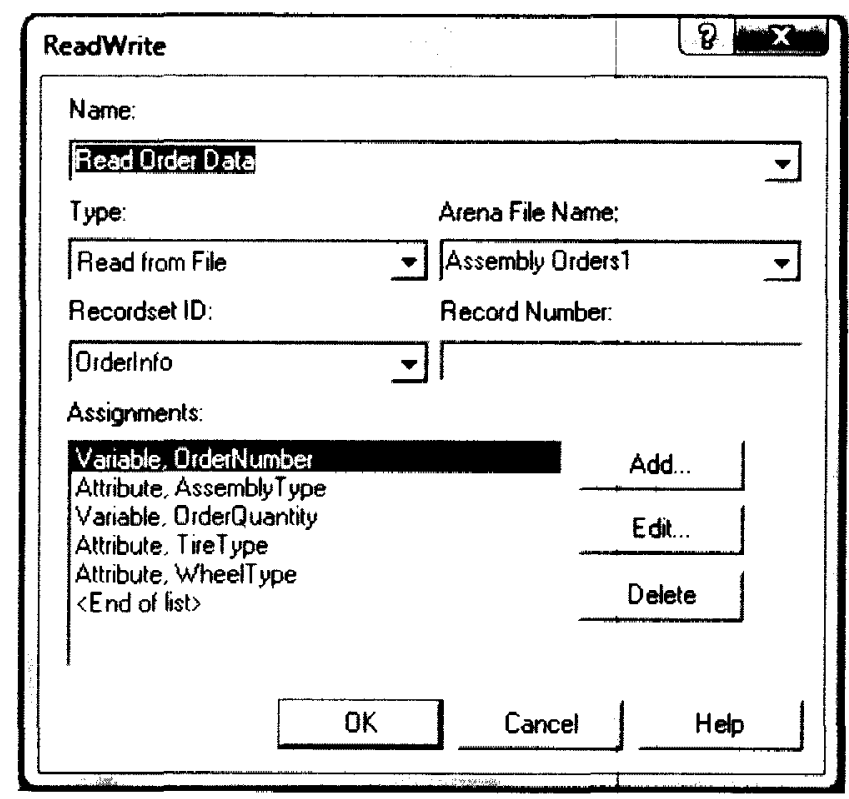

Figure 3. ReadWrite Module: Read Order Data 
The file module, "Assembly Orders1" stores the excel file location.

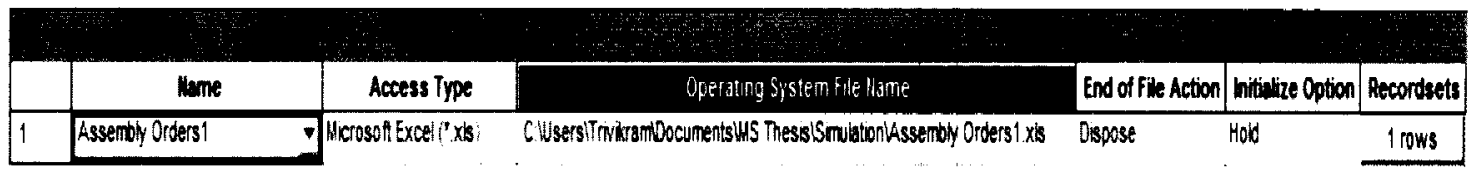

Figure 4. File Module: Assembly Orders1

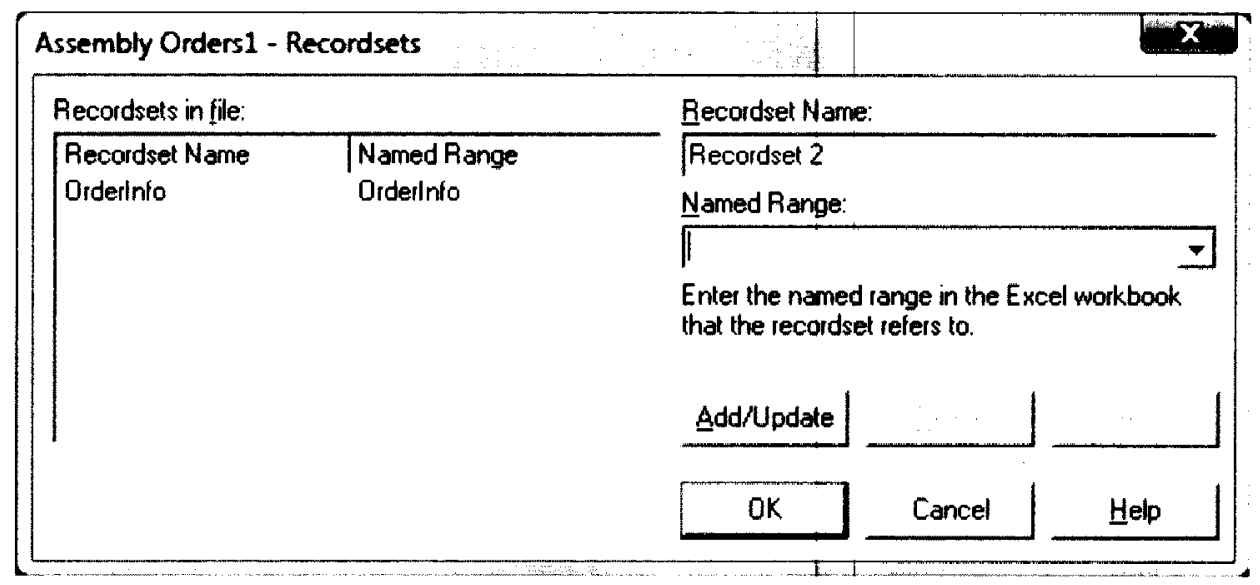

Figure 5. Recordsets: Assembly Orders1

An Attributes Element is used with the ReadWrite module to define some attributes in the ReadWrite module as "Strings" to allow non numerical data.

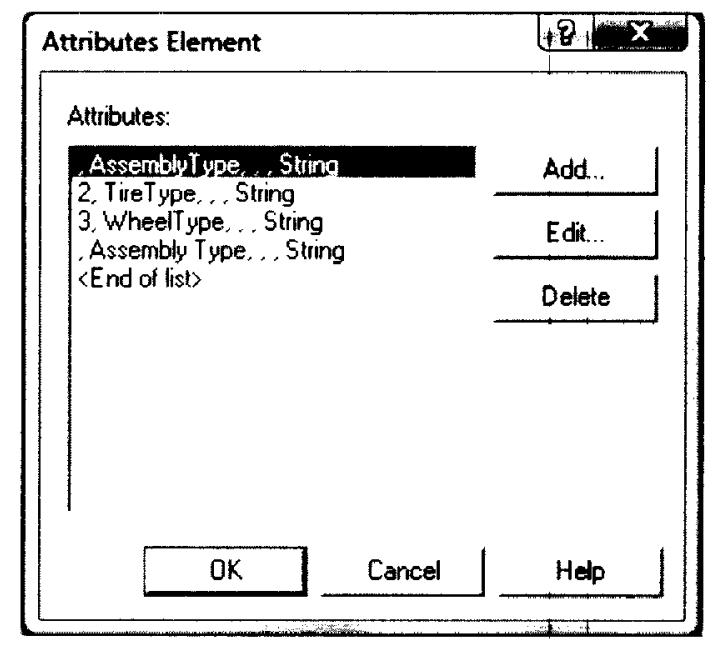

Figure 6. Attributes Element 
Assign Module: Assign Assembly Characteristics

This assigns a "zero" value to the current quantity manufactured.

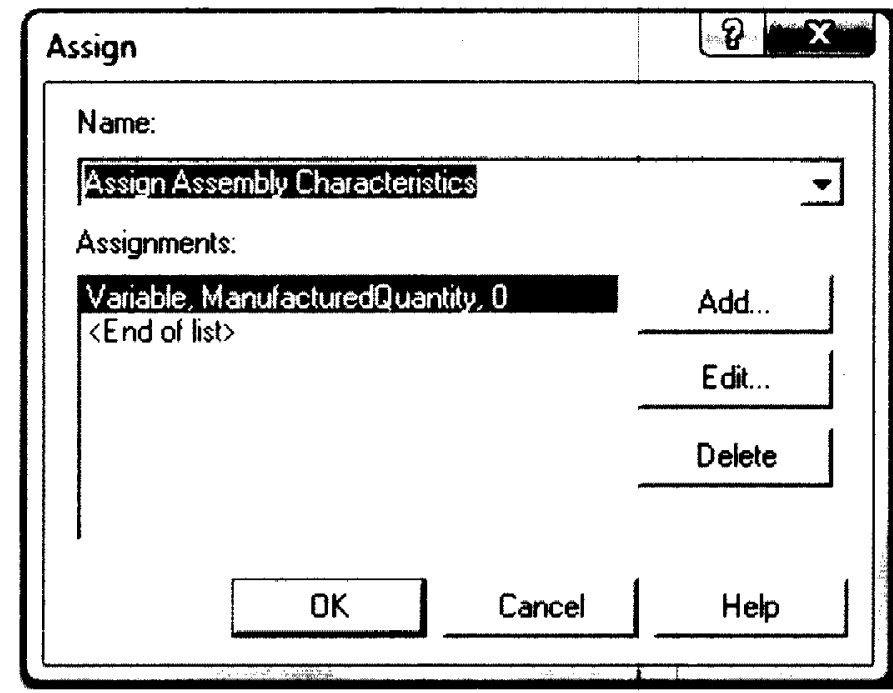

Figure 7. Assign Module: Assign Assembly Characteristics

Record Module: Record Orders Processed

This module records the number of orders generated throughout the simulation and gives a total count of orders processed at the end of the run.

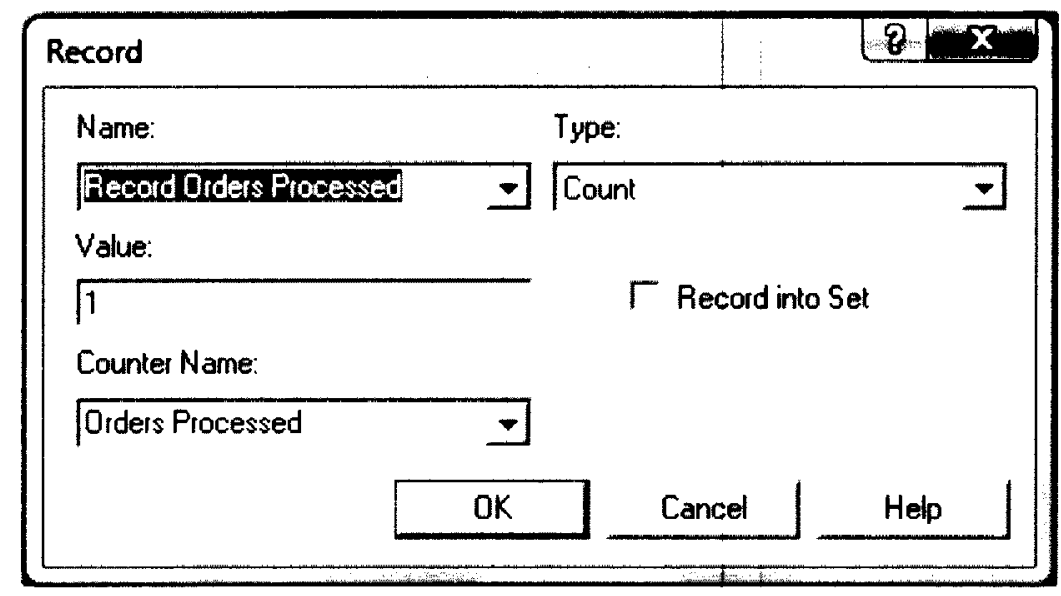

Figure 8. Record Module: Record Orders Processed 
Dispose Module: Order Manufactured

The order generated finally leaves the system through this module.

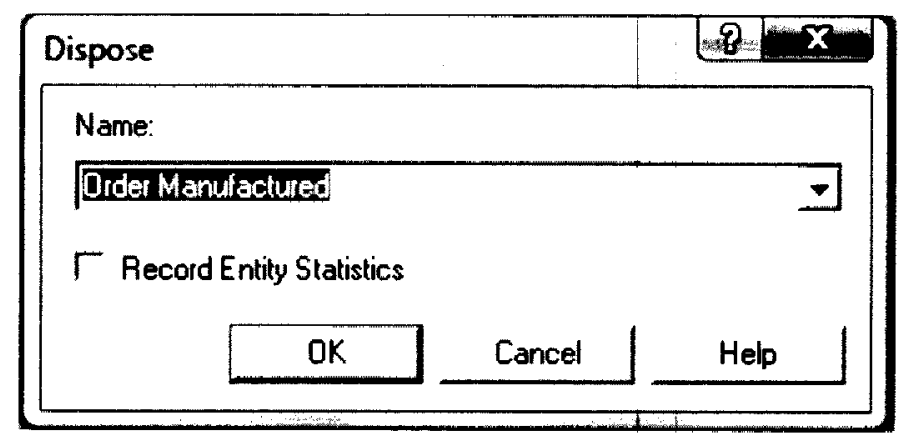

Figure 9. Dispose Module: Order Manufactured

Once the required number of assemblies are created, tested and sent to the stacker, the next order is generated and processed as follows:

Create module: Order Created

After the " 1 st Order" module creates the first order to initiate the system, this module creates the remaining orders at one every minute. The time required to complete order processing is stochastic and cannot be pre-determined due to varying parameters such as order quantities, processing times and downtimes.

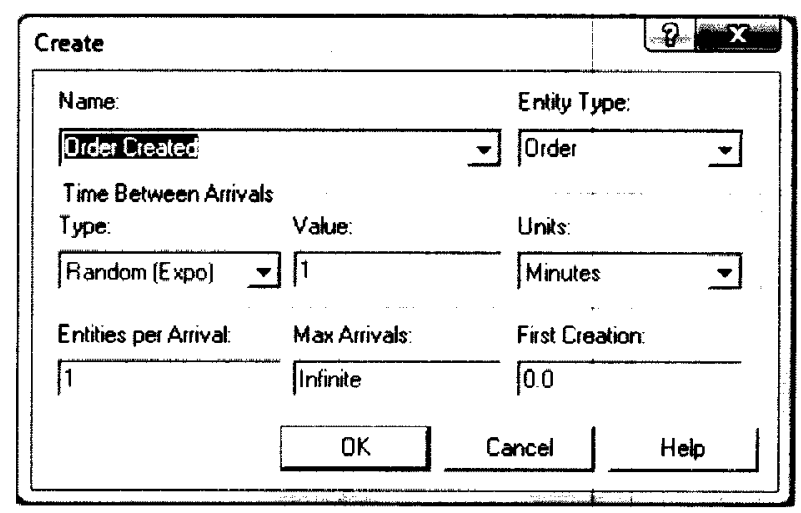

Figure 10. Create module: Order Created 
Hold Module: Hold Order

This holds orders generated in the "Order Created" module. The type of hold is defined as "Infinite Hold" as the order generated cannot be sent until the number of assemblies required per the previous order is processed.

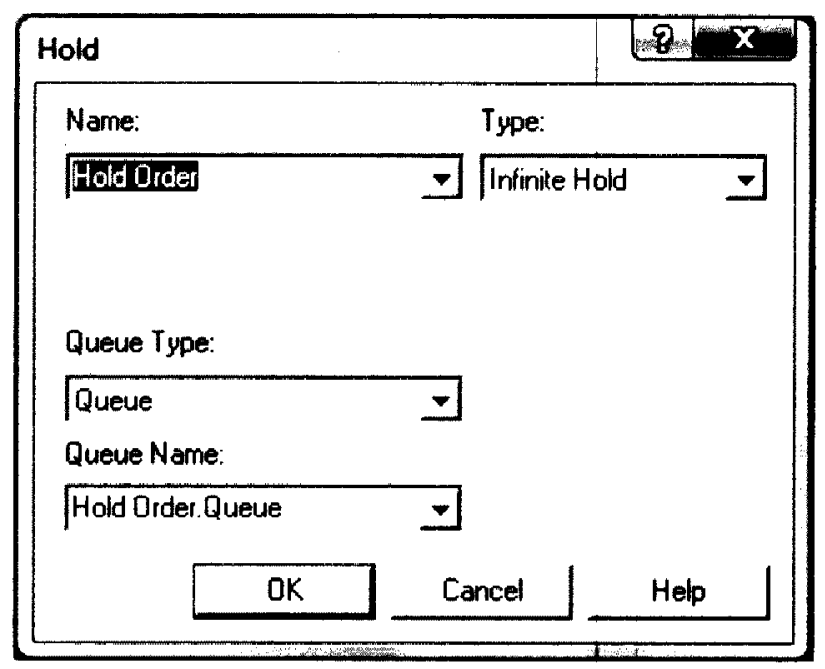

Figure 11. Hold Module: Hold Order

Remove module: Place Next Order

Once assemblies required by the current order are created, a signal sent to this module removes and places the next order from the "Hold Order" Module.

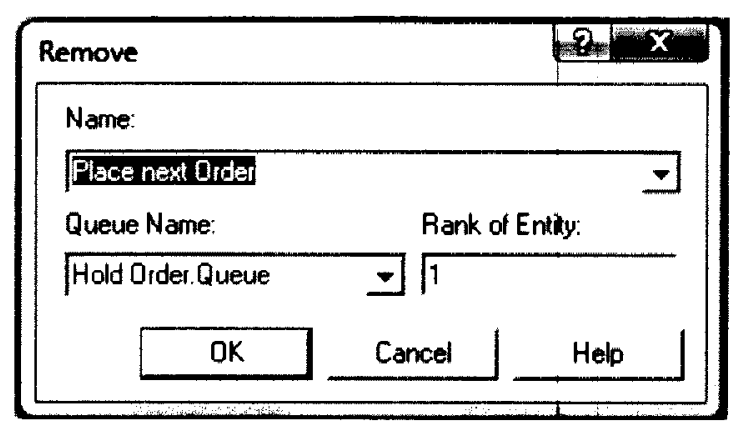

Figure 12. Remove module: Place Next Order 
Assign Module: Update Manufactured Quantity

The entity that is used to send a signal to this module also updates the variable "Manufactured Quantity" to zero for the new order through the "Update Manufactured Quantity" Assign Module and exits the system.

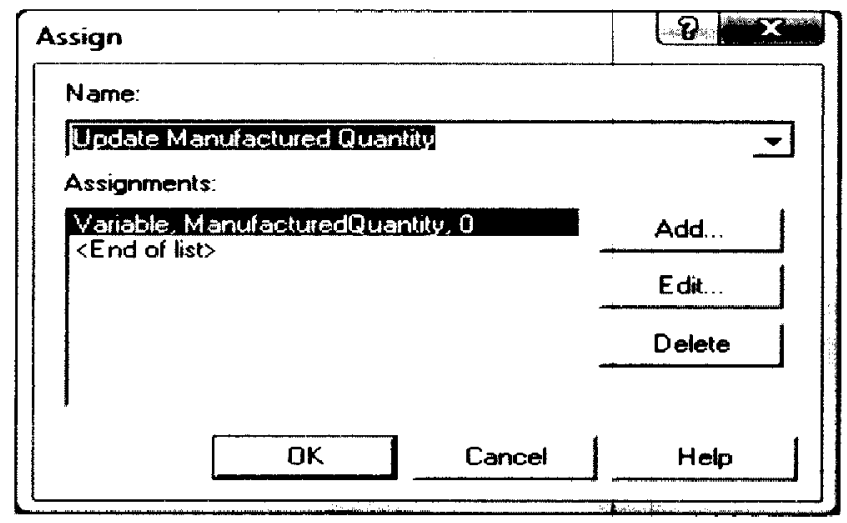

Figure 13. Assign Module: Update Manufactured Quantity

\section{PROCESS FLOWCHART OF ORDER GENERATION SUBMODEL:}

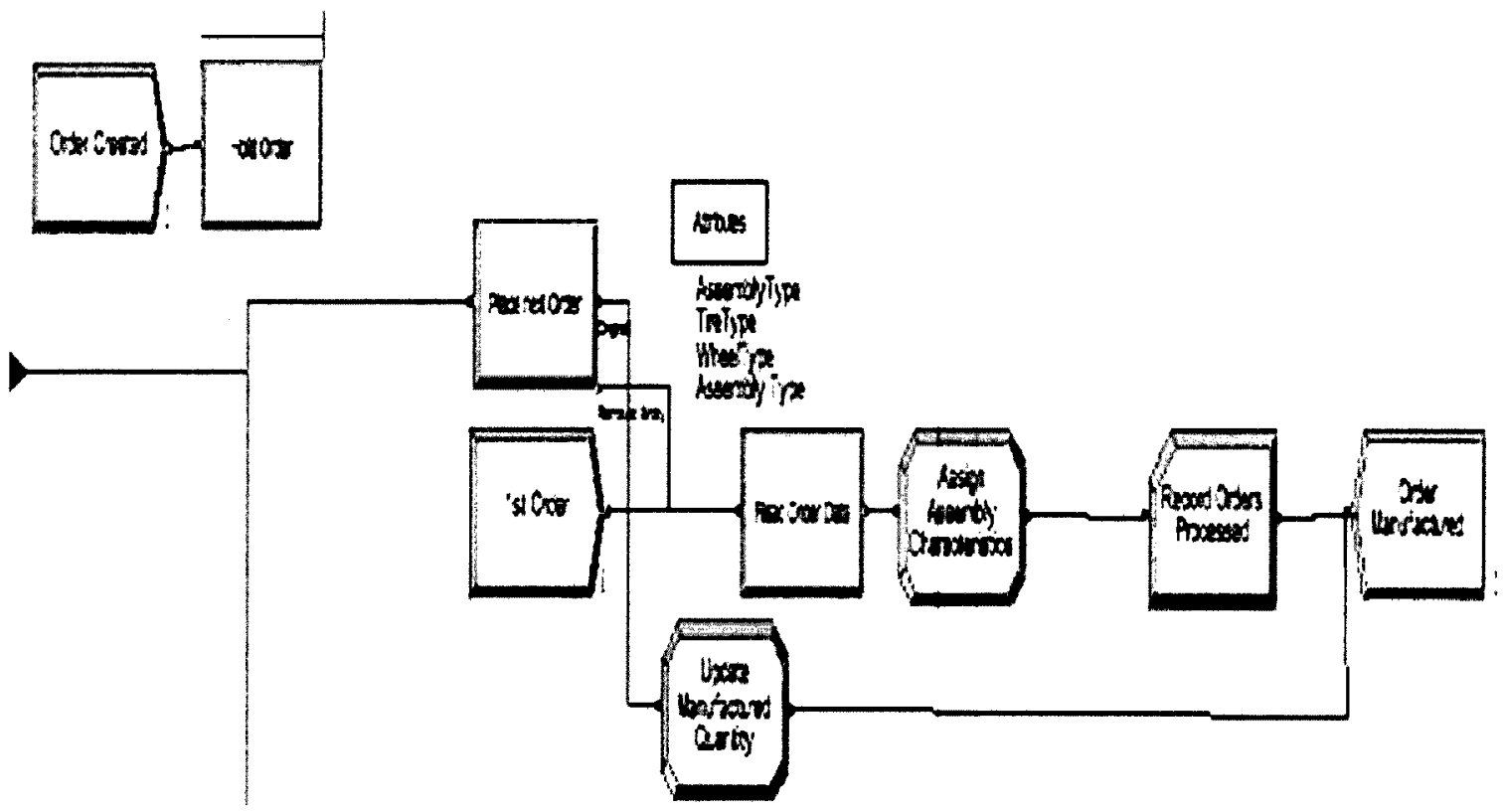

Figure 14. Order Generation Submodel 


\section{TIRE LINE OPERATIONS SUBMODEL}

All the pre-assembly operations performed on the tire are done here.

Create Module: Load Tires

This module creates entities of type-"Tire", one of the two main entities that form the assembly. The inter-arrival times are exponentially distributed with a mean of 11 seconds. This avoids explosion of WIP due to high processing times at some stations (as line stoppages due to the bottle-neck cycle times are not considered here to maintain its simplicity).

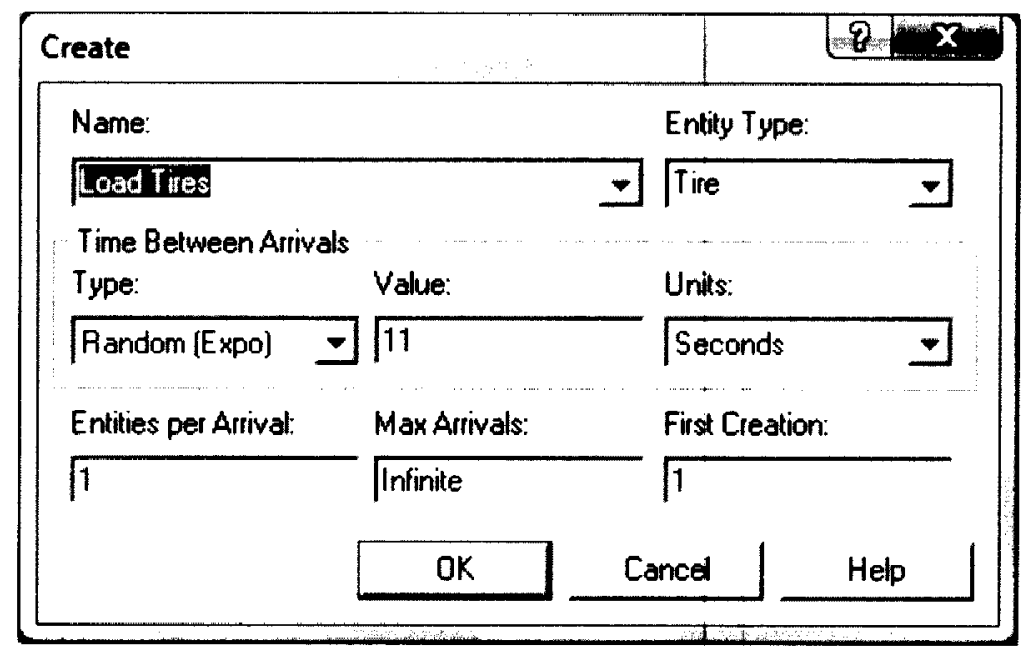

Figure 15. Create Module: Load Tires

\section{Assign Module: Assign Tire Type}

This module assigns the type of tire used and the type of assembly that will be formed when the tire and wheel come together from the data read by the ReadWrite module-"Read Order Data". This replicates the actual system where the type of tire being used may be different for different assemblies. 


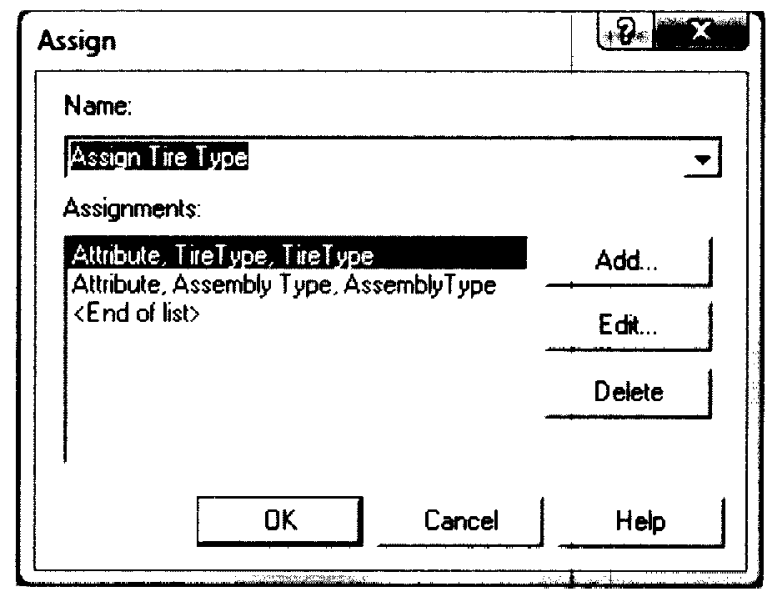

Figure 16. Assign Module: Assign Tire Type

Process Module: Tire Heater

This module simulates the tire being heated to around $70-75^{\circ} \mathrm{F}$. This process is set at a constant delay of 10 seconds.

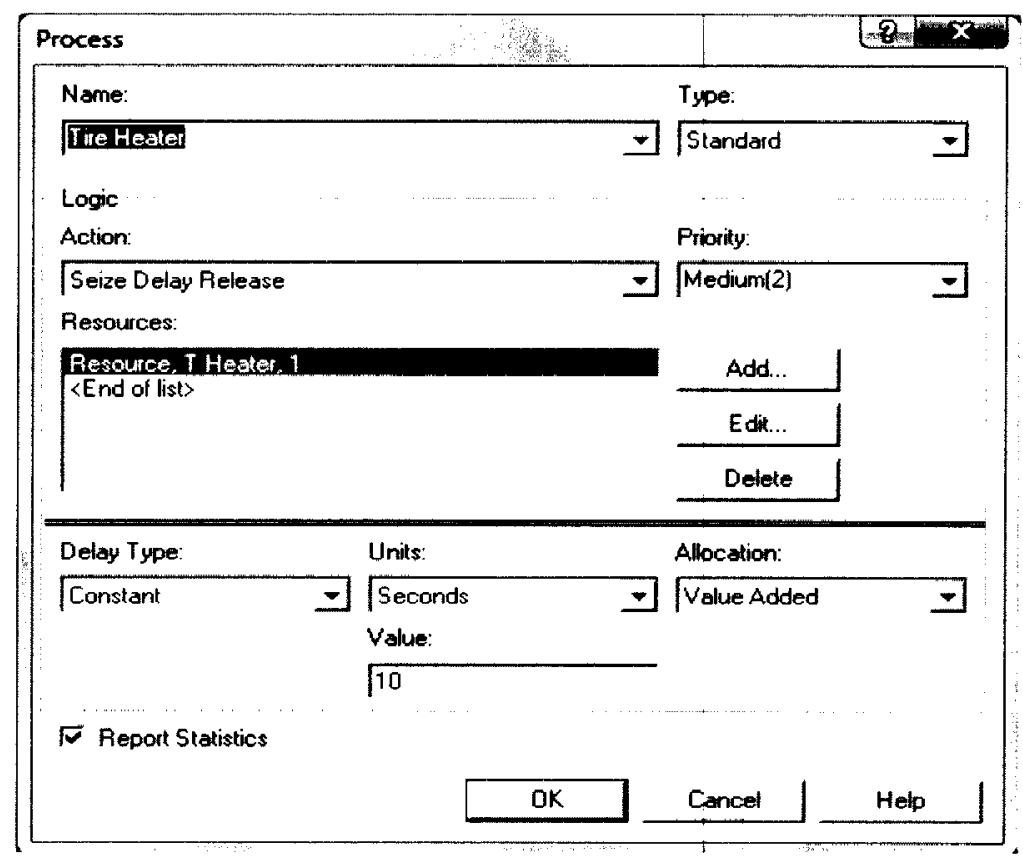

Figure 17. Process Module: Tire Heater 
Process Module: Tire Soaper

This process has a uniform delay with a minimum of 9 seconds and a maximum of 11.4 seconds. In the first Model this process uses only 1 resource.

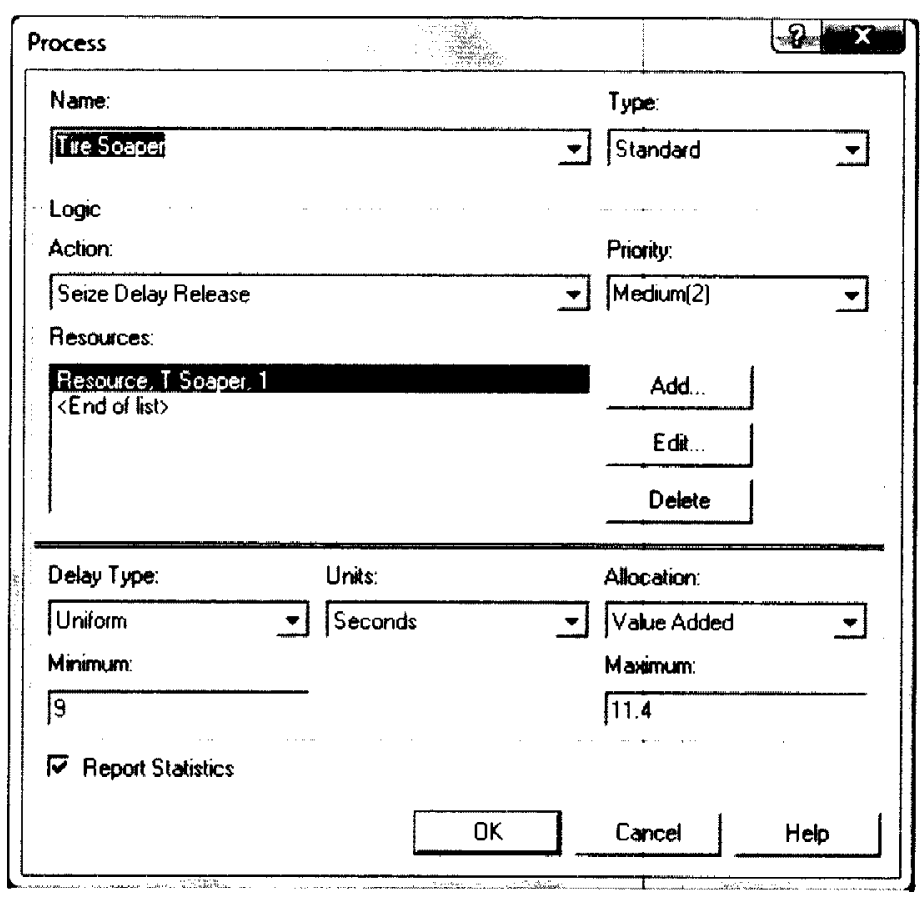

Figure 18. Process Module: Tire Soaper

Process Flow Chart of Tire Line Operations Submodel:

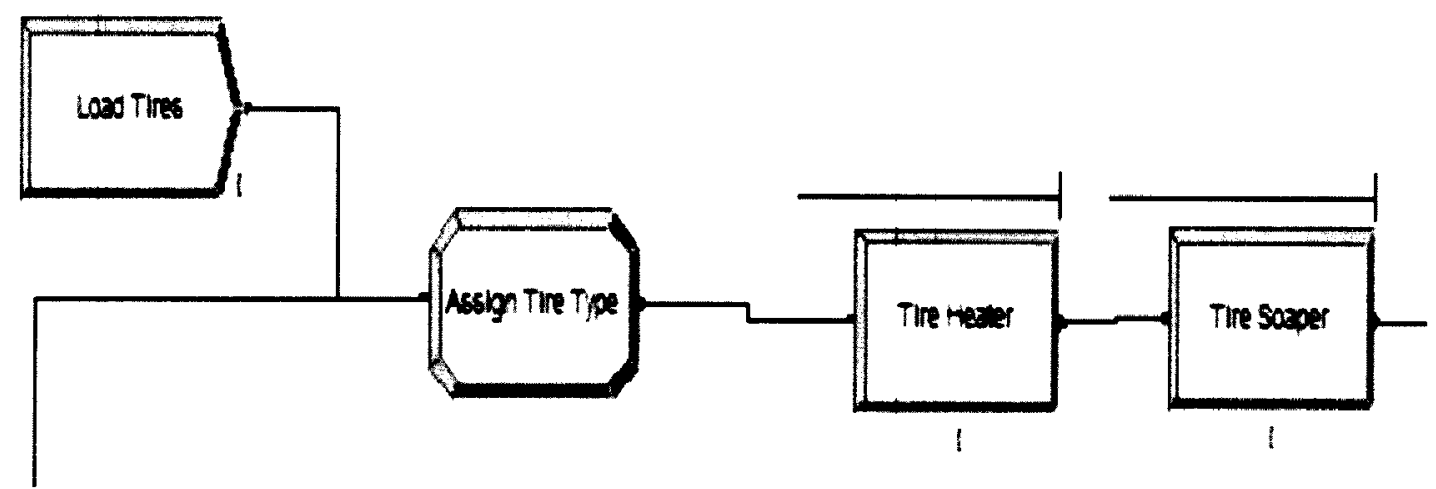

Fiqure 19. Process Flow Chart of Tire Line Operations Submodel 


\section{WHEEL LINE OPERATIONS SUBMODEL}

All the pre-assembly operations are performed on the wheel here.

Create Module: Load Wheel

This module creates entities of type-"Wheel", the second main entity which goes into the tire and wheel assembly.

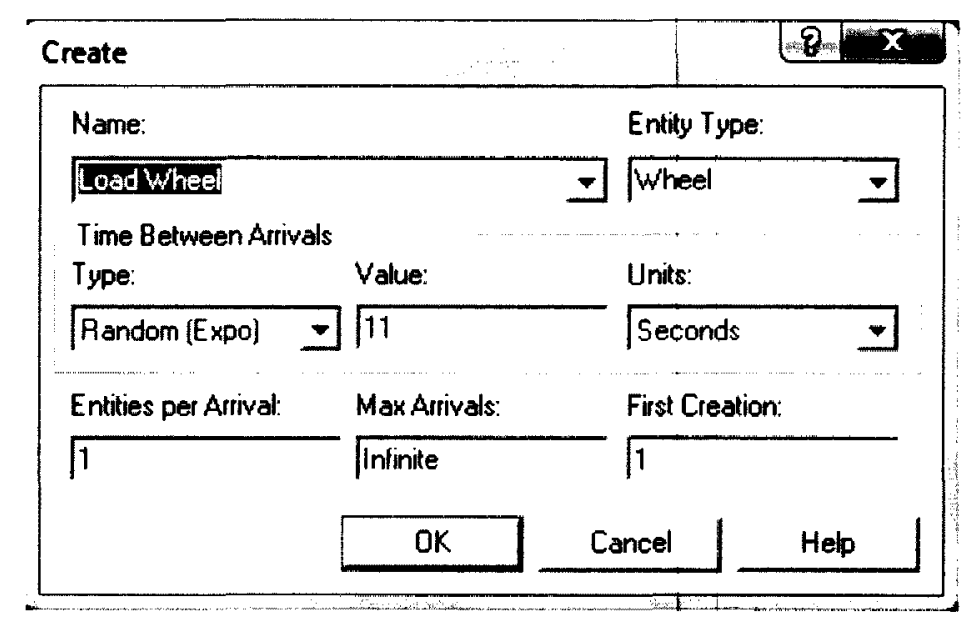

Figure 20. Create Module: Load Wheel

The inter-arrival times are exponentially distributed with a mean of 11 seconds. This value was set to avoid explosion of WIP due to high processing times at some stations (such as the "Load Tire" create module).

Assign Module: Assign Tire Type

This module assigns the type of wheel and the type of assembly that will be formed when the tire and wheel come together. Also, an additional variable"OrderNumber" is assigned to the wheel (the reason for this is explained next). 


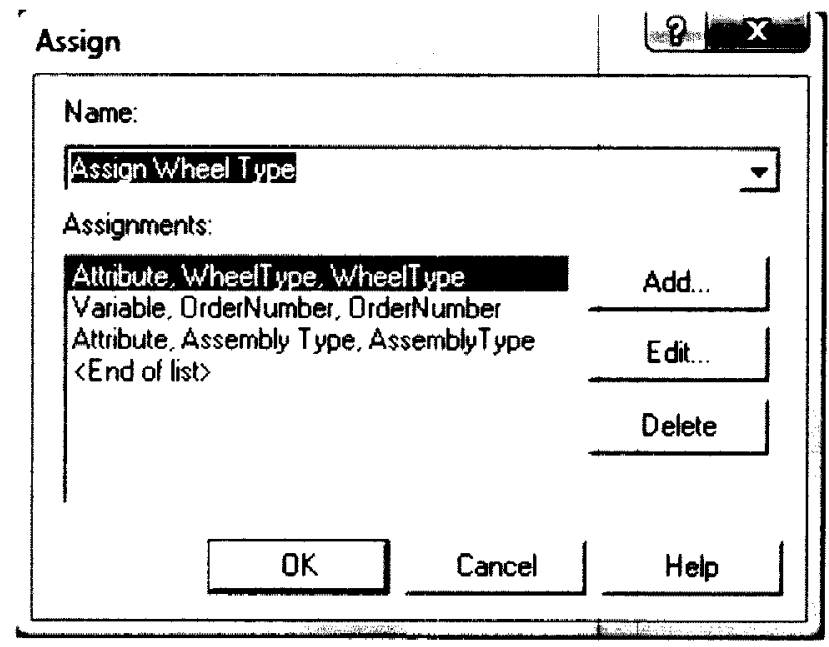

Figure 21. Assign Module: Assign Tire Type

Decide Module: Road or Spare Wheel

This module checks to see if the order is for a road or for spare assembly. The type of decision here is "2-way by Condition". The module checks the value of the variable-"OrderNumber" assigned to the wheel in the assign module "Assign Wheel Type" If it has a value of "Zero" (indicating it is a spare wheel), the wheel is sent to the next Spare tire processing step-"Load Stem". If not, the wheel goes to the Road Tire operation of "Load TPM".

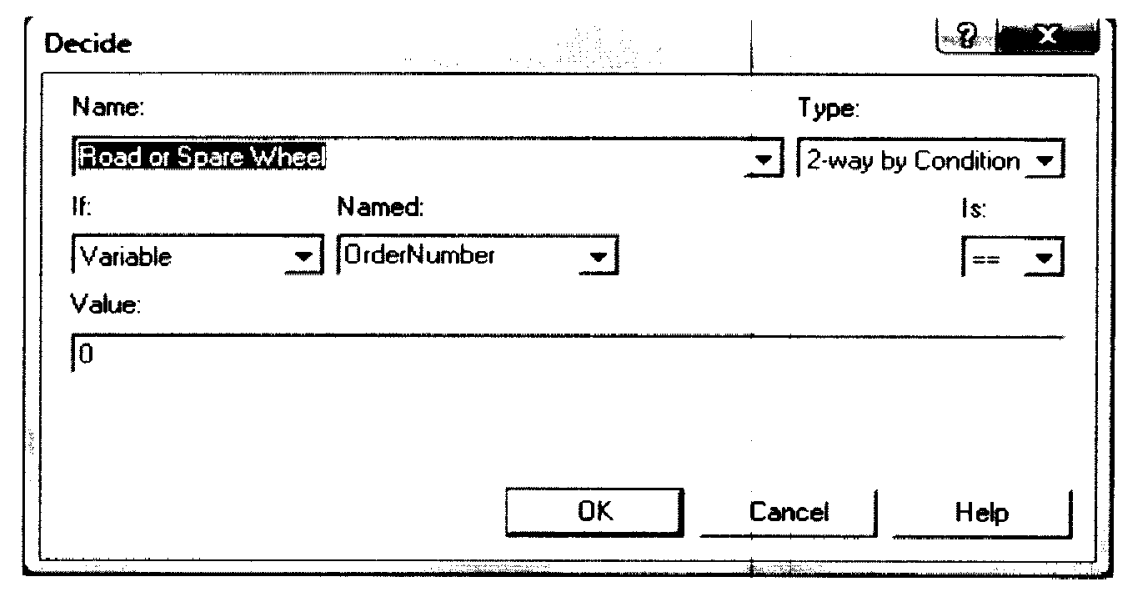

Figure 22. Decide Module: Road or Spare Wheel 
Process Module: Load Stem

If the decide module- "Road or Spare Wheel" determines that the wheel is a "Spare", the entity is sent to the "Load Stem" process where it gets processed with a delay of "10+EXPO (0.313)" seconds.

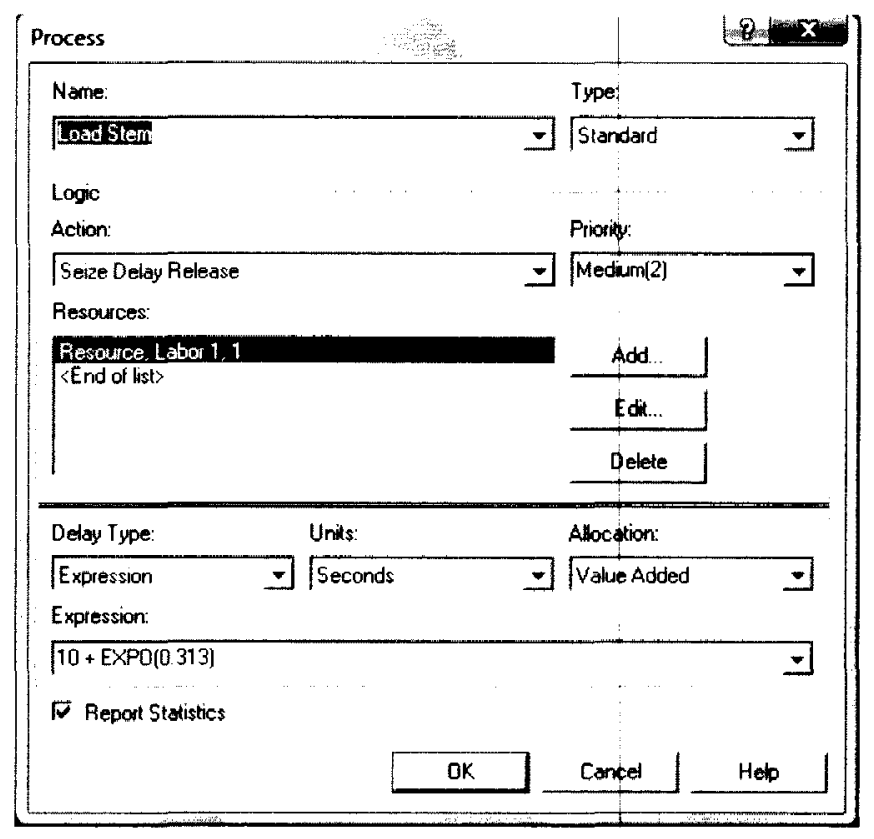

Fiqure 23. Process Module: Load Stem

Process Modules: Load TPM, TPM Scan and Torque and Wheel Orient Wheels determined to be "Road Assemblies" go through the following processes:

Process Module: Load TPM

Delay $=7+2.67^{\star} \operatorname{BETA}(0.767,1.12)$ 


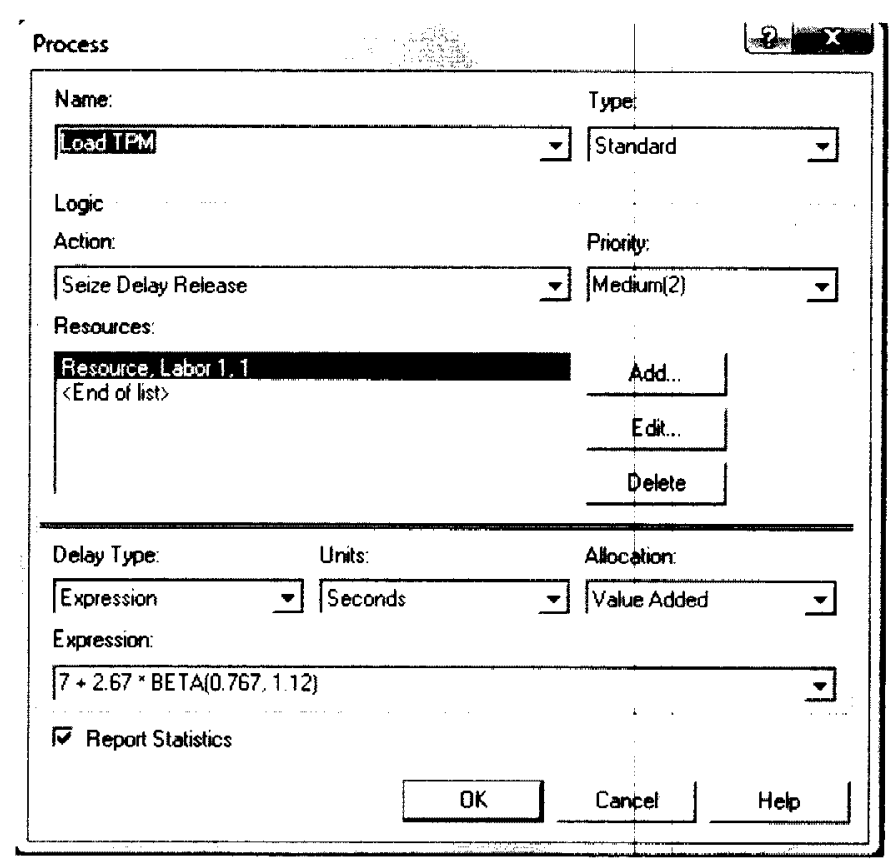

Figure 24. Process Module: Load TPM

\section{Process Module: TPM Scan and Torque}

Delay $=8.03+\operatorname{LOGN}(1.95,1.12)$

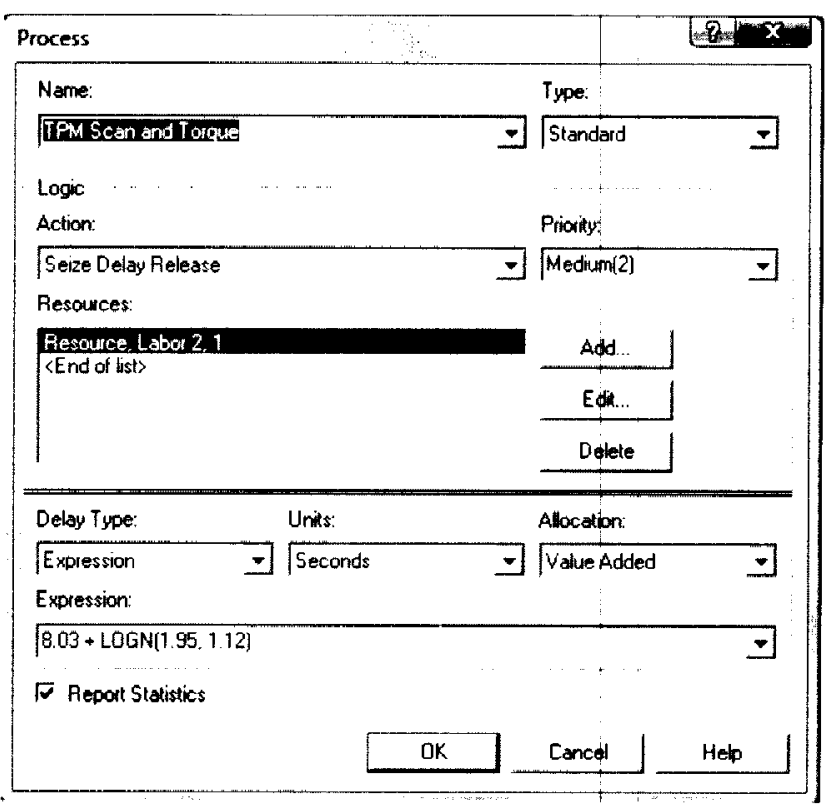

Figure 25. Process Module: TPM Scan and Torque 
Process Module: Wheel Orient

Delay $=$ Normal, Mean $=6.81$ seconds, Standard Deviation $=0.694$ seconds.

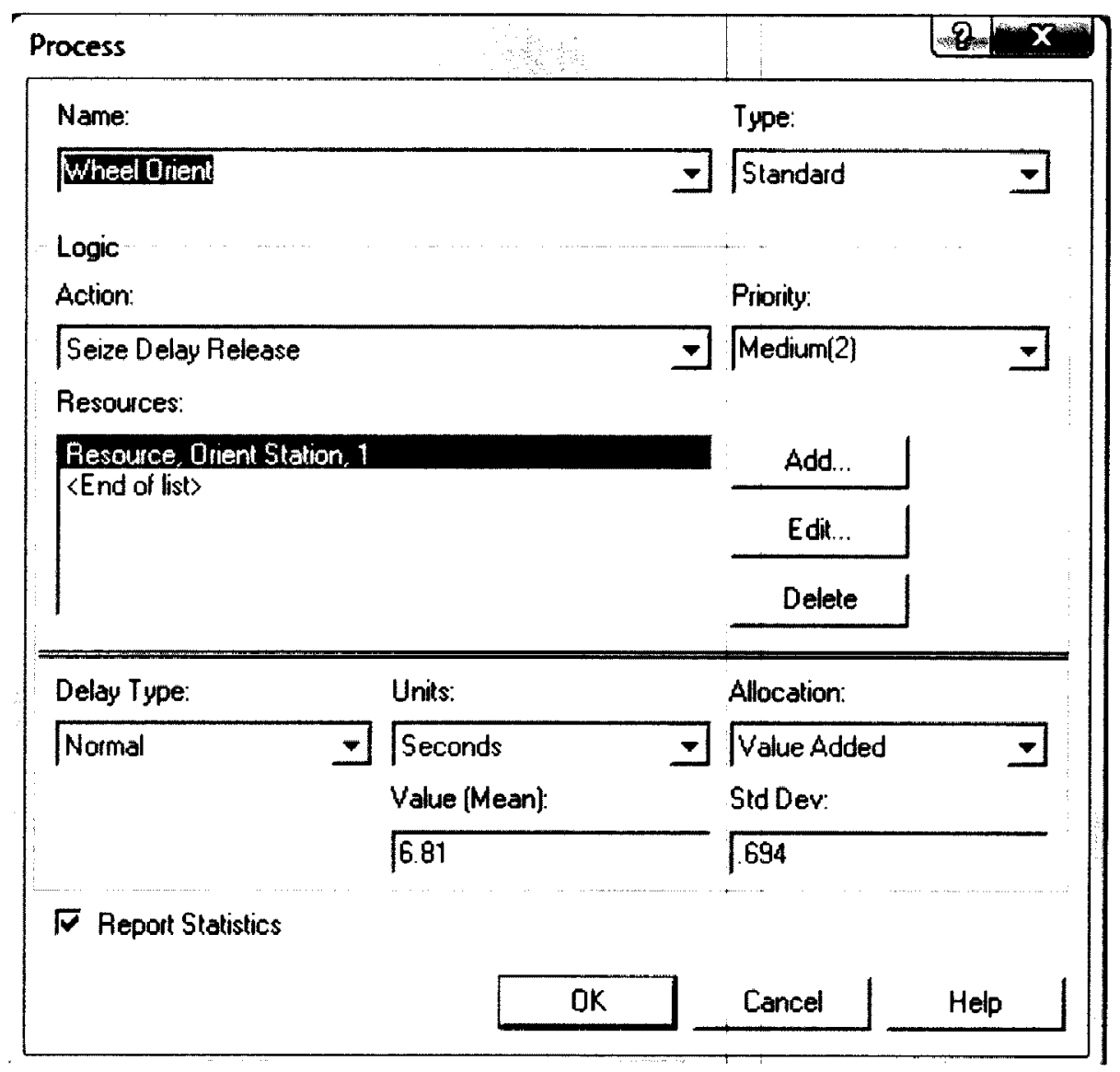

Figure 26. Process Module: Wheel Orient

Process Module: Wheel Soaper

After their respective operations, both road and spare tires go through this operation with a delay of " $8.62+2.38^{*} \mathrm{BETA}(1.88,1.15)$ " seconds. 


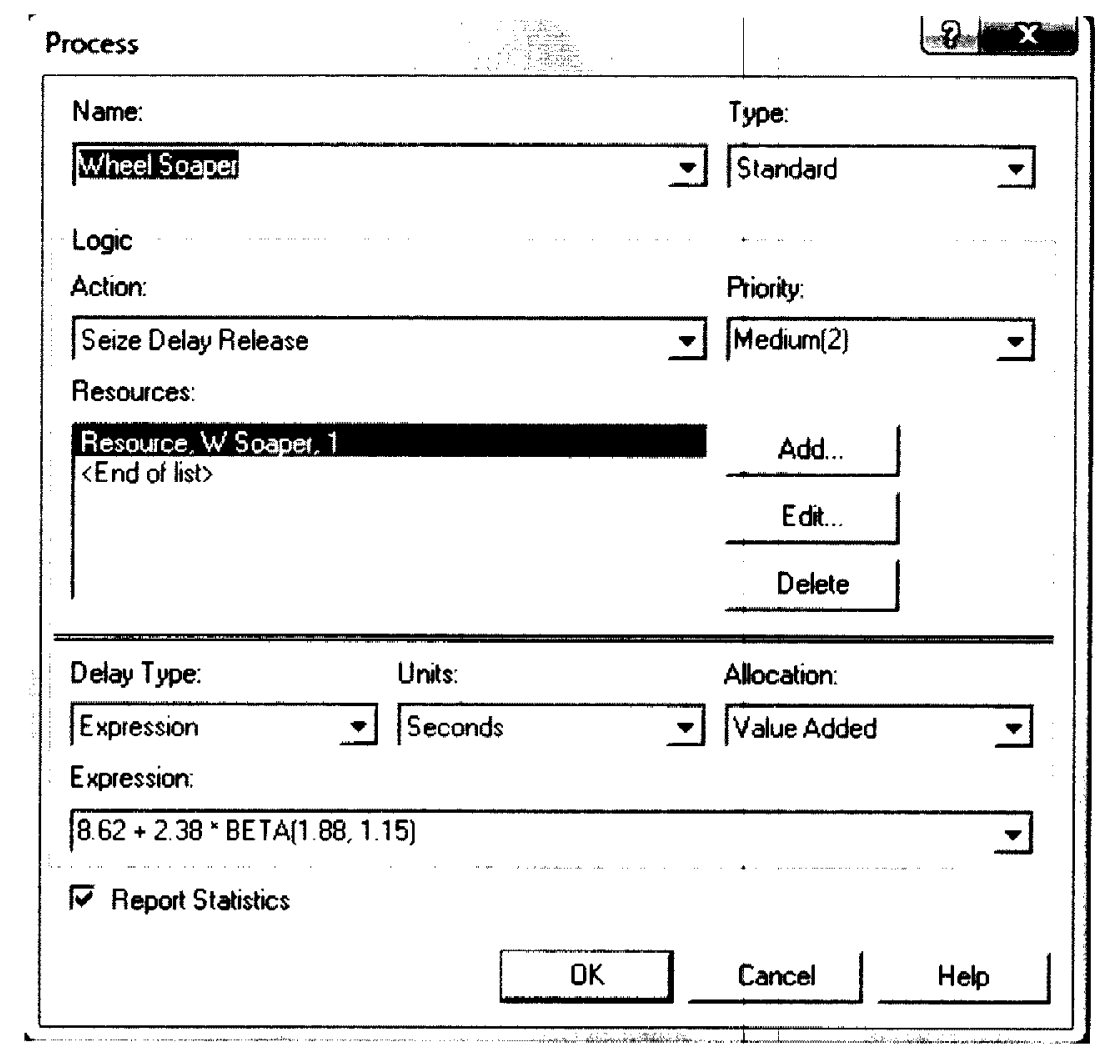

Figure 27. Process Module: Wheel Soaper

Process Flowchart of Wheel Line Operations Submodel:

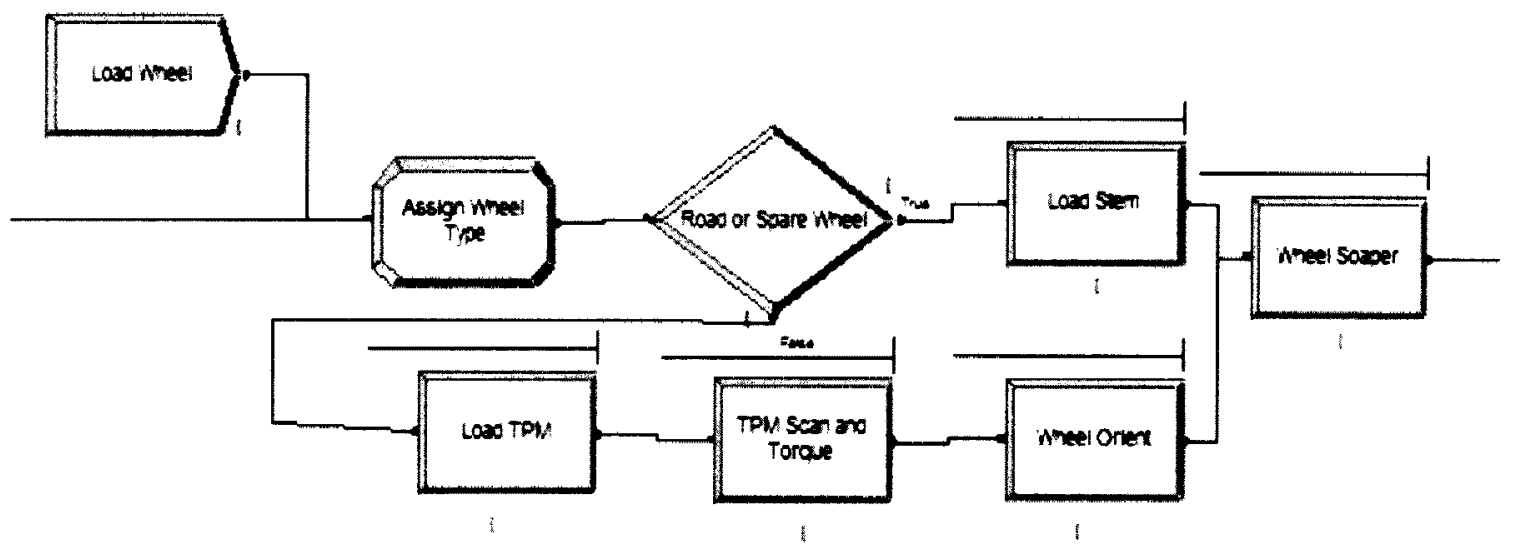

Figure 28. Wheel Line Operations Submodel 
ASSEMBLY AND INFLATION SUB MODEL

All assembly steps are performed here to form Road or Spare Assemblies.

Match Module: Tire and Wheel Arrive

Here one tire and one wheel are matched per the assembly type assigned

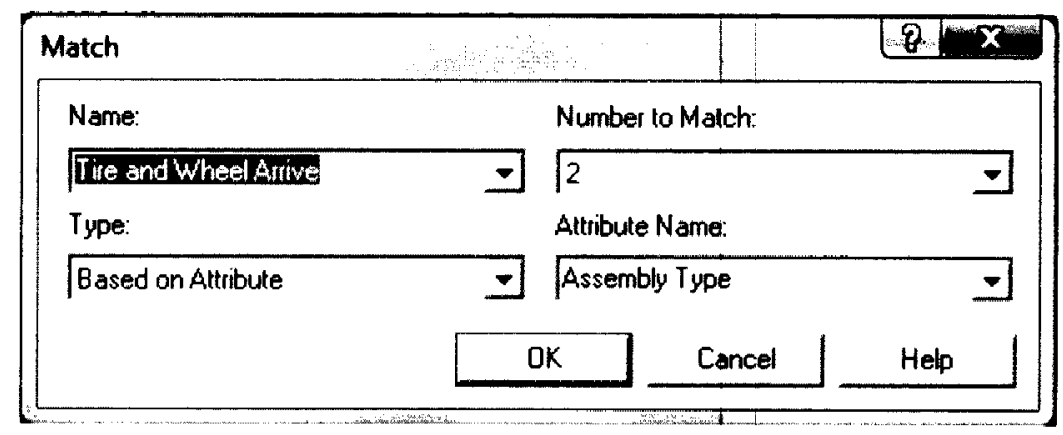

Figure 29. Match Module: Tire and Wheel Arrive

Batch Module: Drop Gate

Here a tire and wheel come together to form a single entity called as "TW Assembly" (TW $\rightarrow$ Tire and Wheel). The batch size is "two" ( 1 tire +1 wheel), the batching rule is "Any Entity" and batch criteria are same as the tire and wheel.

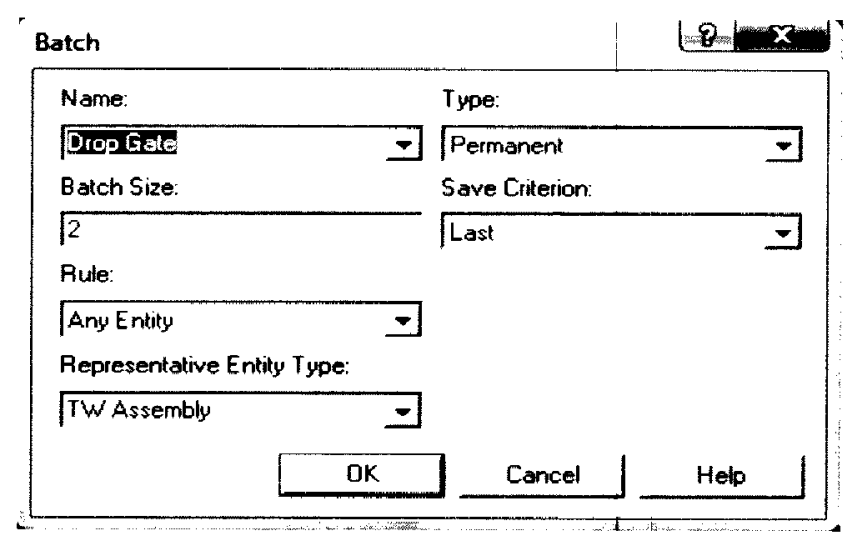

Figure 30. Batch Module: Drop Gate 
Process Module: Mount Tire on Wheel

This module captures the resource used (Mounter) and its processing time. The delay here is specified as " $2.05+5.95^{\star}$ BETA $(1.59,0.597)$ " seconds.

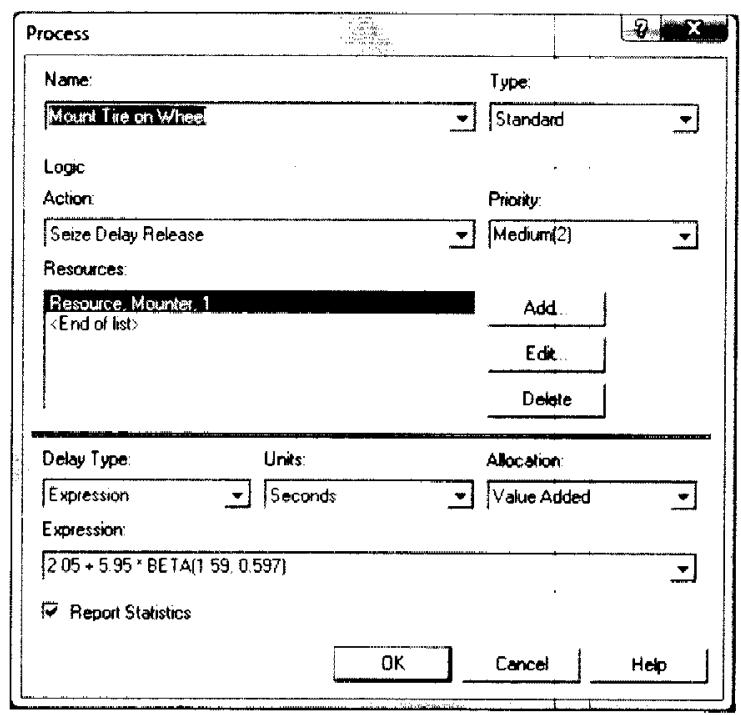

Figure 31. Process Module: Mount Tire on Wheel

Process Module: Match Mark High Point with Low Point

This has 1 "Matcher" resource with a "5.69+EXPO (0.734)" second delay.

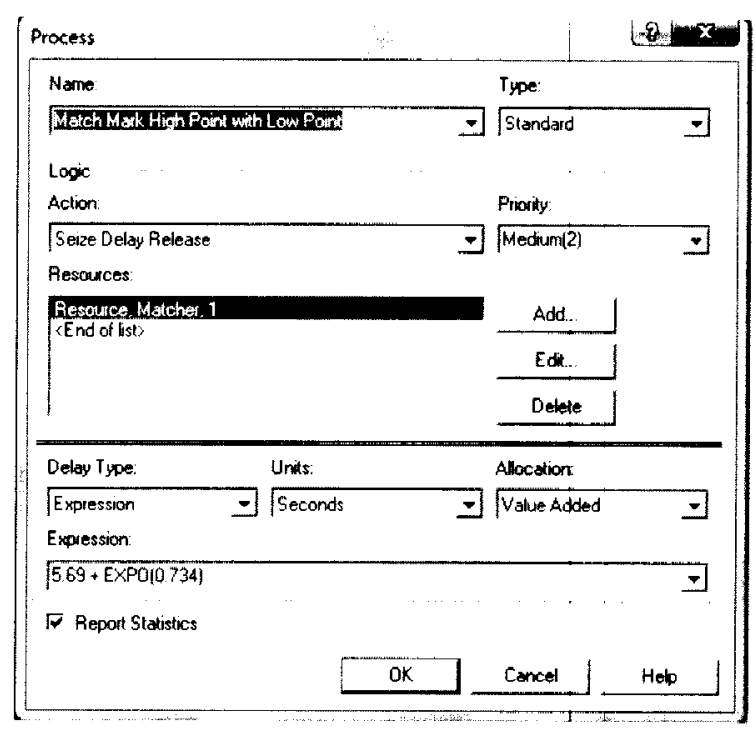

Figure 32. Process Module: Match Mark High Point with Low Point 
Process Module: Inflate Assembly

The assembly is inflated here with a delay period of " $5.56+3.9^{*} \mathrm{BETA}$

$(1.38,1.82)$ " seconds. Note that only one unit of the resource "Inflator" is used.

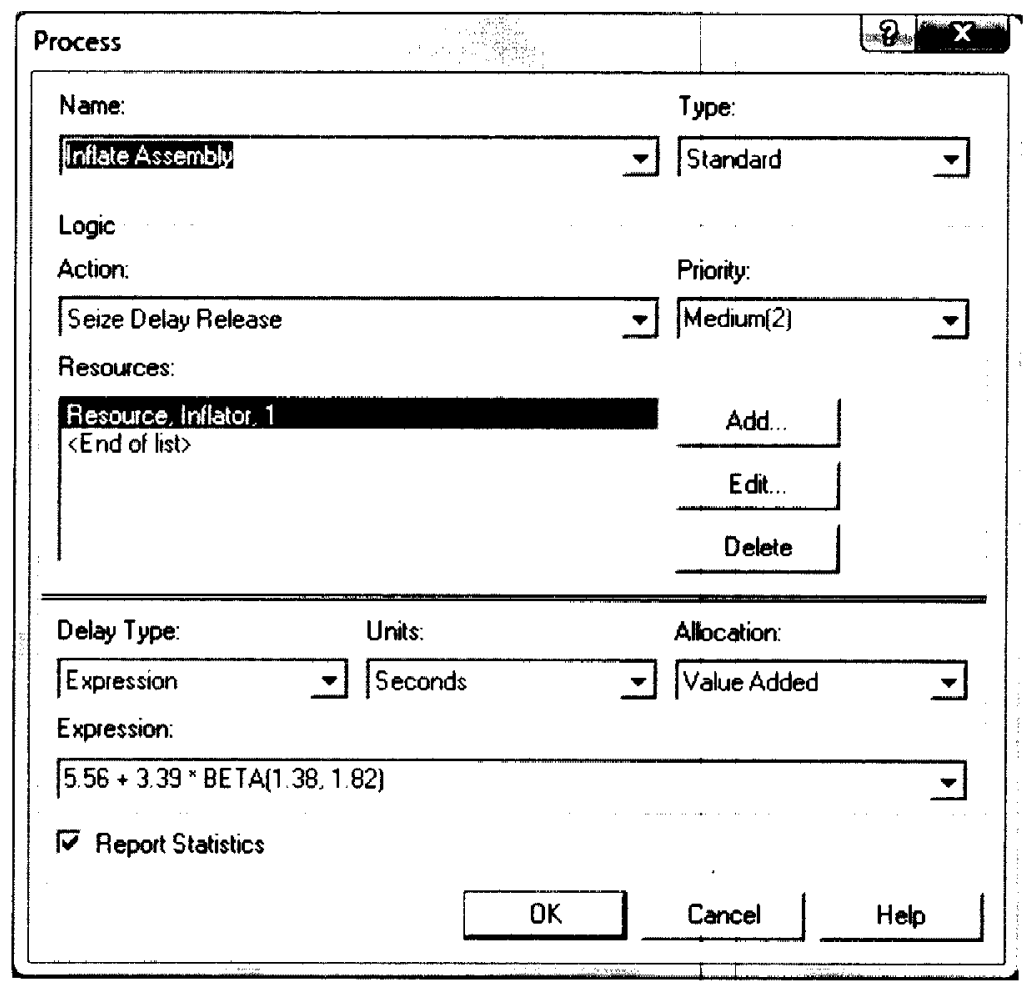

Figure 33. Process Module: Inflate Assembly

Process Flowchart of Assembly and Inflation Submodel:

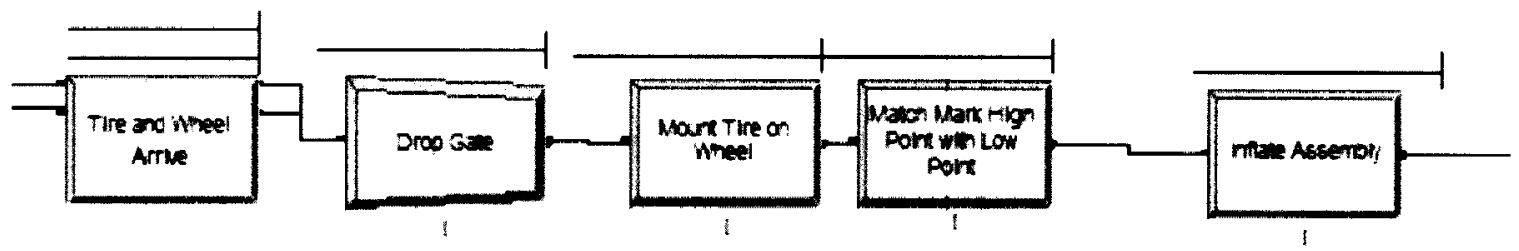

Figure 34. Assembly and Inflation Submodel 


\section{DECIDE MODULE: ROAD OR SPARE ASSEMBLY}

At this module, the assembly is checked to see if it is a "Road" or "Spare" Assembly. This is done similar to the Decide Module-"Road or Spare Wheel". If the variable-"OrderNumber" has a value of "Zero", it sends the assembly to the "Spare Assembly Operations Submodel". If not, it sends the assembly to the "Road Assembly Inspection Processes Submodel".

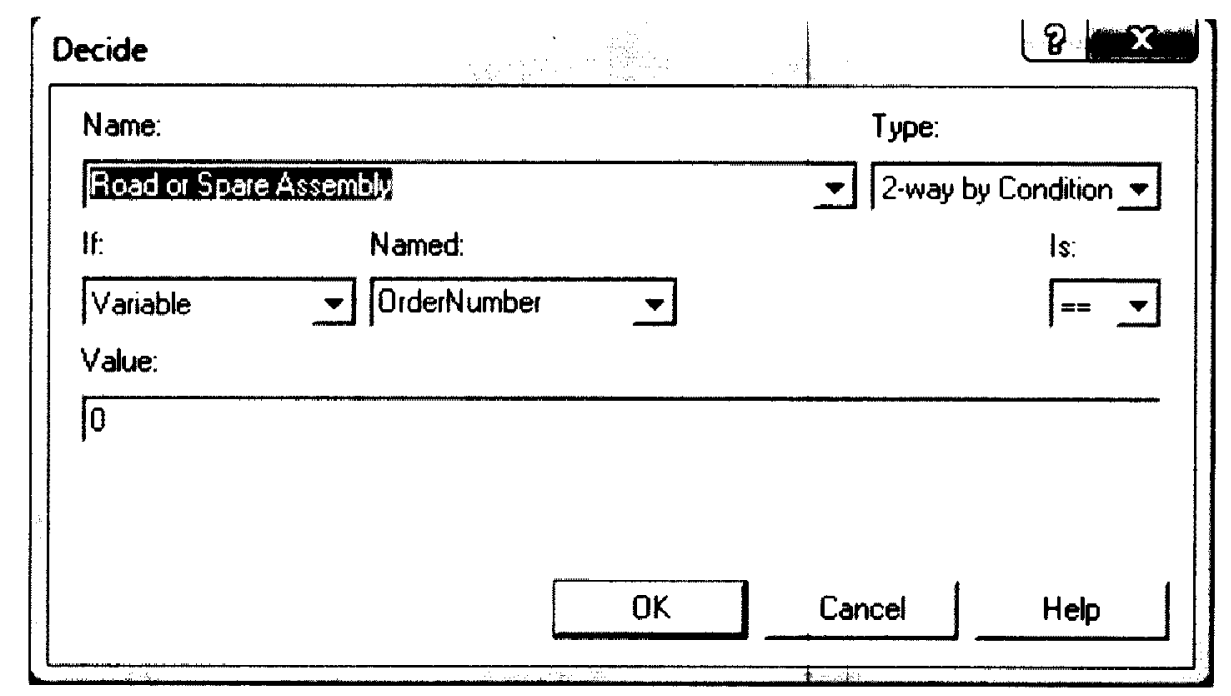

Figure 35. Decide Module: Road or Spare Assembly

SPARE ASSEMBLY OPERATIONS SUBMODEL

In this Submodel, the Spare Assembly related steps are performed.

Decide module: Spare Assembly Good

This module incorporates the first yield percentage for spare assemblies. It checks to see if the spare assembly is good. The event type here is " $\mathrm{N}$-way by Chance" as there are three possible outcomes to this. The probability of this condition being true is same as the percent first yield of the assembly process, 
$89.64 \%$. Around $8.68 \%$ of assemblies are found to be bad and scrapped. The remaining, $1.68 \%$ is sent for rework operations.

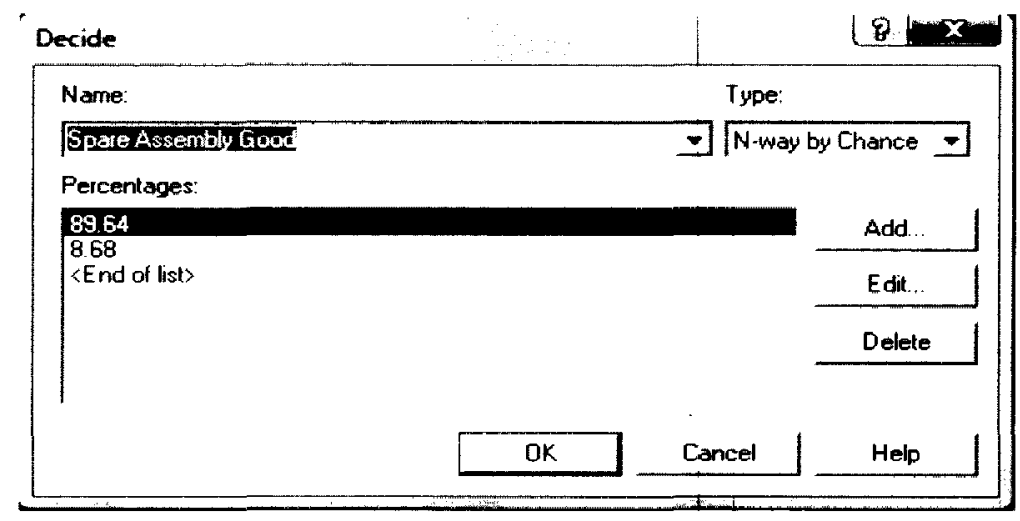

Figure 36. Decide module: Spare Assembly Good

Decide Module: Check Spare Manufactured Quantity

This module checks if the "Good" spare assemblies manufactured meet the order quantity specified. The type is "2-way by condition". It checks if the condition "NQ(SpareTire.Queue) $=$ OrderQuantity" is true $(N Q \rightarrow$ Number in Queue) (SpareTire.Queue $\rightarrow$ Entities held in queue for the Hold Module-"Spare Tire Storage"). If yes, a signal sent to the "Order Generation Submodel" generates the next order. If not, spare assembly manufacture continues.

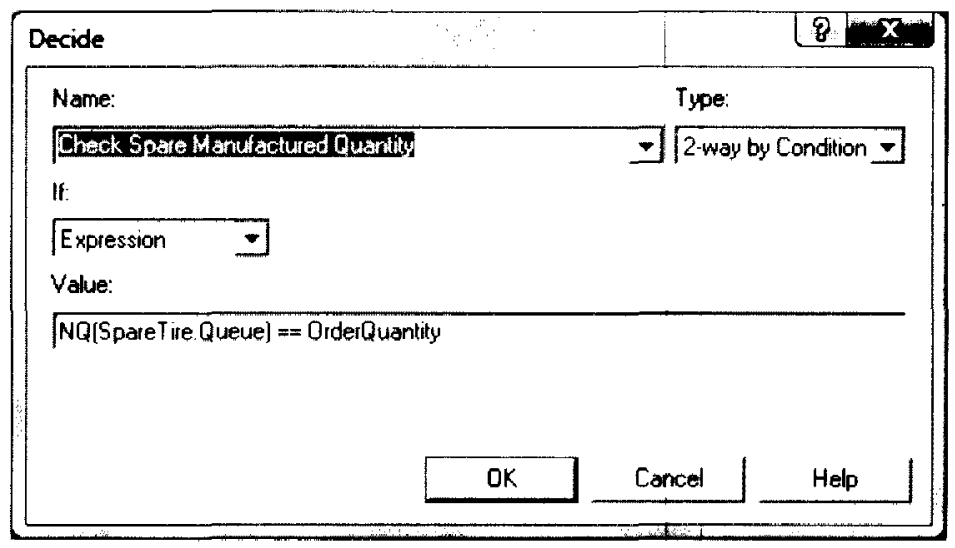

Figure 37. Decide Module: Check Spare Manufactured Quantity 
Record Module: Record Spare Assemblies Manufactured

This module records the total spare assemblies manufactured. The type of record here is specified as "Count" and the initial value of the counter is set to 1 .

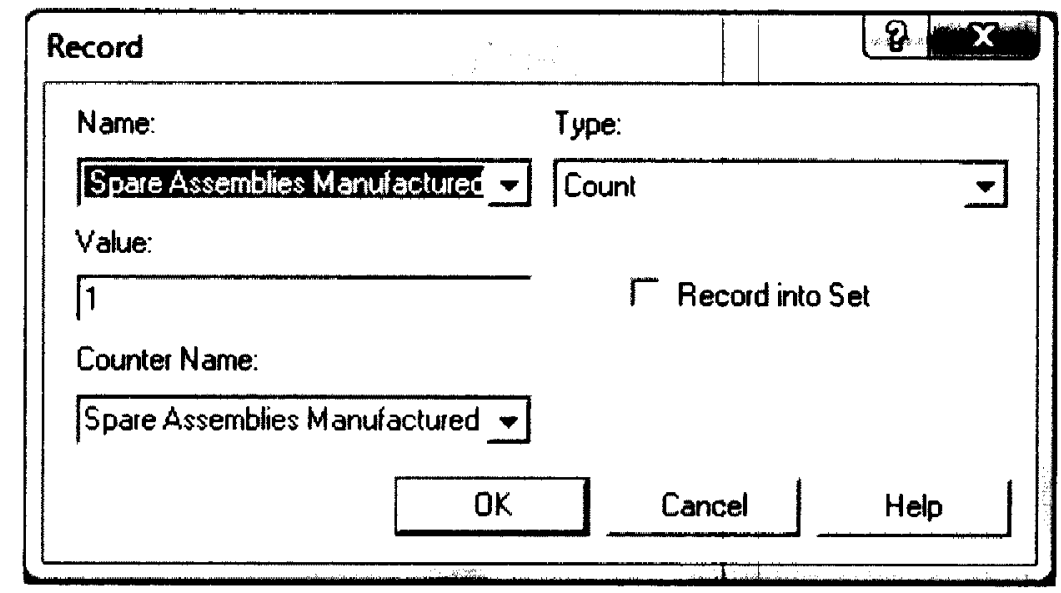

Figure 38. Record Module: Record Spare Assemblies Manufactured

Record Module: Average Spare Tires in Inventory

This records the average spare assembly inventory in the system. It is of type "Tally" and the value of the "DAVG(SpareTire.Queue.NumberInQueue)" expression is the one being recorded (DAVG $\rightarrow$ Average Value).

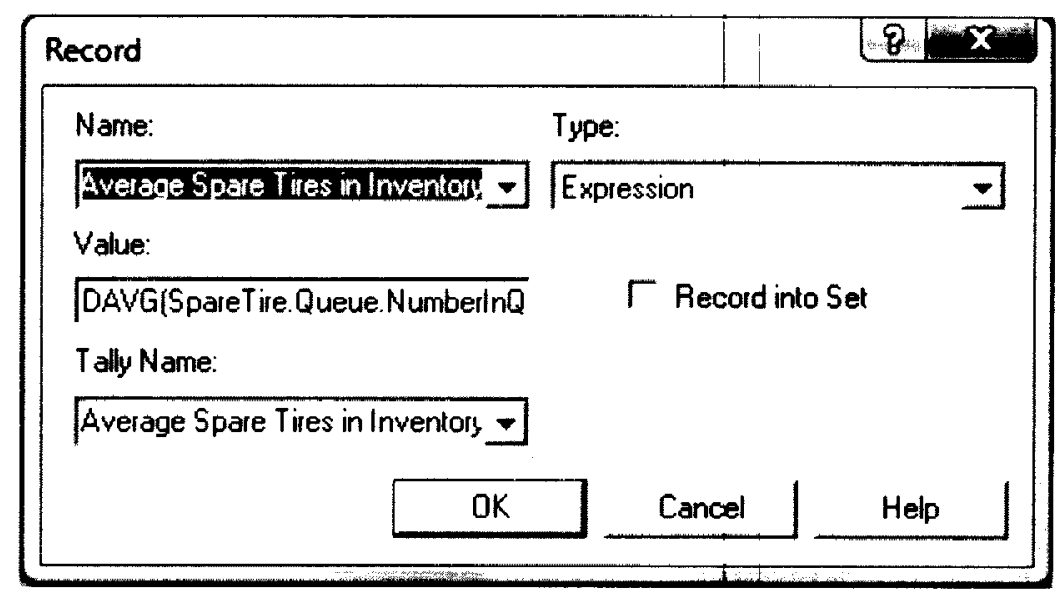

Figure 39. Record Module: Average Spare Tires in Inventory 
Hold Module: Spare Tire Storage

This acts as the storage for spare assemblies until they are required to form sets with a batch of four road tires. The assemblies are on "Infinite Hold" as they will be here until the remove module "Pick Up Spare Tire" removes them.

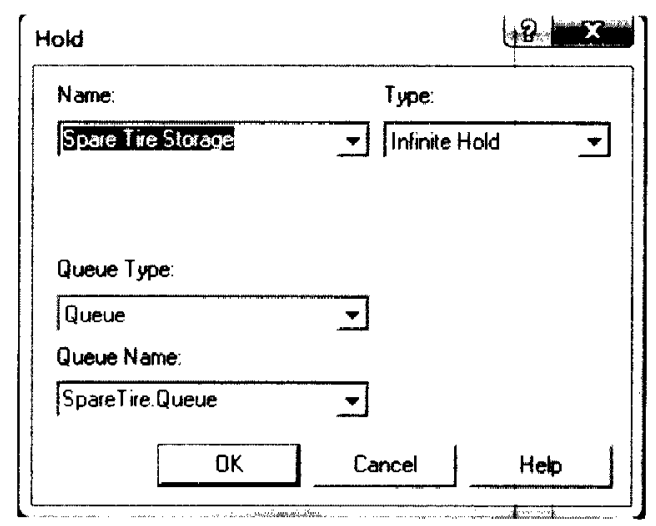

Figure 40. Hold Module: Spare Tire Storage

Record Module: Record Spare Assemblies Sent for Rework

This module records the total number of spare tires sent for rework.

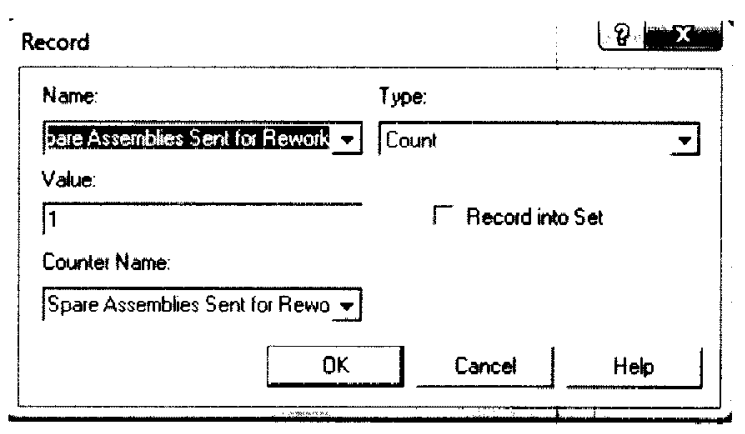

Figure 41. Record Module: Record Spare Assemblies Sent for Rework

Record Module: Record Spare Assemblies Scrapped

This module records the total number of spare tires scrapped. 


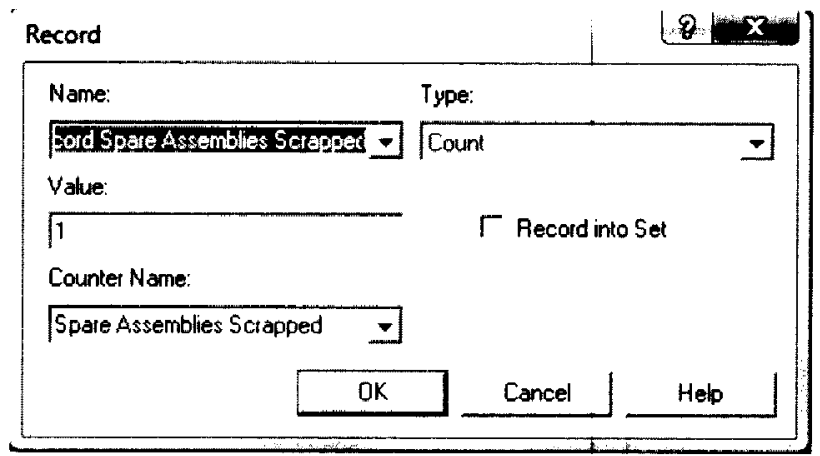

Figure 42. Record Module: Record Spare Assemblies Scrapped

Dispose Module: Spare Assembly Scrapped

The scrapped spare assemblies exit the system through this module.

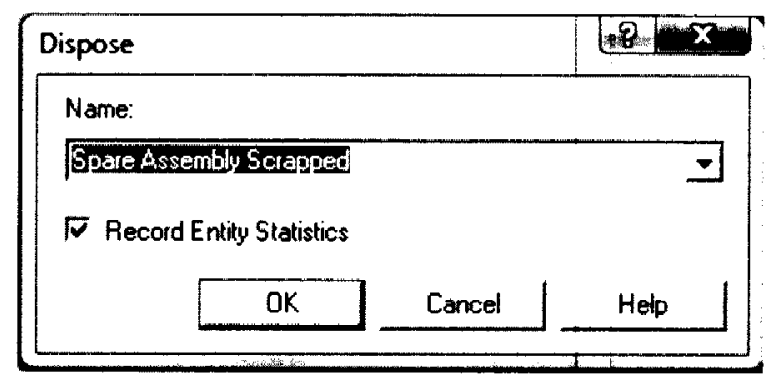

Figure 43. Dispose Module: Spare Assembly Scrapped

Process Flowchart of Spare Assembly operations Submodel:

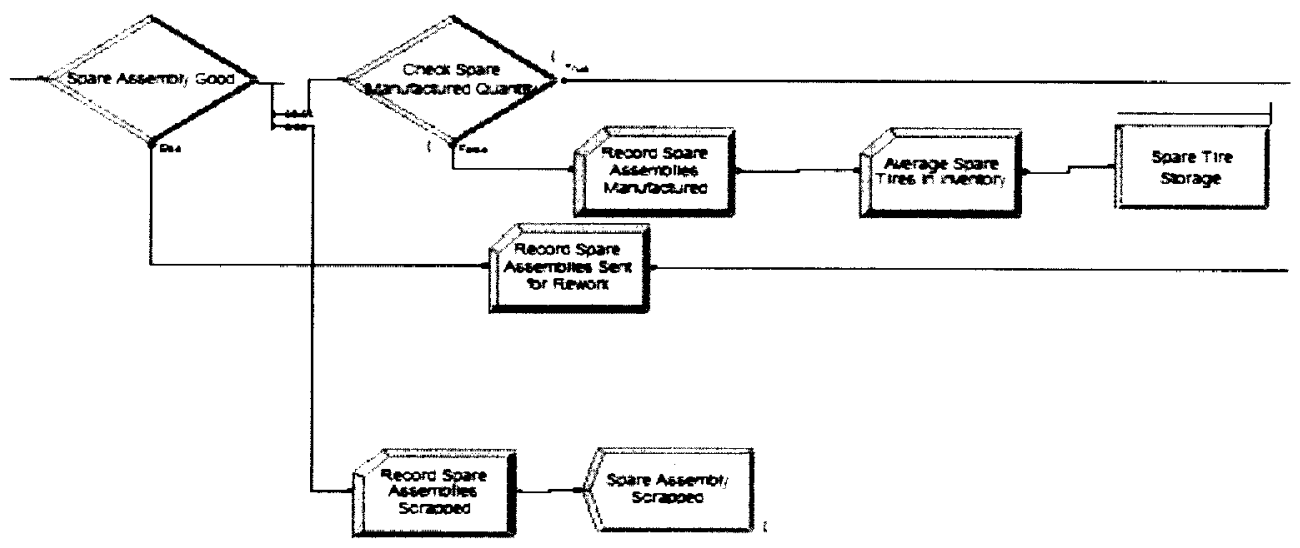

Figure 44. Spare Assembly operations Submodel 


\section{ROAD ASSEMBLY INSPECTION PROCESSES SUBMODEL}

All the inspection processes and are performed on road assemblies here.

Process Module: Load Simulator

Here, the road assemblies undergo load simulation with a processing time of " $0.12+7.88{ }^{*} \operatorname{BETA}(3.98,1.44)$ " seconds. The resource used here is a Simulator. This is the first process to have a "Non-Value Added" allocation while all the previous process modules are "Value Added" as this is an inspection operation while the previous processes all represent manufacturing operations.

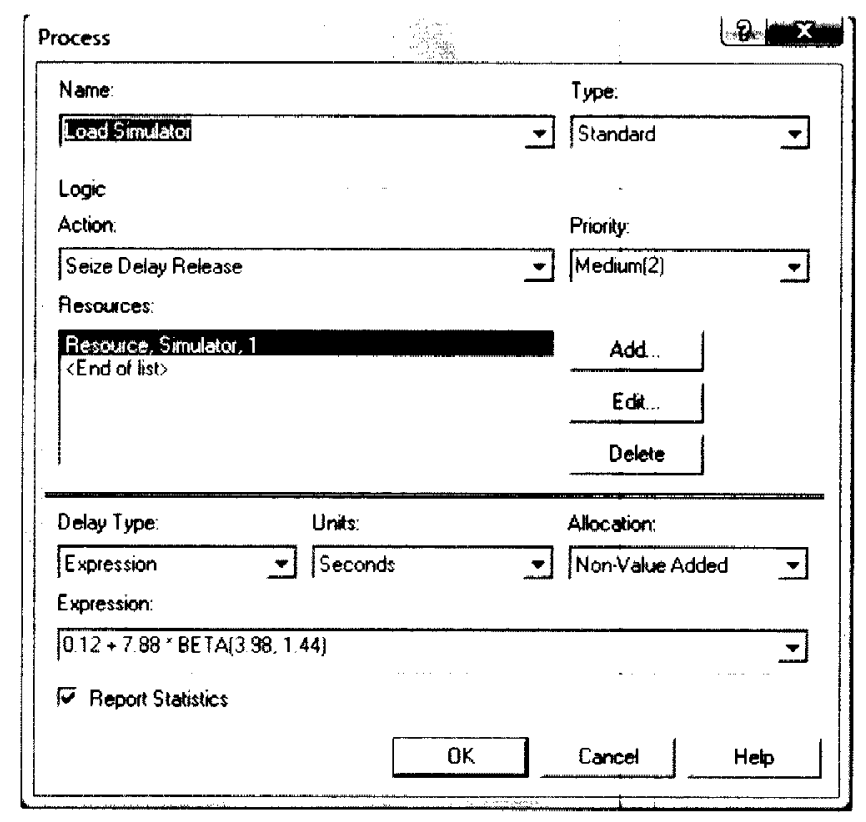

Figure 45. Process Module: Load Simulator

Decide Module: Transfer Assembly for RFV Testing

This module checks the availability of an RFV machine to send the next assembly for testing. It is of type "2-way by Condition". The condition it scans for 
is "NQ(RFV Testing 2.Queue) $>=3$ ". So, if the number of entities waiting in queue at the process module "RFV Testing 2 " is greater than or equal to three, it sends the entity to module "RFV Testing 1". This is basically to split assemblies into the two RFV queues and also to ensure that there is no explosion of waiting entities at "RFV Testing 2" module, which has a higher processing time.

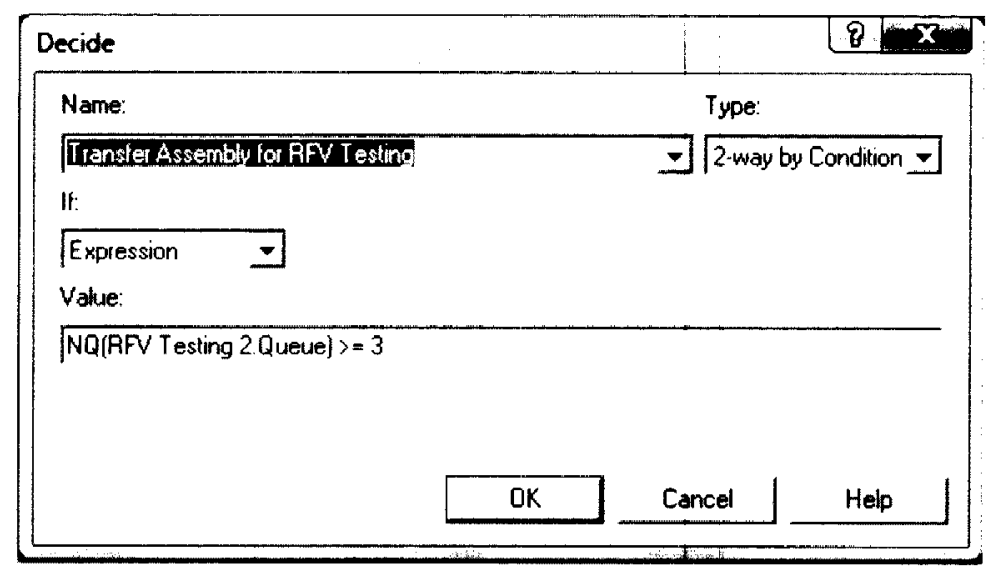

Figure 46. Decide Module: Transfer Assembly for RFV Testing

Process Modules: "RFV Testing 1" and "RFV testing 2"

The next process in the system is RFV testing. There are two parallel stations, "RFV Station 1" and "RFV Station 2". The delay time for RFV Station 1 which uses resource "RFV 1 " is " $15.4+\operatorname{LOGN}(0.717,0.446)$ " seconds and that for RFV Station 2 using resource is "RFV 2" is Normal delay with a mean 17.31 seconds and Standard Deviation of "0.83" seconds. The allocation for these two stations is also "Non-Value Added". 


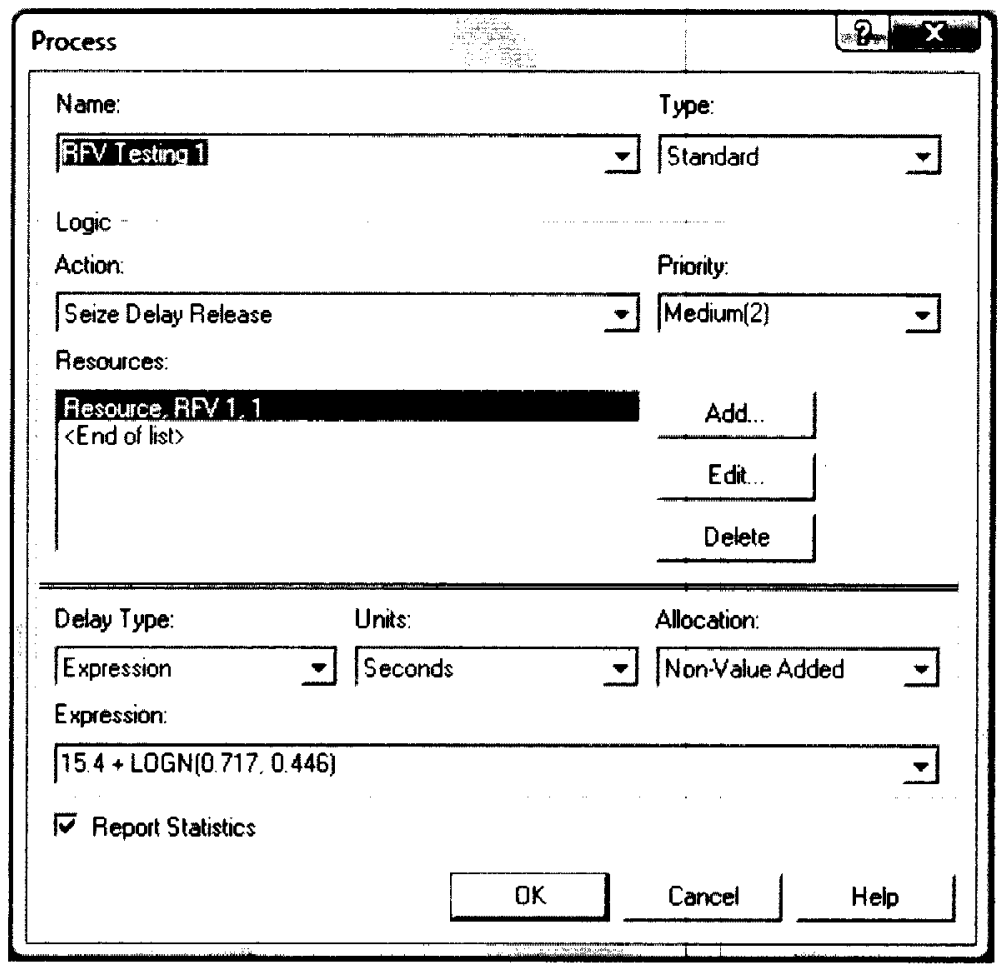

Figure 47. Process Module: RFV Testing 1

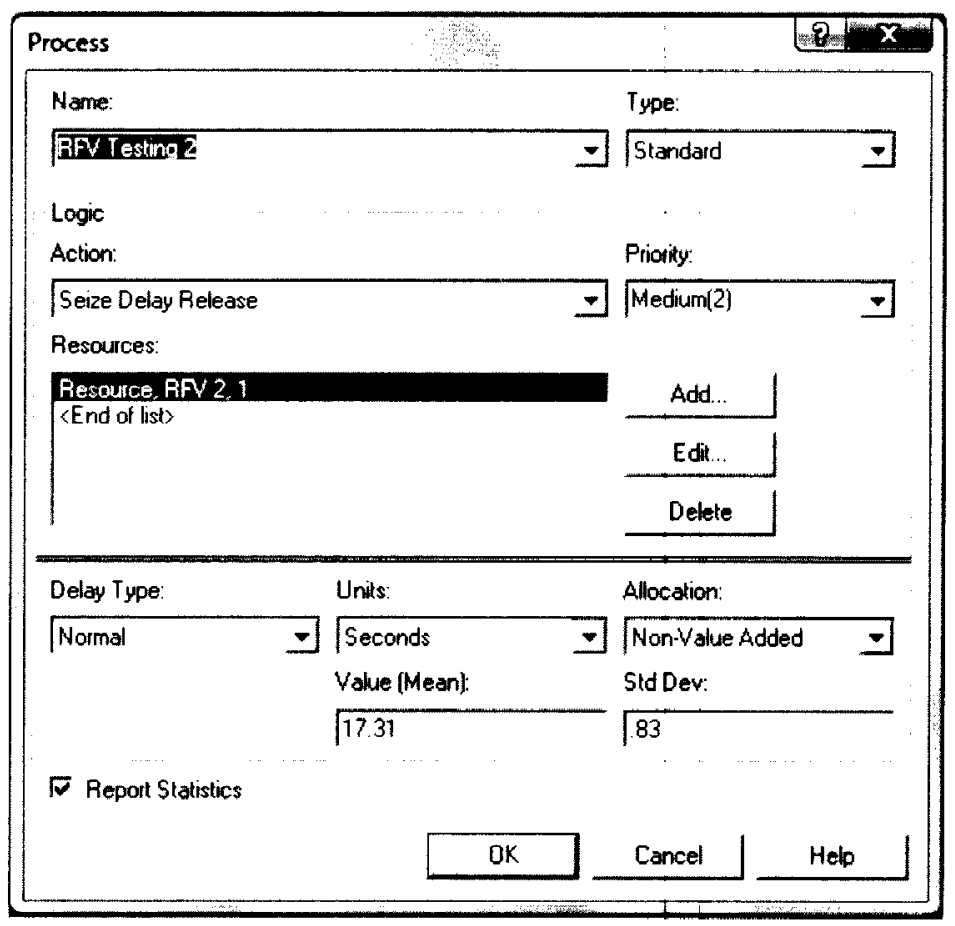

Figure 48. Process Module: RFV testing 2 


\section{Process Modules: "Primary Balancer 1" and "Primary Balancer 2"}

The RFV testing is followed by two parallel Primary Balancer modules.

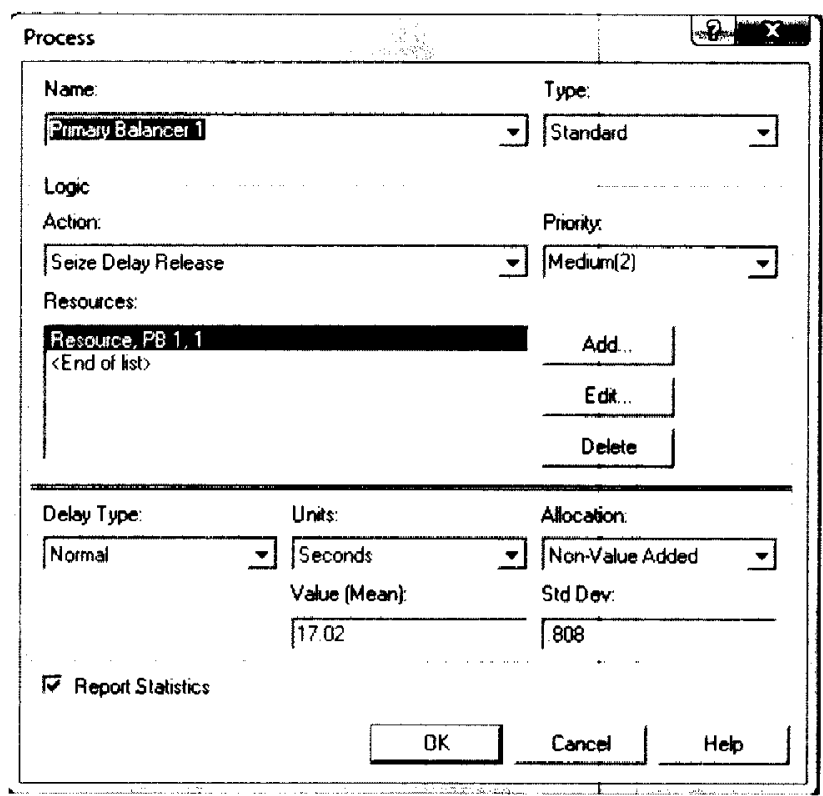

Figure 49. Process Modules: Primary Balancer 1

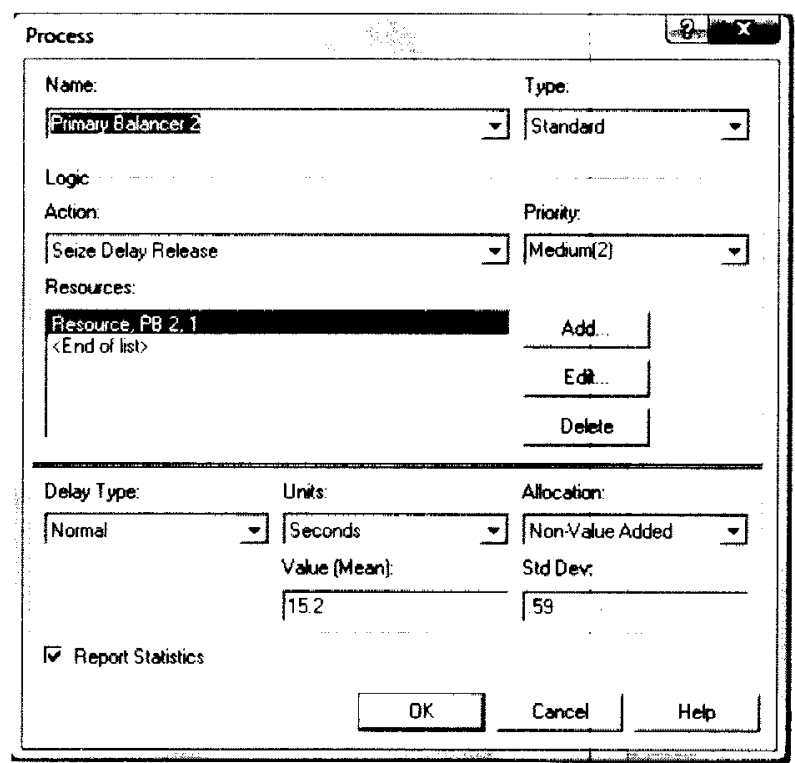

Fiqure 50. Process Module: Primary Balancer 2 
Primary Balancer 1 is connected to RFV 1 and Primary Balancer 2 to RFV 2. Primary Balancer 1 using resource "PB 1" has a normal delay with mean 17.02 seconds and standard deviation of 0.808 seconds. Primary Balancer 2 using resource "PB 2" has a normal delay with a mean 15.2 seconds and Standard Deviation of 0.59 seconds. These two stations is also "Non-Value Added".

\section{Process Modules: "Weight Application 1" and "Weight Application 2"}

The two parallel Primary Balancer process modules are followed by the two Weight Application Modules respectively. The delay for Weight Application 1 using resource "Labor 3" is " $11+\operatorname{LOGN}(7.51,6.32)$ " seconds and for Weight Application 2 with resource "Labor 4" is " $8+16$ * $\operatorname{BETA}(1.24,1.2)$ " seconds. The allocation here is "Value Added" as this is a corrective assembly operation.

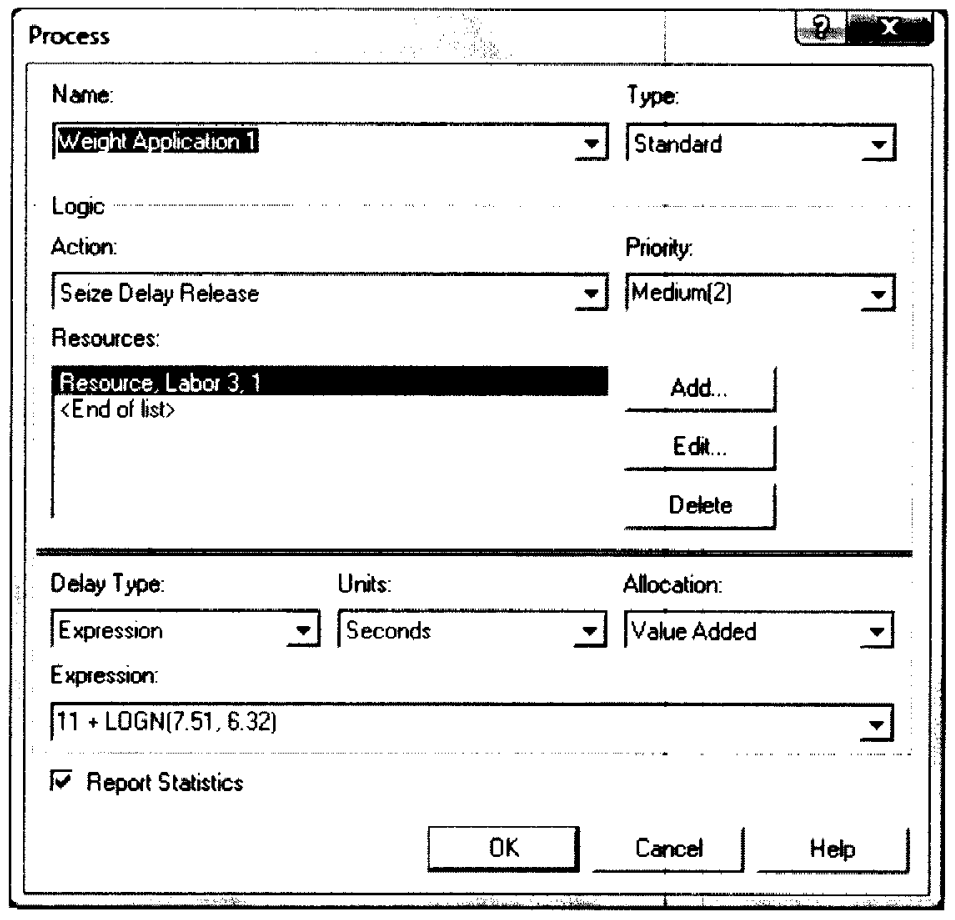

Figure 51. Process Module: Weight Application 1 


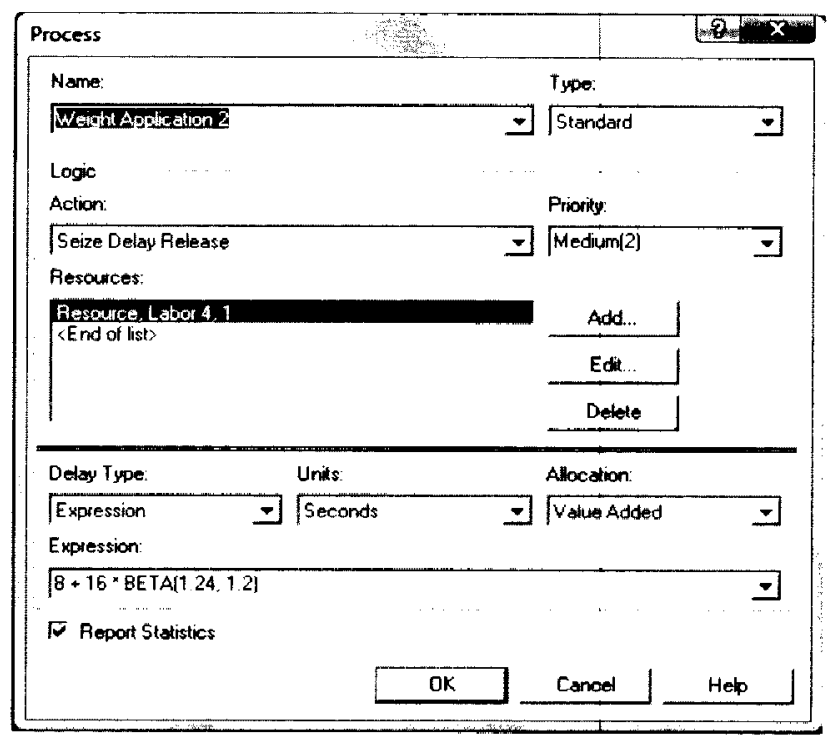

Figure 52. Process Modules: Weight Application 2

\section{Process Module: Audit Balancer}

Assemblies go through the "Audit Balancer", an inspection process with a "Non-Value Added" allocation after weight addition. In Model 1, there is one Audit Balancer with resource "AB1". The delay here is "11.6 + EXPO(1.41)" seconds.

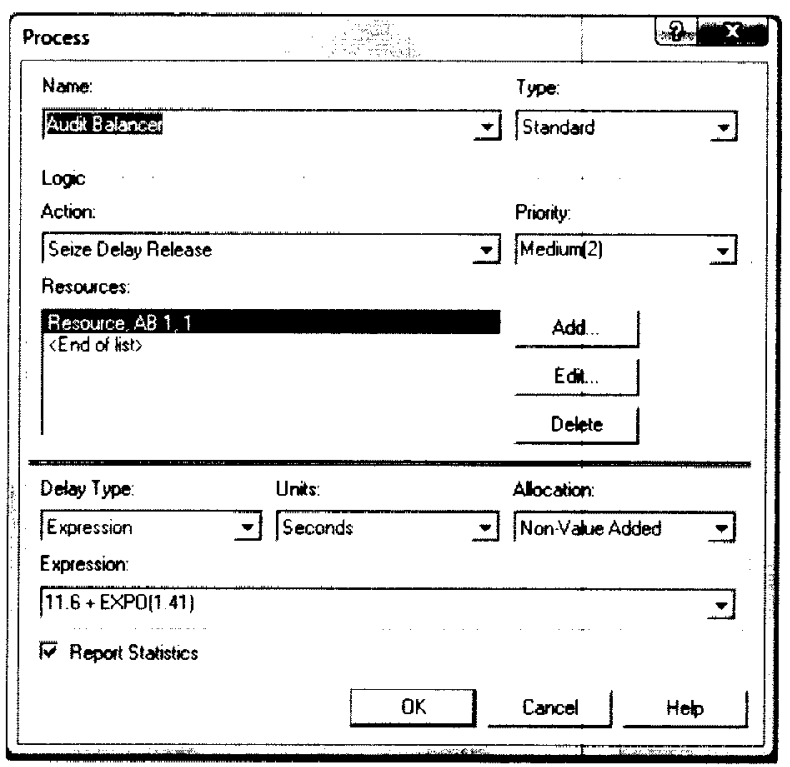

Figure 53. Process Module: Audit Balancer 
Process Modules: TPM Retorque and ID

This follows the Audit Balancer and is a "Value Added" activity. The delay is " $6.22+4.78$ * $\operatorname{BETA}(2.39,0.897)$ " seconds with one resource called "Labor 5 ".

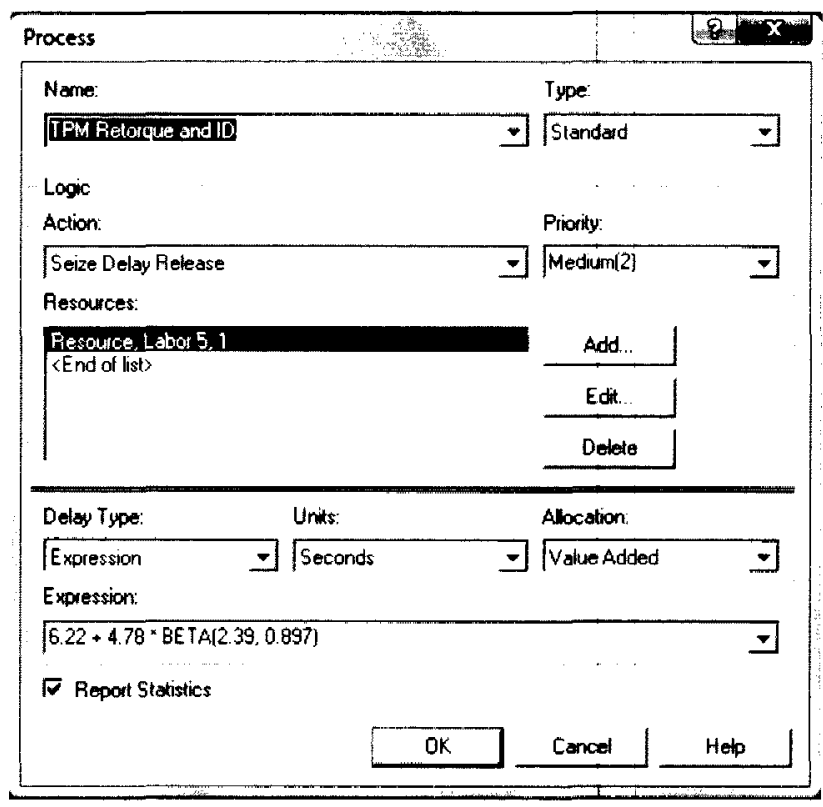

Figure 54. Process Modules: TPM Retorque and ID

Decide module: Road Assembly Good

This module incorporates the first yield percentage for road assemblies. It is similar in operation and values to the Decide module: "Spare Assembly Good".

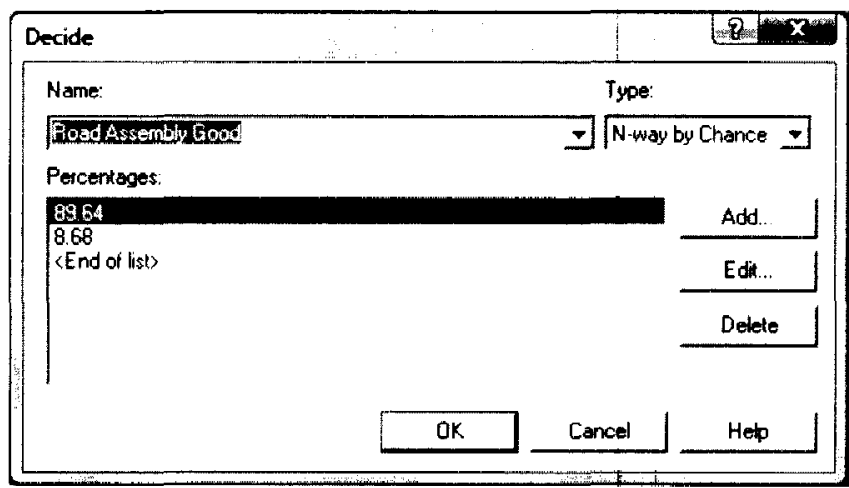

Figure 55. Decide module: Road Assembly Good 
Assign Module: Count Number of Assemblies Manufactured

This module counts the "good" assemblies manufactured. The variable

"ManufacturedQuantity" assigned a value "zero" before, gets a new value

"ManufacturedQuantity+1" incrementing its value when entities passes through it.

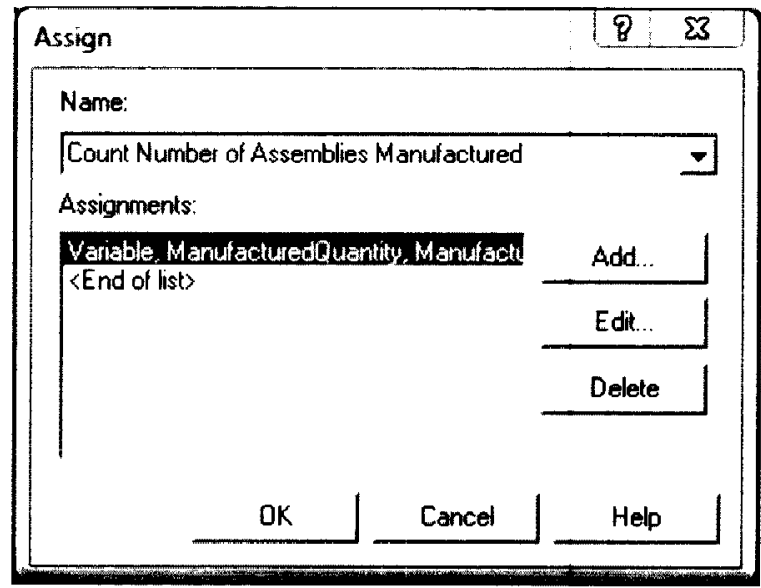

Figure 56. Assign Module: Count Number of Assemblies Manufactured

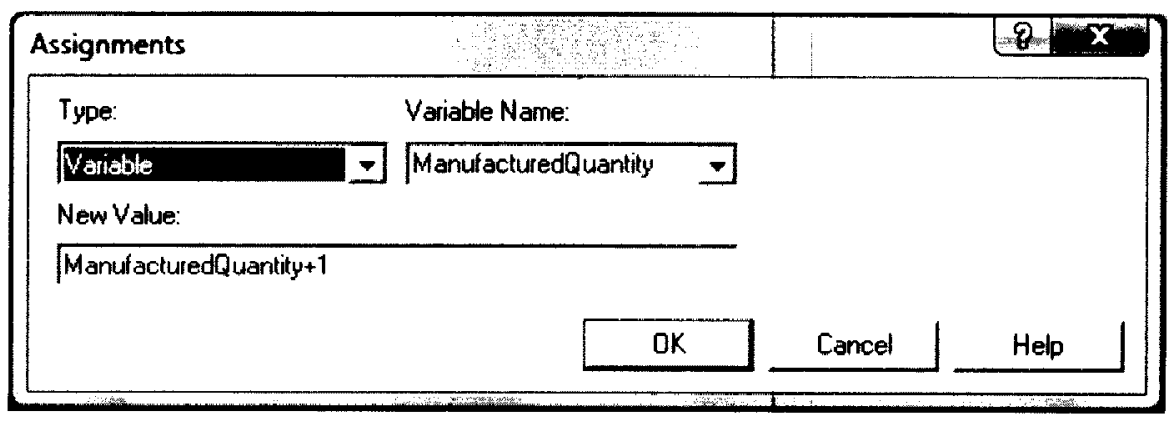

Figure 57. Assignments Module

Record Module: Record Road Assemblies Manufactured

This module records the total road assemblies manufactured in the entire replication. The type of record here is specified as "Count" and the initial value of the counter is set to 1 . The counter name is Road Assemblies Manufactured. 


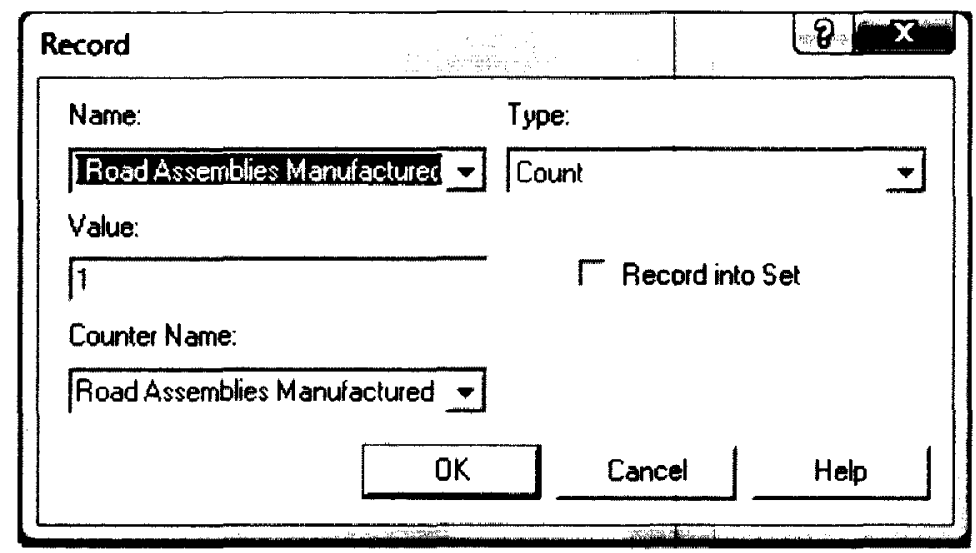

Fiqure 58. Record Module: Record Road Assemblies Manufactured

Decide Module: Check Manufactured Quantity

Once road assemblies are rendered "Good", this module checks to see if the road assemblies manufactured meet the quantity specified in the order. The type of module is "2-way by condition". It checks if the condition that the variable, "ManufacturedQuantity" is equal to the variable "OrderQuantity" specified during order generation. If not, road assembly manufacture continues. If the condition becomes true, production for the current order ceases and a signal is sent to the Order Generation Submodel to generate the next order.

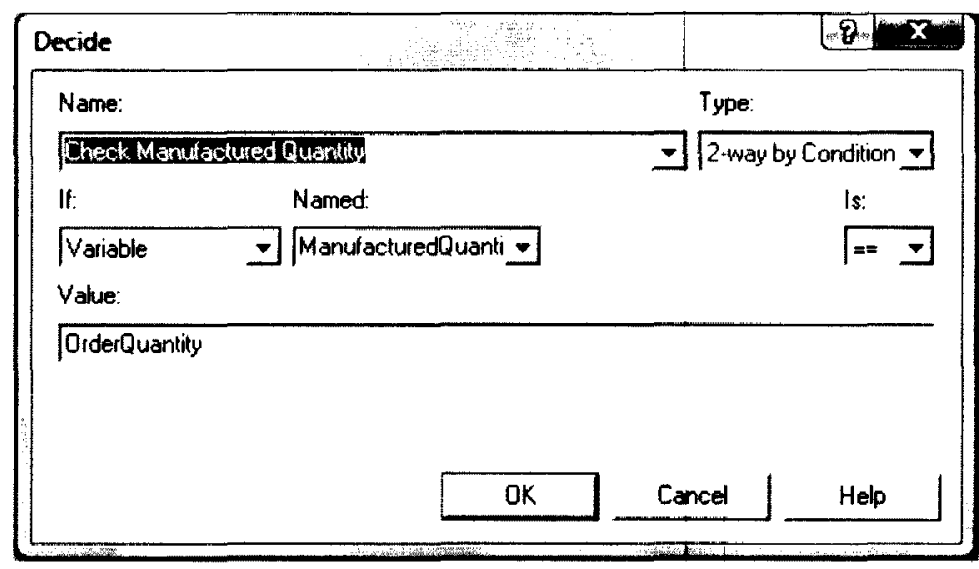

Figure 59. Decide Module: Check Manufactured Quantity 
Record Module: Record Road Assemblies Sent for Rework

This records the number of road assemblies sent for rework.

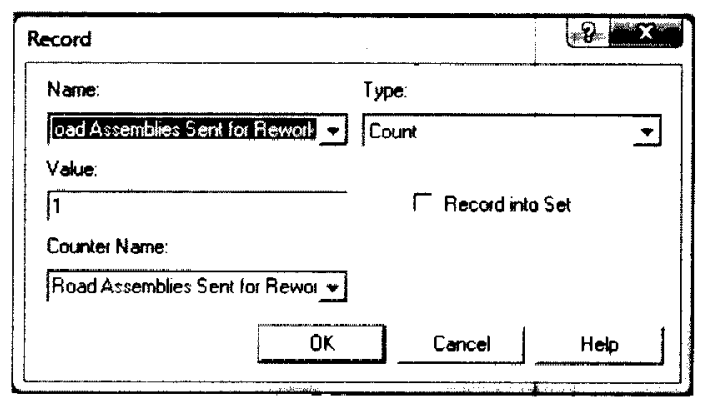

Figure 60. Record Module: Record Road Assemblies Sent for Rework

Record Module: Record Road Assemblies Scrapped

This module records the total number of road assemblies scrapped.

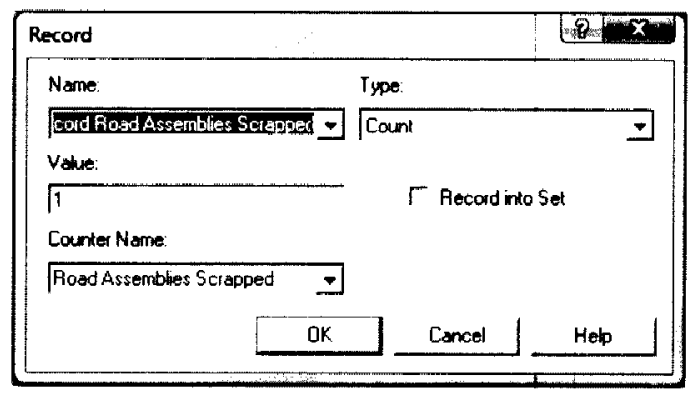

Figure 61. Record Module: Record Road Assemblies Scrapped

Dispose Module: Assembly Scrapped

The scrapped road assemblies exit the system through this module.

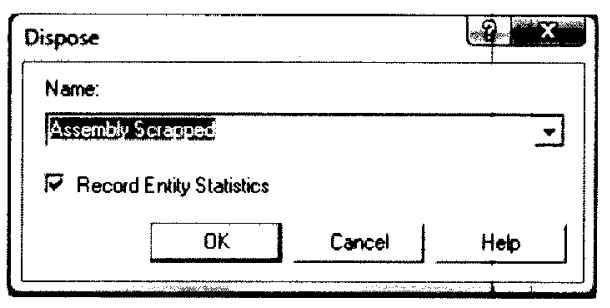

Fiqure 62. Dispose Module: Assembly Scrapped 
Process Flowchart of Road Assembly Inspection Process Submodel:

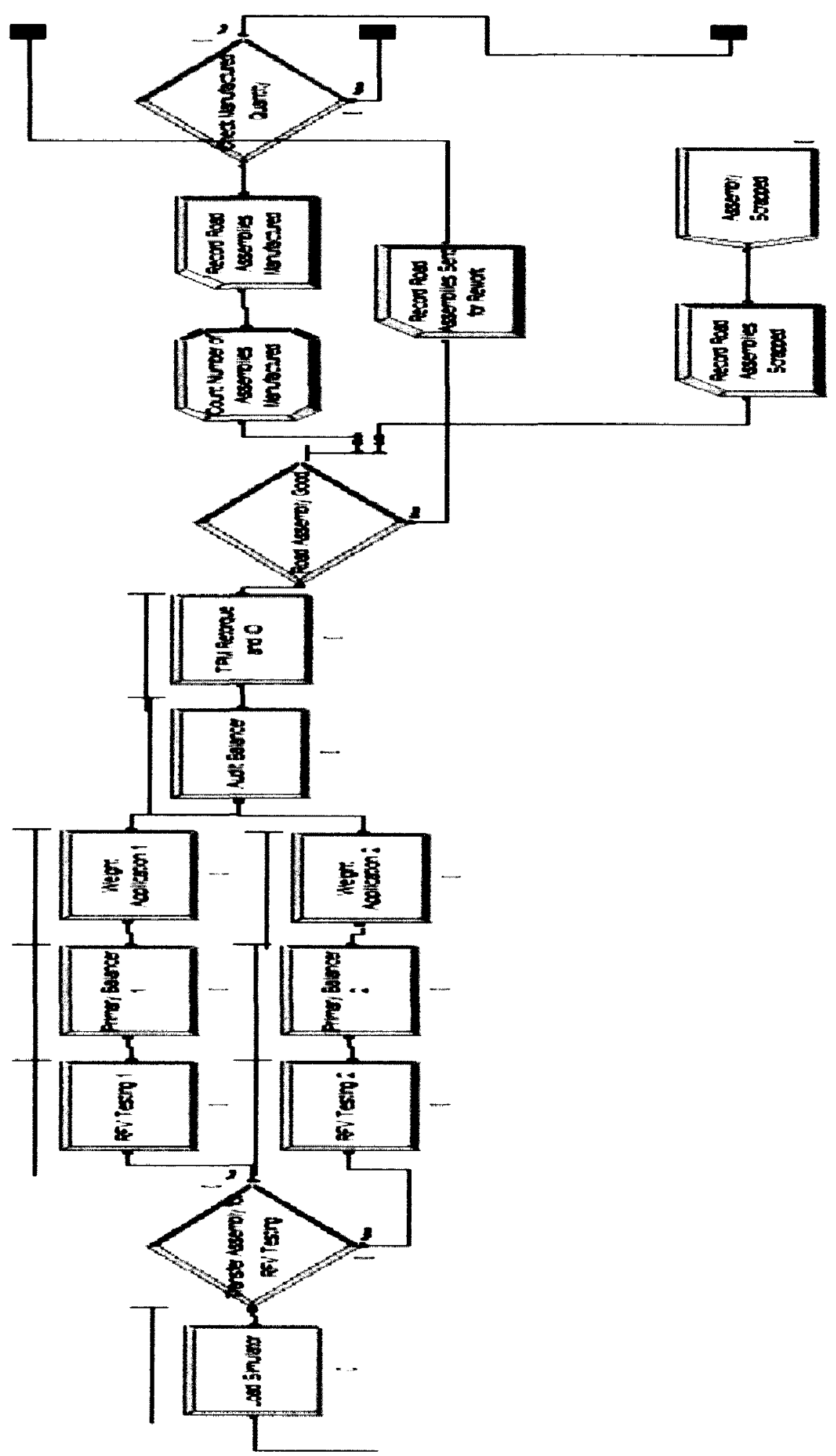

Figure 63. Road Assembly Inspection Process Submodel 


\section{SEPARATE MODULE: SPLIT ASSEMBLY INTO TIRE AND WHEEL}

In this module, road and spare assemblies sent for rework are split into their components- tire and wheel and sent to the tire and wheel stations where they are reassigned to a different order or processed for the same order.

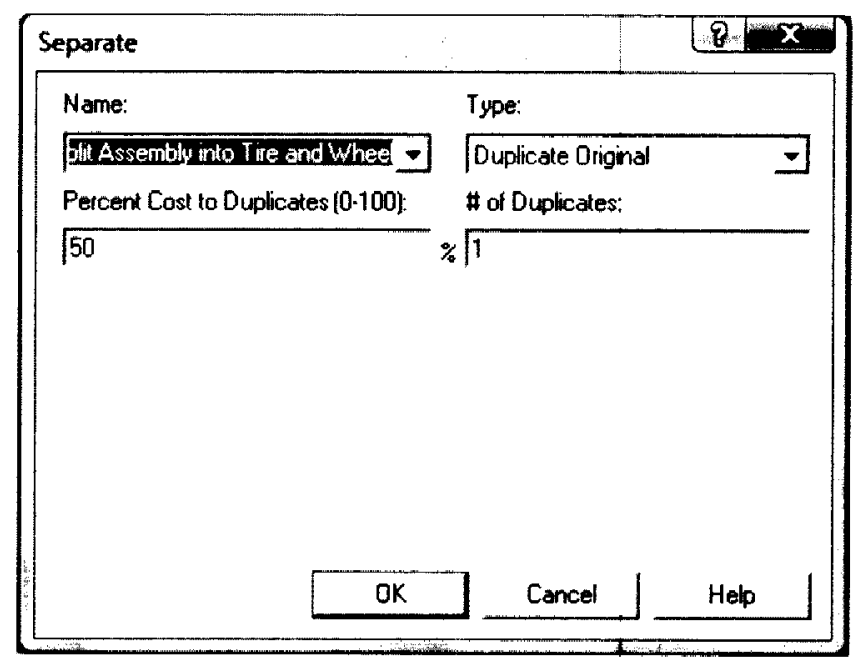

Figure 64. Separate Module: Split Assembly Into Tire and Wheel

\section{FINAL SETS AND STORAGE SUBMODEL}

Here the assemblies built and tested are batched into sets of four road tires and one spare tire and sent to storage.

\section{Batch Module: Road Tire Set}

At this Batch Module, permanent sets of 4 Road Tires are formed. The sets formed retain the criteria of the road assemblies and their Batch Size is specified as "4". The Batching rule in this module is specified as "By Attribute" and Attribute Name as "Entity.Type", to ensure that only batches of similar assemblies are formed. The batch is called as "Road TW Assembly Set". 


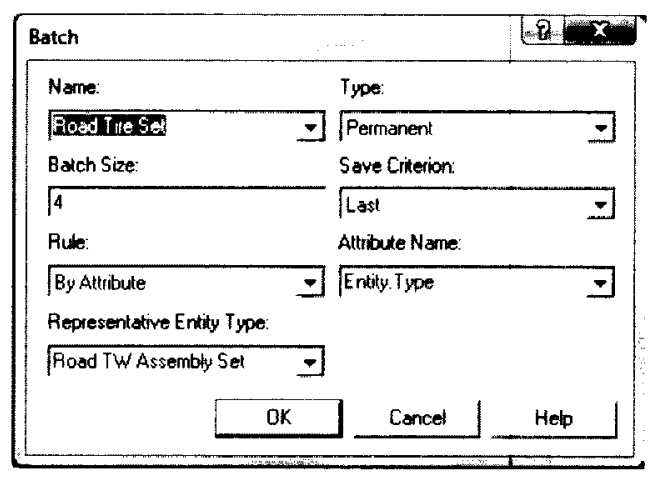

Figure 65. Batch Module: Road Tire Set

Scan Block: Check Availability of Spare Tire

This block checks the availability of a spare tire for a batch of four road assemblies. The condition is "NQ(SpareTire.Queue) >= 1". If true, the batch moves to the next operation. If not, it waits until a spare assembly is available.

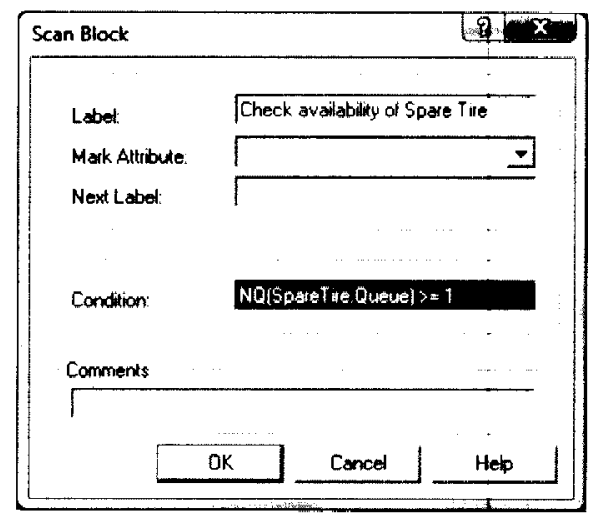

Figure 66. Scan Block: Check Availability of Spare Tire

Remove Module: Pick Up Spare Tire

This module removes one spare tire from the Spare Tire Storage (SpareTire.Queue) when a batch of four Road Assemblies arrives and sends both the entities to the next module. 


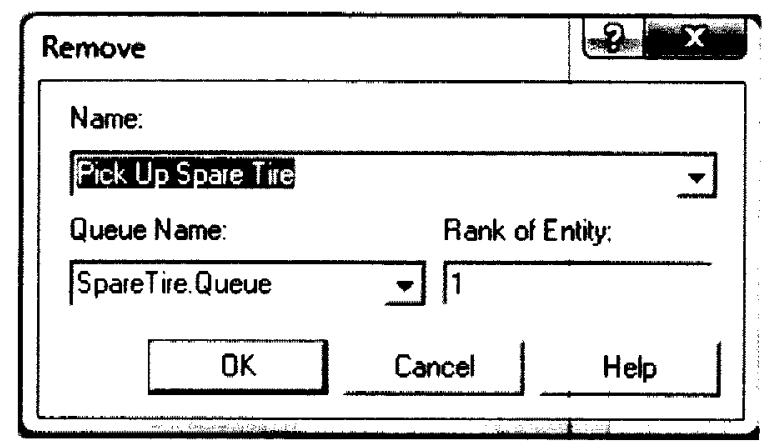

Figure 67. Remove Module: Pick Up Spare Tire

Match Module: SpareTire matched with Road Tires

As the name indicates, at this module the spare tire is brought together with the batch of four road assemblies and sent to form a set. The Number to Match is specified here as "2", because the four Road Tire batch is treated as one entity and the spare assembly as the second entity.

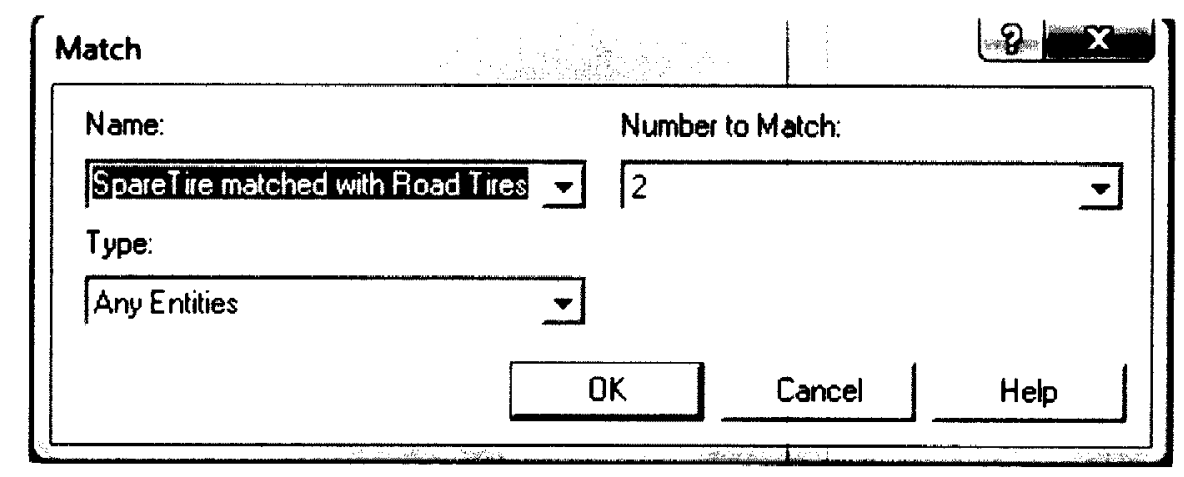

Figure 68. Match Module: SpareTire matched with Road Tires

Batch Module: 4 Road Tires and 1 Spare Tire

At this module the four road assemblies and the single spare assembly are combined to form one entity. This module depicts the combinational aspect of the operation. The representative entity formed is called "Assembly Sets". 


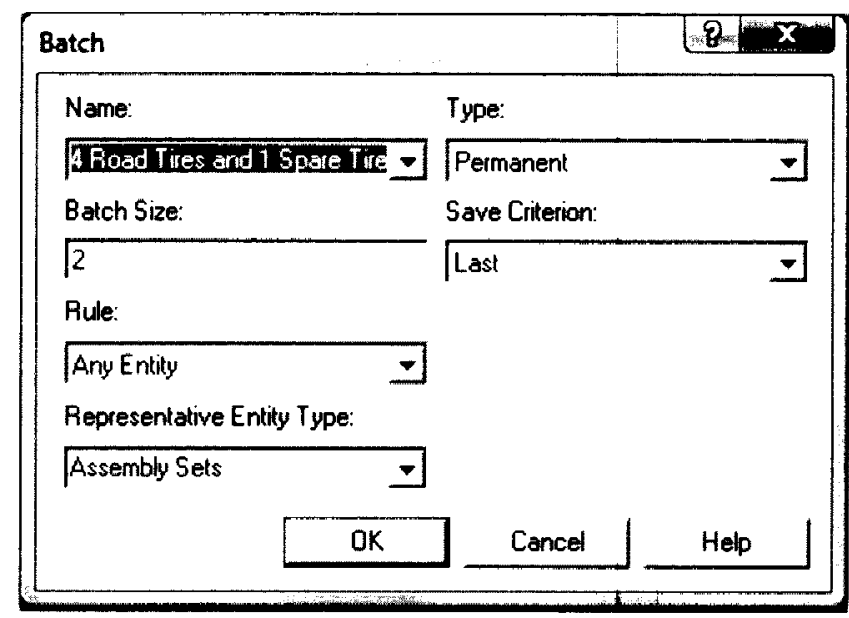

Figure 69. Batch Module: 4 Road Tires and 1 Spare Tire

\section{Process Module: Full Set and Stock}

This module accounts for the processing time and resource used for the operation to form the set of four road and one spare assembly. The delay here is "28+17 * $\operatorname{BETA}(1.16,0.975)$ " seconds and the resource used is "Labor 6".

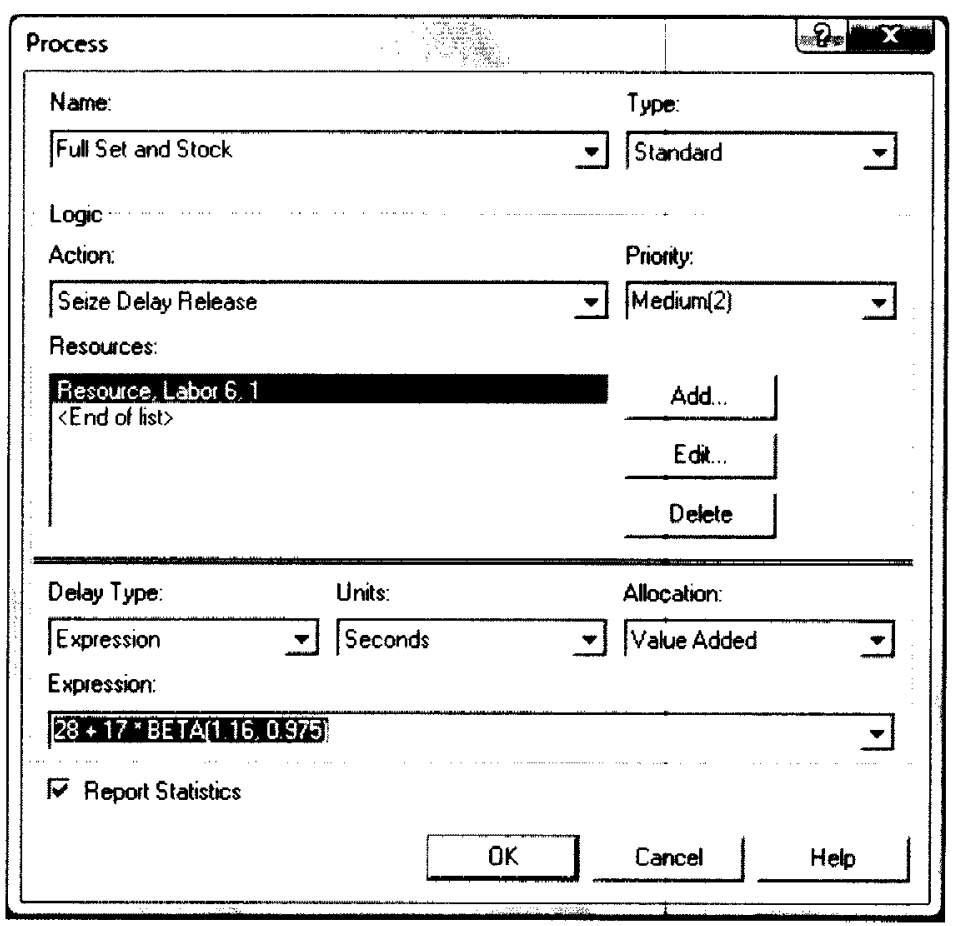

Fiqure 70. Process Module: Full Set and Stock 
Process Module: Film Application

Here, a resource "Labor 7" is used with an exponential delay of 8 seconds.

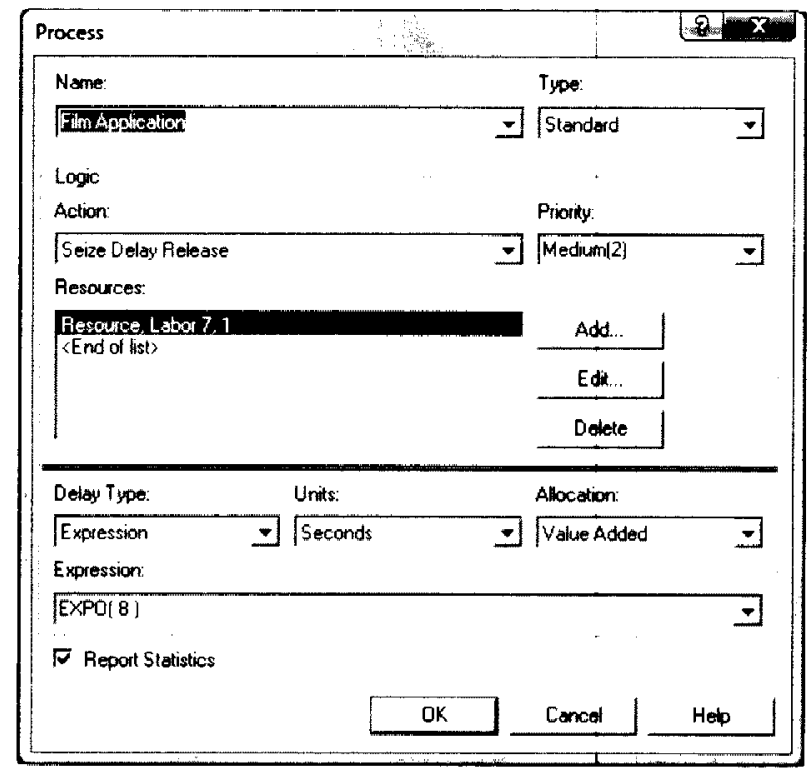

Figure 71. Process Module: Film Application

Record Module: Count Total Assemblies Manufactured

This module records the total assembly sets manufactured and sent to the gantry for supply to the customer. It is of type "Count" and the counter is named "Total Assembly Sets Manufactured".

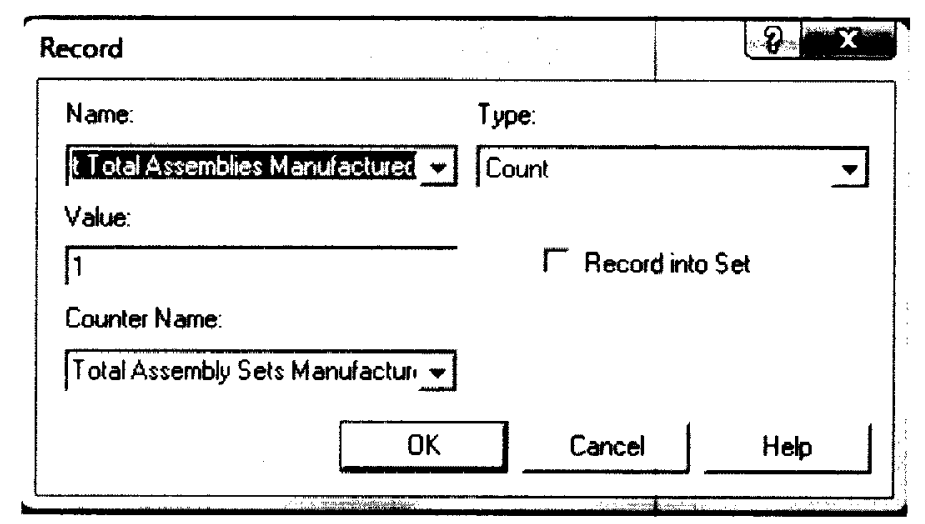

Figure 72. Record Module: Count Total Assemblies Manufactured 
Dispose Module: To Stacker

The assemblies sets manufactured exit out of the system to the stacker at this module.

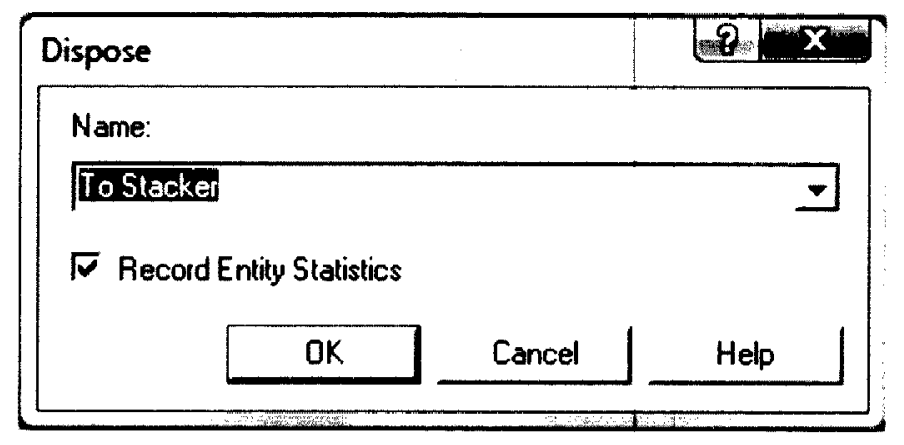

Figure 73. Dispose Module: To Stacker

Process Flowchart of Final Sets and Storage Submodel:

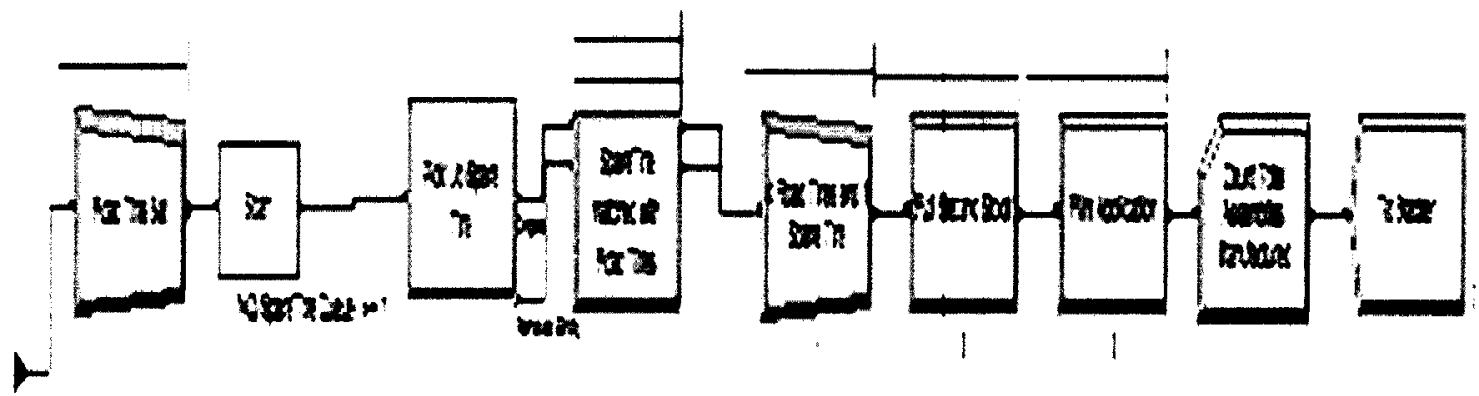

Figure 74. Final Sets and Storage Submodel 


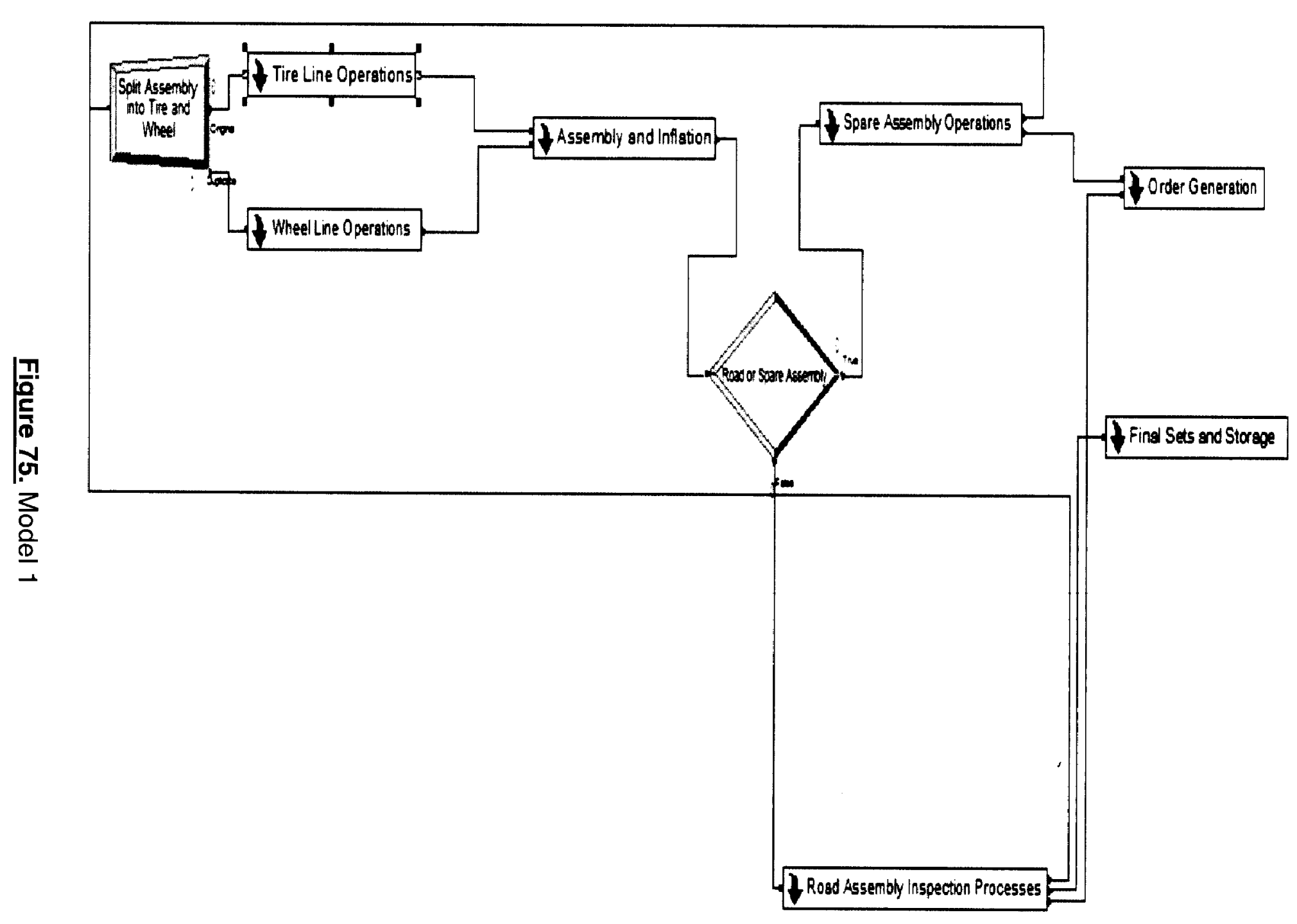


DOWNTIME DATA FOR ALL RESOURCES

\begin{tabular}{|c|c|c|c|c|}
\hline Name & Type & Uptime & Downtime & Units \\
\hline Labor 1 Failure & Time & 0.9965 & 0.0035 & Hours \\
\hline Labor 2 Failure & Time & 0.997 & 0.003 & Hours \\
\hline Orient Failure & Time & 0.9985 & 0.0015 & Hours \\
\hline W Soaper Failure & Time & 0.9996 & 0.0004 & Hours \\
\hline T Soaper Failure & Time & 1 & 0 & Hours \\
\hline T Heater Failure & Time & 0.9953 & 0.0047 & Hours \\
\hline Mounter Failure & Time & 0.9891 & 0.0109 & Hours \\
\hline Matcher Failure & Time & 0.9985 & 0.0015 & Hours \\
\hline Inflator Failure & Time & 0.9971 & 0.0029 & Hours \\
\hline Simulator Failure & Time & 0.995 & 0.005 & Hours \\
\hline RFV2 Failure & Time & 0.9984 & 0.0016 & Hours \\
\hline RFV1 Failure & Time & 0.9984 & 0.0016 & Hours \\
\hline PB1 Failure & Time & 0.9882 & 0.0118 & Hours \\
\hline PB2 Failure & Time & 0.9914 & 0.0086 & Hours \\
\hline AB1 Failure & Time & 0.9987 & 0.0013 & Hours \\
\hline Labor 3 Failure & Time & 1 & 0 & Hours \\
\hline Labor 4 Failure & Time & 1 & 0 & Hours \\
\hline Labor 5 Failure & Time & 0.9982 & 0.0018 & Hours \\
\hline Labor 6 Failure & Time & 0.9989 & 0.0011 & Hours \\
\hline Labor 7 Failure & Time & 0.9974 & 0.0026 & Hours \\
\hline
\end{tabular}

Table 1. Downtime Data for Model 1 Resources 


\section{STATISTICS AND VARIABLES}

Several attributes and variables have been used in this model to represent the real setting closely. Three attributes namely Tire Type, Wheel Type and Assembly type, and variables such as manufactured quantity, order quantity, processing times and downtimes for each operation and scrap and rework rate for the process are employed to execute the simulation similar to the actual process. Some of the statistics used for comparison are:

1. Average Cycle time: This is defined as the reciprocal of the average exit rate of entities from the system. It is given by the formula: "Average Cycle Time = 1/Exit rate" Where 'Exit Rate' is the number of entities exiting the system per unit time.

2. Work in process: WIP is the inventory of partly finished products in a production process.

3. Total time per entity: The total time an operation spends on a single entity before it goes to the next operation. This includes the actual processing time and the waiting time at the operation.

4. Resource Utilization: The percentage of time that a resource is actually in use during the process.

5. Processed Quantity: This is the general term we use for total number of units of an entity manufactured, scrapped or reworked. 


\section{MODEL VALIDATION}

Results obtained from Model 1 are compared with real data from the assembly line. The following parameters are compared:

1. Average Cycle Time

a. Simulation Model 1

Total Assembly Sets Manufactured $=190961.50$

Total Replication Length $=200$ Days

Warm-up Period $=40$ Days

Effective Replication Length $=160$ Days

Average Cycle Time $=\left(160^{\star} 20^{\star} 3600\right) /\left(190961.5^{\star} 5\right)=12.065$ seconds

b. Manufacturing Line Data

\begin{tabular}{|l|c|c|c|c|c|c|c|c|}
\hline Month & $\begin{array}{c}\text { Apr- } \\
\mathbf{0 8}\end{array}$ & $\begin{array}{c}\text { Mar- } \\
\mathbf{0 8}\end{array}$ & $\begin{array}{c}\text { Feb- } \\
\mathbf{0 8}\end{array}$ & $\begin{array}{c}\text { Jan- } \\
\mathbf{0 8}\end{array}$ & $\begin{array}{c}\text { Nov- } \\
\mathbf{0 7}\end{array}$ & $\begin{array}{c}\text { Oct- } \\
\mathbf{0 7}\end{array}$ & $\begin{array}{c}\text { Sep- } \\
\mathbf{0 7}\end{array}$ & $\begin{array}{c}\text { Aug- } \\
\mathbf{0 7}\end{array}$ \\
\hline $\begin{array}{l}\text { Average } \\
\text { Production }\end{array}$ & 5102 & 5187 & $\mathbf{4 8 2 3}$ & 4925 & 5159 & 4893 & 5057 & 5162 \\
\hline
\end{tabular}

Table 2. Manufacturing Line: Monthly Production Data

Average Monthly Production $=5038$ assemblies .

Production Time per day $=20$ Hours $=(20)(60)(60)=72000$ seconds .

Average Maintenance Equipment Downtime $=11.08 \%$

Average Cycle Time $=\left(72000-\left(0.1108^{\star} 72000\right)\right) / 5038=12.708$ seconds.

Percentage Variability between real and simulation data $=$

$$
=(12.708-12.065)(100) / 12.707=5.06 \%
$$


2. Average Equipment Utilization

a. Simulation Model 1

\begin{tabular}{|c|c|}
\hline Station & Average \\
\hline AB 1 & 0.9615 \\
\hline Inflator & 0.6474 \\
\hline Matcher & 0.5938 \\
\hline Mounter & 0.589 \\
\hline Orient Station & 0.503 \\
\hline PB 1 & 0.4721 \\
\hline PB 2 & 0.7012 \\
\hline RFV 1 & 0.4471 \\
\hline RFV 2 & 0.7985 \\
\hline Simulator & 0.4375 \\
\hline T Heater & 0.9246 \\
\hline T Soaper & 0.9431 \\
\hline W Soaper & 0.9344 \\
\hline Average Utilization & $\mathbf{0 . 6 8 7 7 4 6 1 5 4}$ \\
\hline
\end{tabular}

Table 3. Model 1: Equipment Utilization Data

b. Manufacturing Line Data

\begin{tabular}{|l|l|l|l|l|l|l|l|}
\hline Jan & 60 & Apr & 60 & Jul & 87 & Oct & 79 \\
\hline Feb & 57 & May & 60 & Aug & 90 & Nov & 79 \\
\hline Mar & 58 & Jun & 62 & Sep & 90 & Dec & 79 \\
\hline
\end{tabular}

Table 4. Manufacturing Line: Monthly Utilization Data

Average Equipment Utilization $=0.7175$

Percentage Variability between real and simulation data $=$ $=(0.7175-0.6877)(100) / 0.7175=4.15 \%$. 
3. First Piece Yield

a. Simulation Model 1

\begin{tabular}{|l|l|}
\hline Road Assemblies Manufactured & 763346.4 \\
\hline Road Assemblies Scrapped & 73747.7 \\
\hline Road Assemblies Sent for Rework & 14268.2 \\
\hline Spare Assemblies Manufactured & 191776.6 \\
\hline Spare Assemblies Scrapped & 18530.6 \\
\hline Spare Assemblies Sent for Rework & 3571.8 \\
\hline Total Assemblies Processed & 1065241.3 \\
\hline Total Good Assemblies Processed & 955123 \\
\hline First Piece Average Yield & $\mathbf{8 9 . 6 6 \%}$ \\
\hline
\end{tabular}

Table 5. Model 1: First Piece Yield Data

b. Manufacturing Line Data (2007)

\begin{tabular}{|c|c|c|c|c|c|c|c|c|c|c|c|}
\hline Jan & Feb & Mar & Apr & May & Jun & Jul & Aug & Sep & Oct & Nov & Dec \\
\hline 89 & 89 & 84 & 83 & 84 & 90 & 90.6 & 91 & 95 & 93.77 & 93.2 & 93.08 \\
\hline
\end{tabular}

Table 6. Manufacturing Line: First Piece Yield Data

First Piece Average Yield in $2007=89.64 \%$

Percentage Variability between real and simulation data $=$

$$
=(89.66-89.64)(100) / 89.64=2.23 \% \text {. }
$$




\section{CHAPTER IV}

\section{OPERATIONS MODEL II}

\section{OVERVIEW}

Model 2 represents the manufacturing scenario where five new types of assembly combinations are added to the existing mix of 32 configurations increasing the variety manufactured in the plant to 37 . The new variety is in the form of combinations 19 and 20 inch diameter assemblies which also weigh more than the existing combinations.

\section{MODELING ASSUMPTIONS}

The following assumptions are made in the simulation model

- Changes to existing equipment have been made only when existing equipment was not capable of processing new variety to meet design requirements (dimensional and weight variation). None of these changes are intended to affect the average cycle time.

- Downtimes, scrap and rework rates of all individual resources are same in the three systems.

- For operations where changes were not made to cycle time due to new variety, it is assumed that the changes made to accommodate design changes also takes care that cycle times do not change. 
- The addition of new equipment and other changes do not affect the scrap and rework rate.

- Processing costs per second increases due to additional investments made to accommodate design requirements.

- Order quantities for the new variety are not actual. They are calculated based on reasonable estimates from existing order quantities.

\section{CHANGES FROM MODEL I}

- Five more types of assembly are added.

- Processing times for new variety are different for some operations (due to increase in dimensions and weight). The assign module in Order Generation assigns varying cycle time for the operations.

- Changes to existing resources are made only to accommodate design needs, not takt time requirements.

- Additional resources were included in some cases because the resource is not capable of processing new variety (as they were not meeting design needs). The changes made were:

-Additional Tire Soaper.

-Additional Inflator.

\section{MODEL CONSTRUCTION AND APPROACH}

Model 2 has many modules similar to Model 1 . The changes made to accommodate the new variety are mentioned below. 


\section{ORDER GENERATION SUBMODEL}

ReadWrite Module: Read Order Data

The file from which data is read in this module is different and contains data pertaining to the new variety as well. It is named "Assembly orders2.xls".

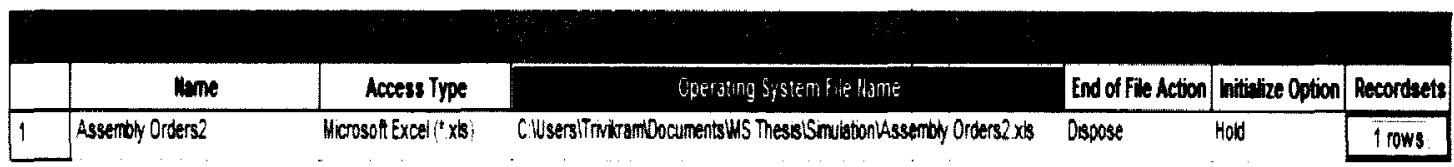

Figure 76. File Module

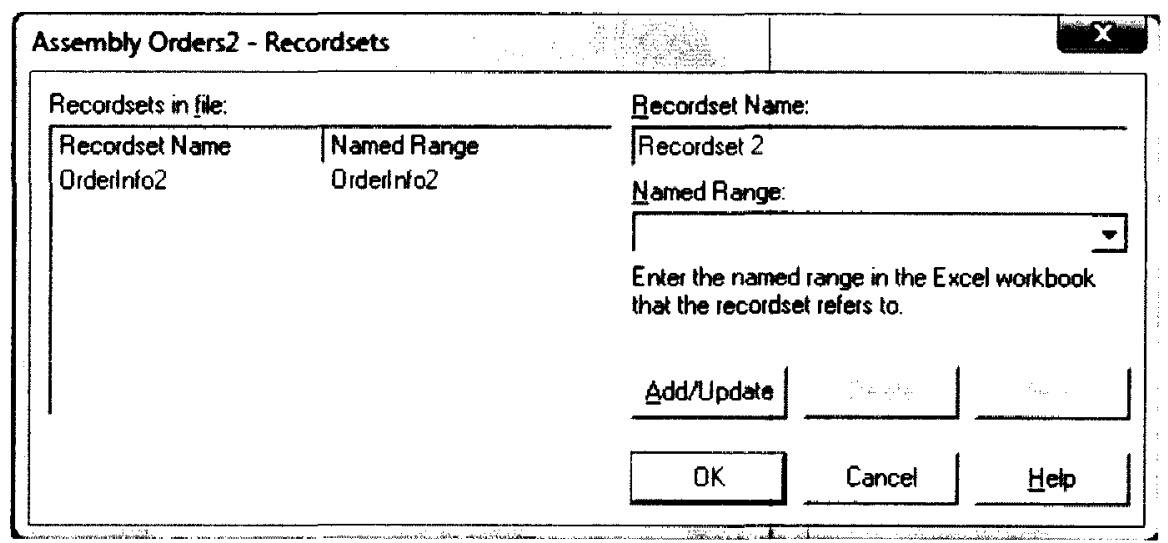

Figure 77. Recordsets: Assembly Orders2

Decide Module: Check if 16 to 18 inch order

This module checks to see if the new order generated is for Spare Tires (Variable: Order Number=0),16-18 inch road tires (Variable: Order Number $=1$ ) or 19-20 inch road tires (new variety) (Variable: Order Number=2). The type is defined as "N-way by condition". If the first two conditions are met, the order goes to one assign module, otherwise it goes to another assign module. 


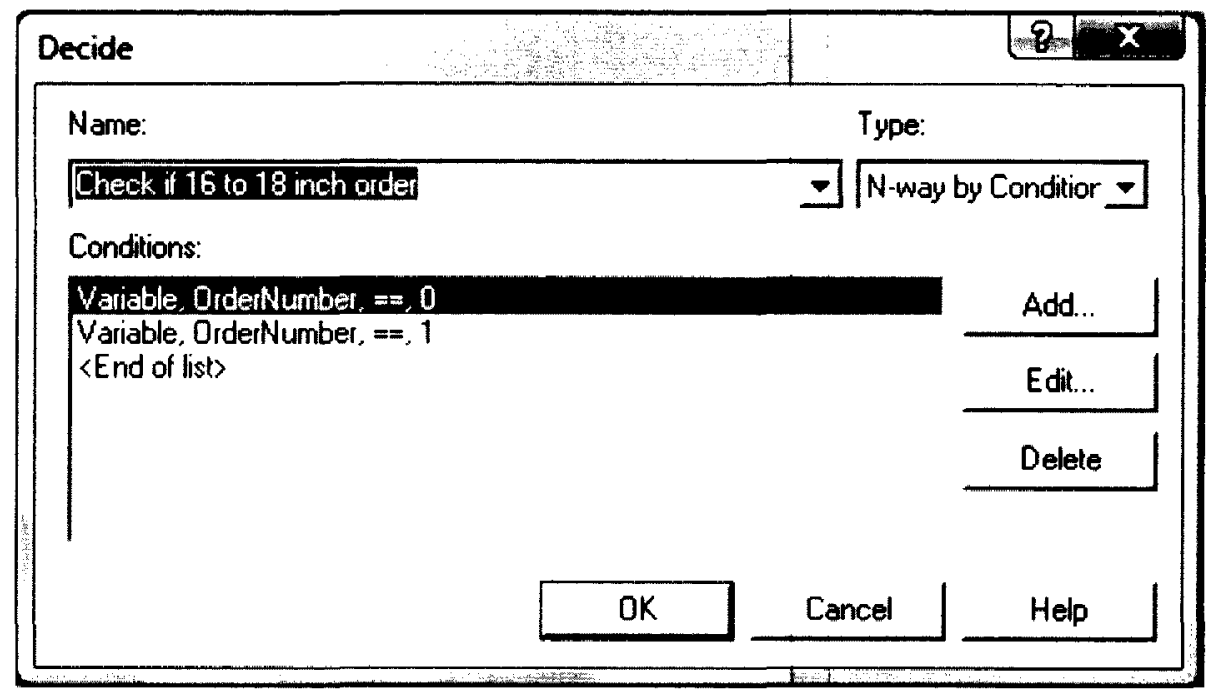

Figure 78. Decide Module: Check if 16 to 18 inch order

Assign Module: "Assign Assembly Characteristics 1" and "Assign Assembly Characteristics 2"

The contrasting change here from Model 1 is the addition of a new Assign module after the Decide Module-"Check if 16 to 18 inch order". Also, each of the two Assign Modules, along with assigning the variable "ManufacturedQuantity" as "zero", also assigns different cycle times to five stations depending on weather the order is for spare assembly, 16-18 inch road assembly or 19-20 inch road assembly. The assignment tables with cycle times are in the figures below. 


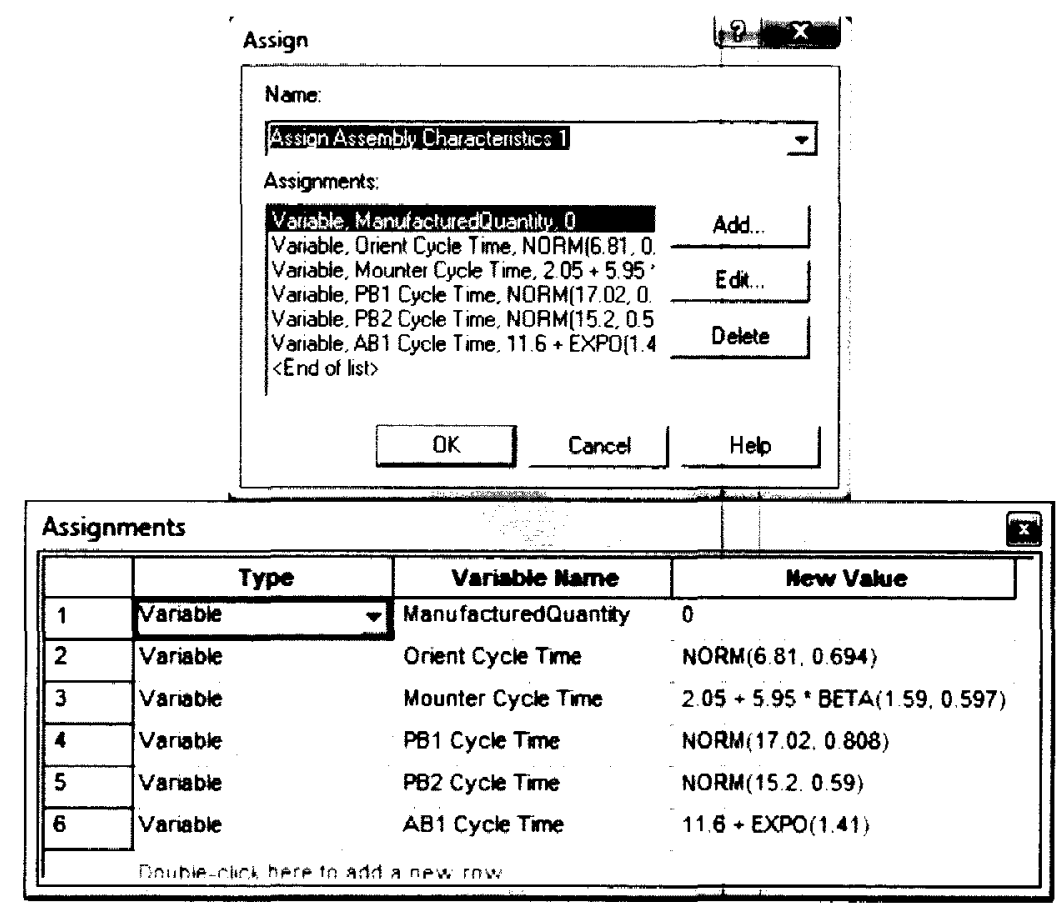

Figure 79. Assign Module: Assign Assembly Characteristics 1

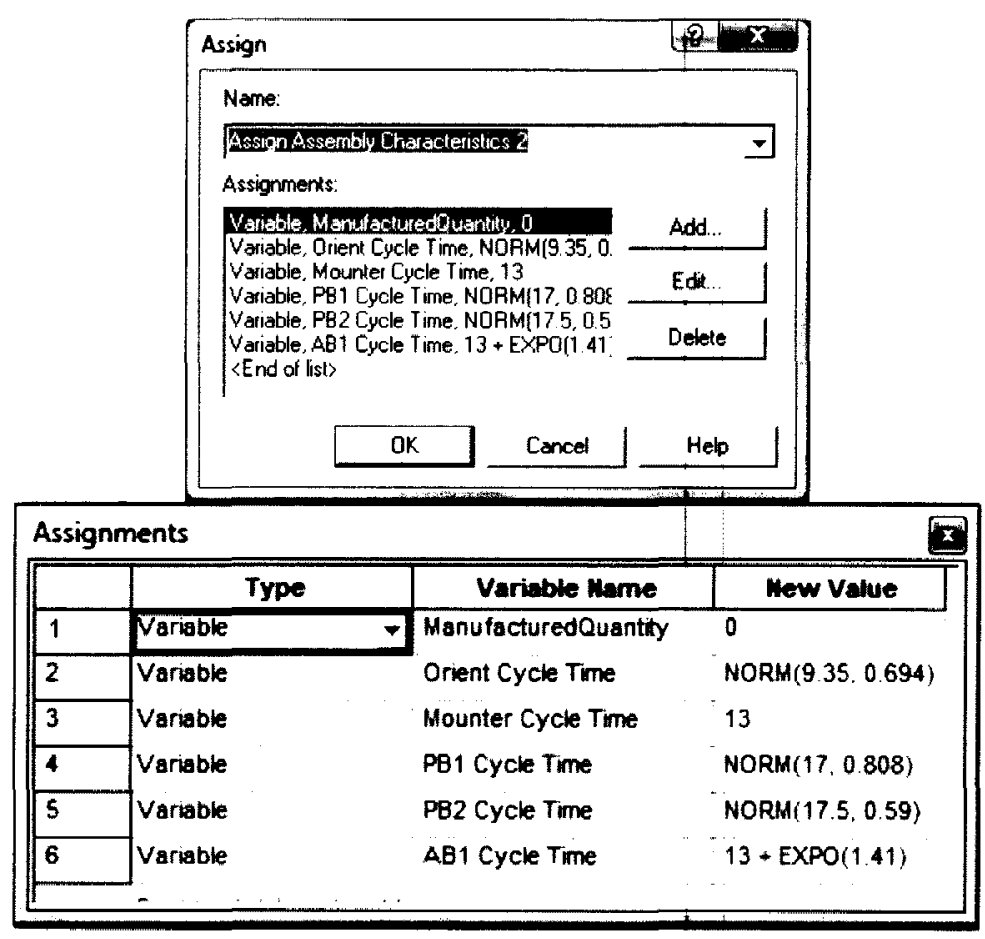

Figure 80. Assign Module: Assign Assembly Characteristics 2 
Process Flowchart of new Order Generation Submodel:

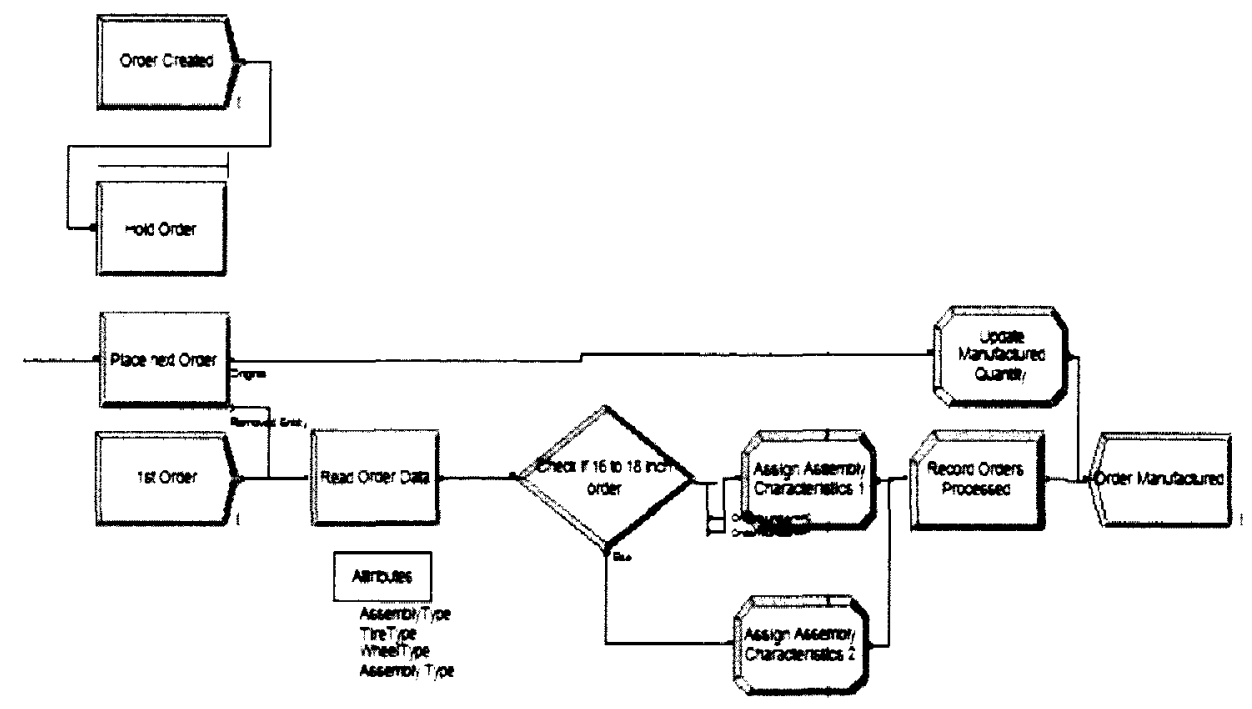

Figure 81. Order Generation Submodel

\section{TIRE LINE OPERATIONS SUBMODEL}

Decide Module: Check if 16 to 18 inch Tire:

This module is added after the "Tire Heater" process module to check if the order is for spare assembly, $16-18$ inch road assembly or 19-20 inch road assembly. The condition used here is however, different. It is of type "2-way by Condition". If the variable "OrderNumber" is less than or equal to one, the tire goes to the "16 to 18 inch Tire Soaper" process, otherwise it goes to the "19 to 20 inch Tire Soaper" process. 


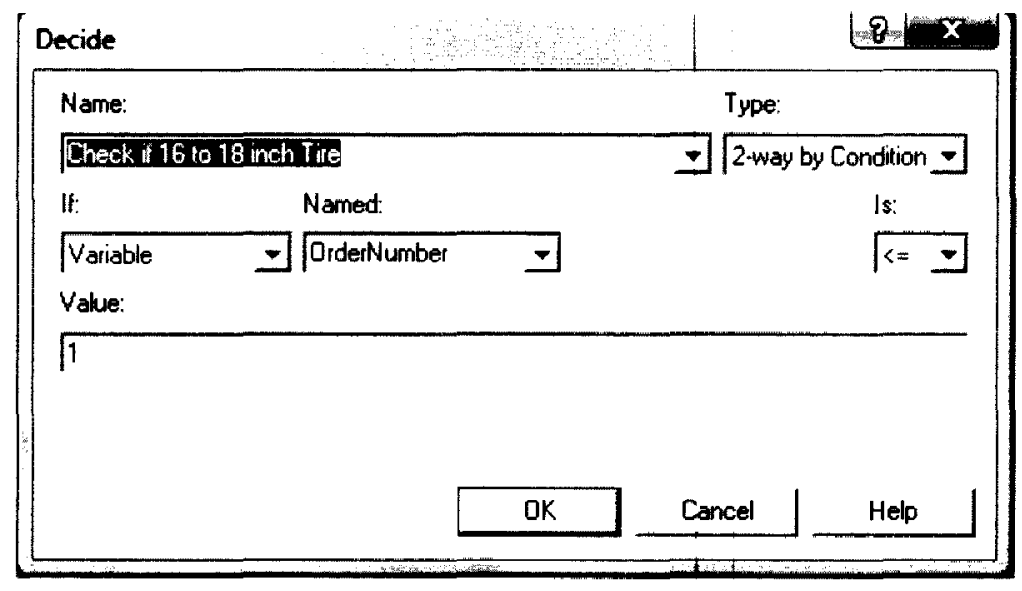

Figure 82. Decide Module: Check if 16 to 18 inch Tire

Process Modules: "16 to 18 inch Tire Soaper" and "19 to 20 inch Tire Soaper"

Here an additional Tire Soaper is added to the process for the 19 and 20inch tires. The original resource is now called "T Soaper 1" and the new resource is called "T Soaper 2". The processing times are specified as same for both.

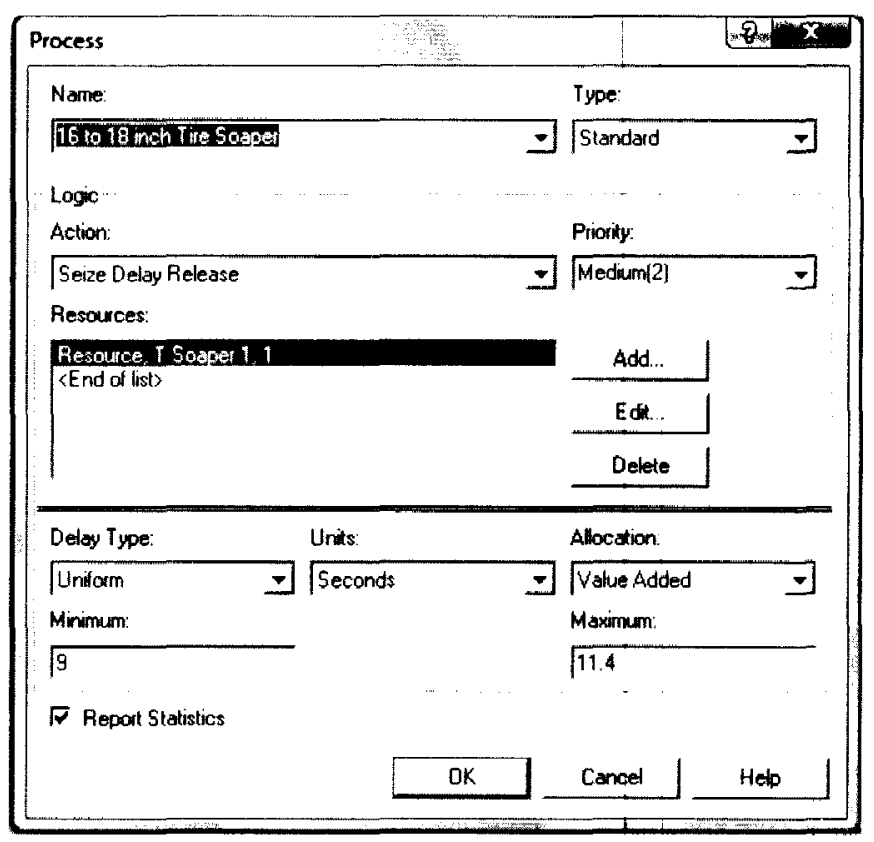

Figure 83. Process Module: 16 to 18 inch Tire Soaper 


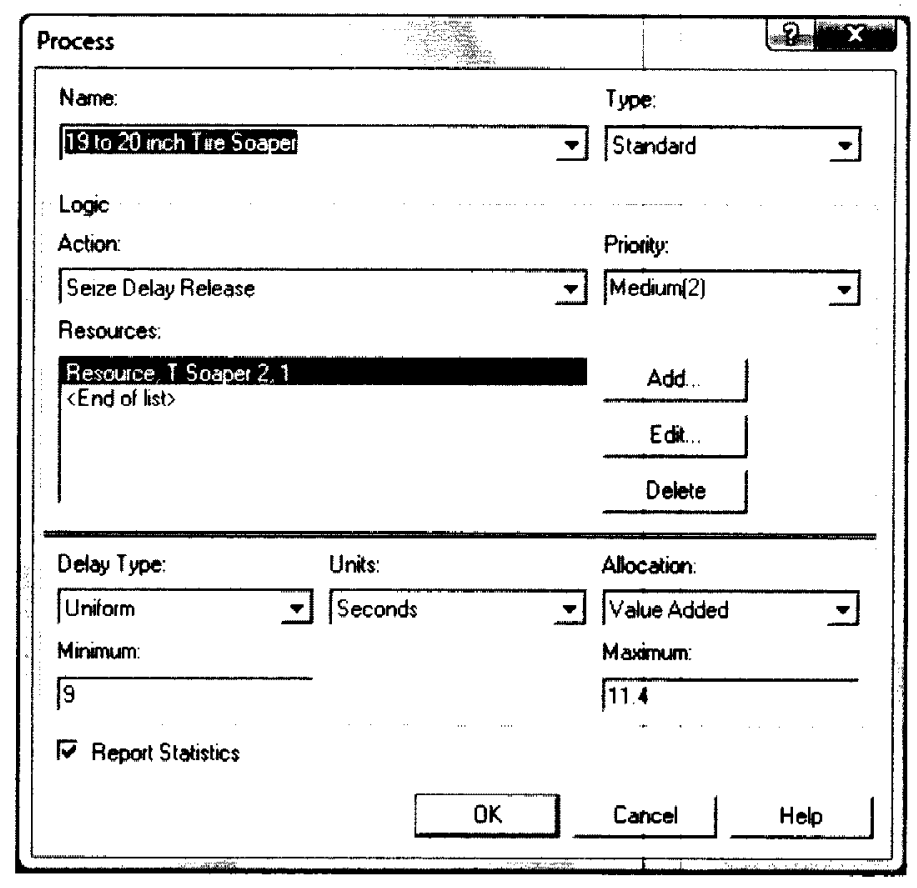

Figure 84. Process Module: 19 to 20 inch Tire Soaper

Process Flowchart of new Tire Line Operations Submodel:

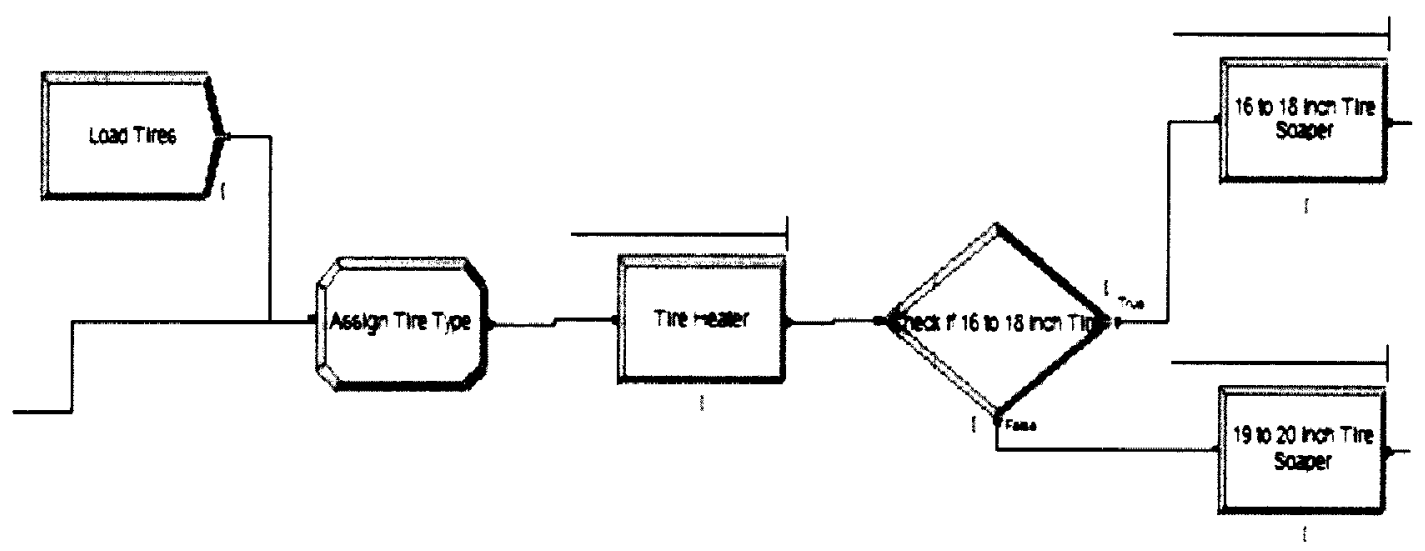

Fiqure 85. Tire Line Operations Submodel 


\section{WHEEL LINE OPERATIONS SUBMODEL}

Process Module: Wheel Orient

The change in this process module is, the processing time in this station changes for different size assemblies. Hence, the value of the processing times defined as, "Orient Cycle Time" is assigned by the Assign Modules: "Assign Assembly Characteristics 1" and "Assign Assembly Characteristics 2".

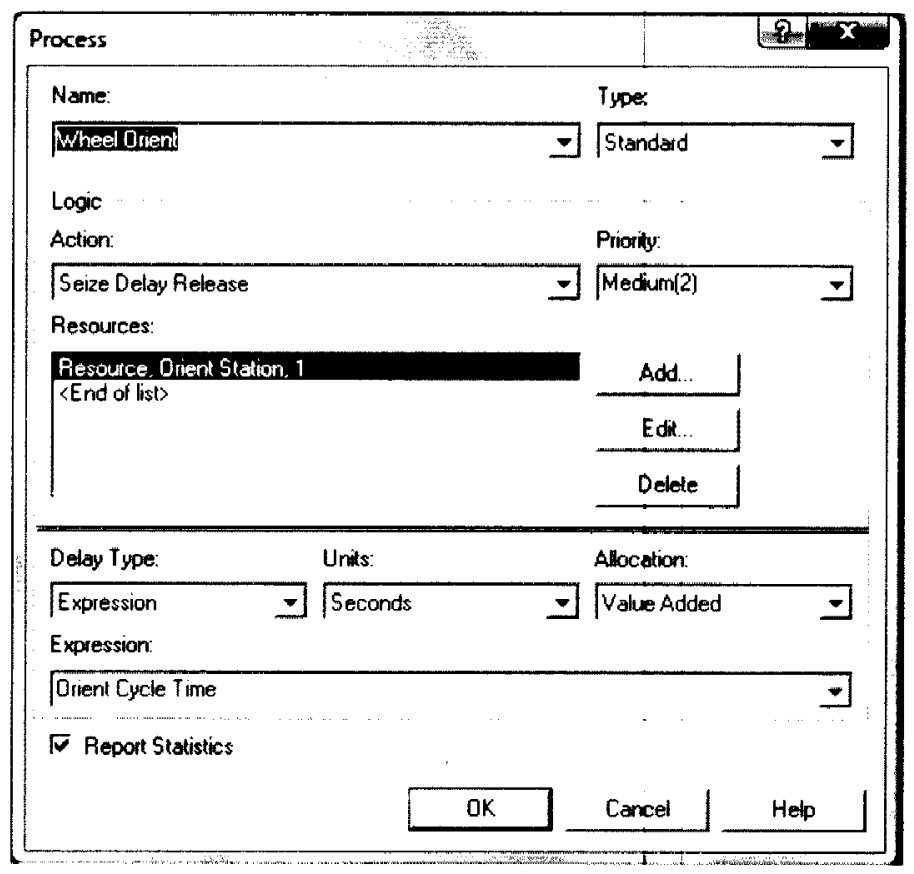

Figure 86. Process Module: Wheel Orient

\section{ASSEMBLY AND INFLATION SUB MODEL}

Process Module: Mount Tire on Wheel

The change here is that the processing time in this station changes for different size assemblies. Hence, the value of the processing times is defined as, "Mounter Cycle Time" is assigned by the Assign Modules: "Assign Assembly Characteristics 1" and "Assign Assembly Characteristics 2" 


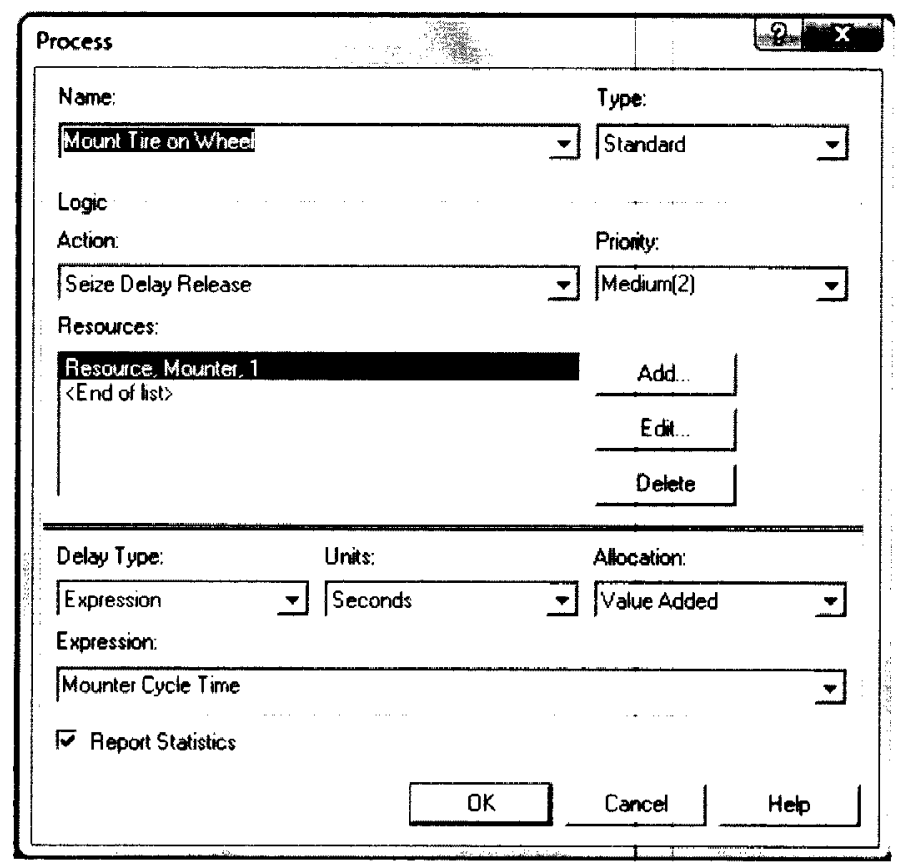

Figure 87. Process Module: Mount Tire on Wheel

Decide Module: Check if 16 to 18 inch assembly:

This module is added to check if the order is for spare assembly, 16-18 inch road assembly or 19-20 inch road assembly. The condition used here is same as the decide module "Check if 16 to 18 inch tire".

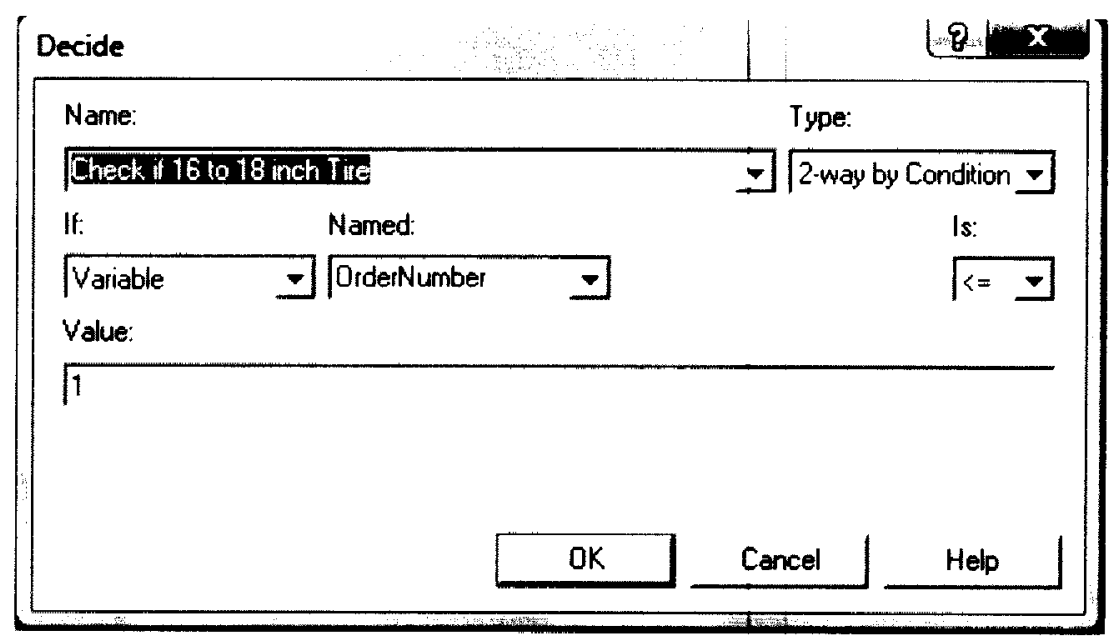

Figure 88. Decide Module: Check if 16 to 18 inch Tire 
Process Modules: "Inflate 16 to 18 inch Assembly" and "Inflate 19 to 20 inch Assembly":

An additional Inflation Station is added to the process for the 19-20 inch tires. The original is called "Inflator 1" and the new resource is called "Inflator 2". The processing times are the same for both the stations.

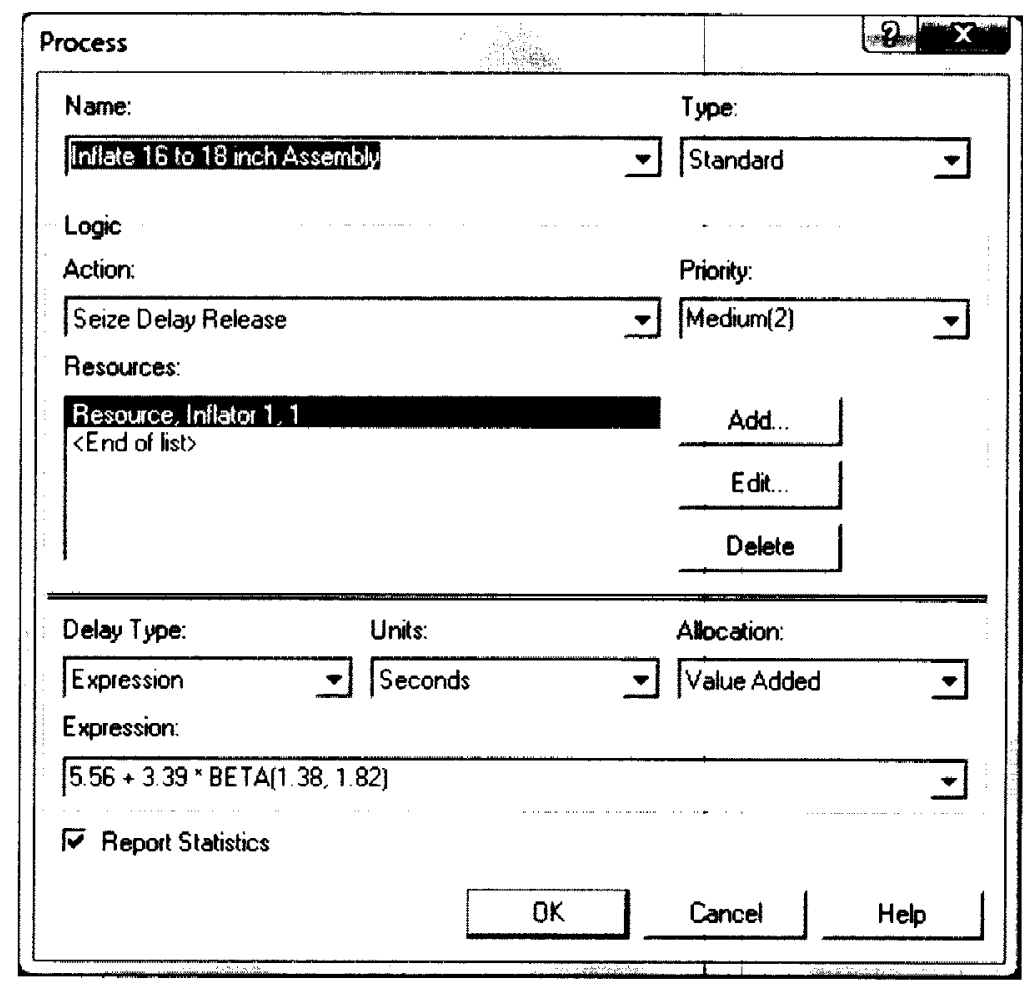

Figure 89. Process Module: Inflate 16 to 18 inch Assembly 


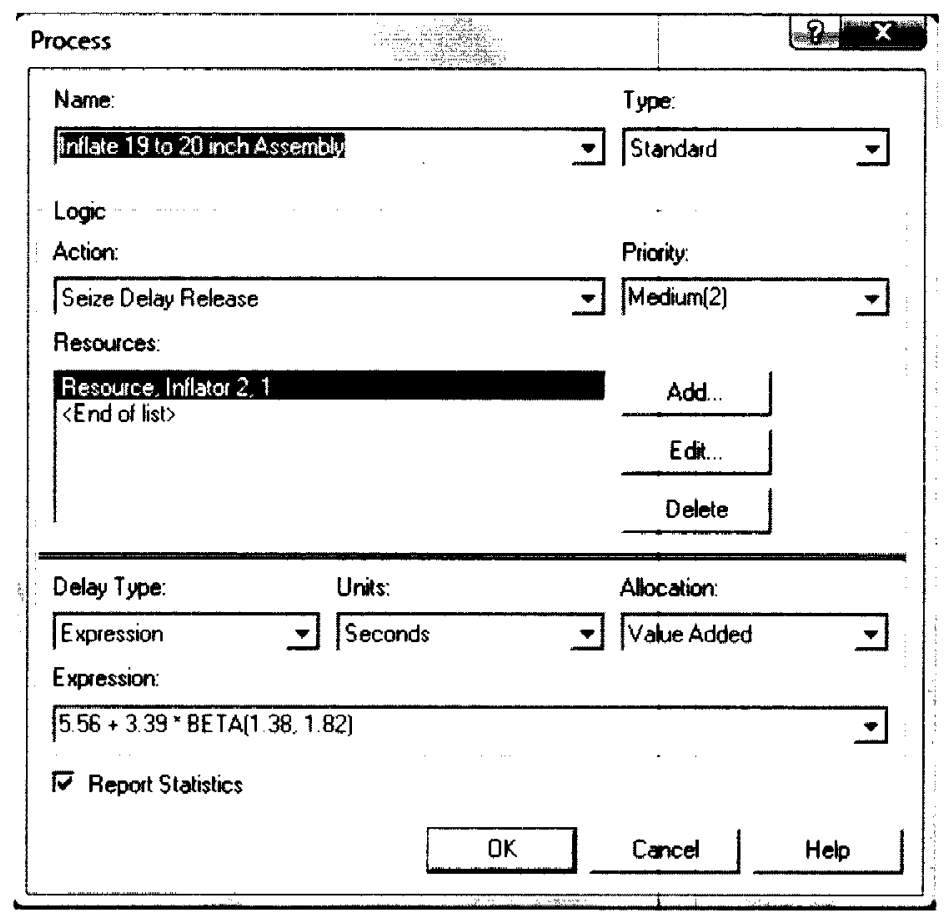

Figure 90. Process Module: Inflate 19 to 20 inch Assembly

Process Flowchart of Assembly and Inflation Submodel:

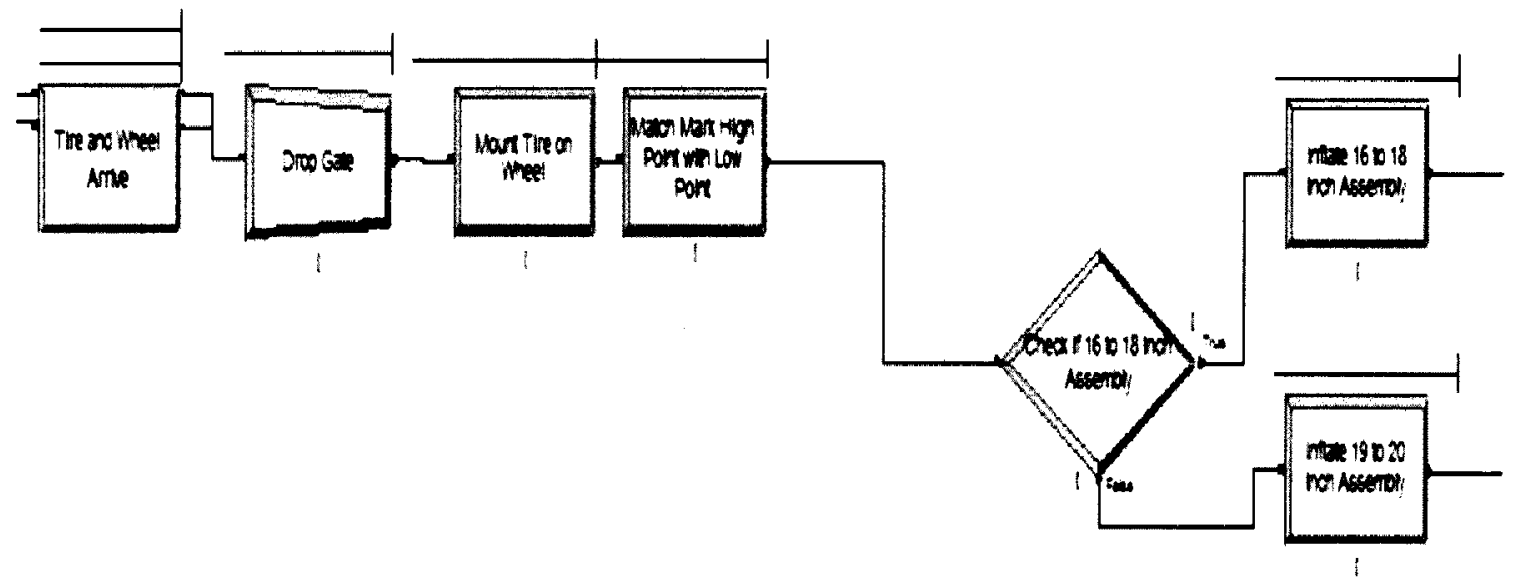

Figure 91. Assembly and Inflation Submodel 
SPARE ASSEMBLY OPERATIONS SUBMODEL

There are no changes here, as the spare tires variety does not change.

ROAD ASSEMBLY INSPECTION PROCESSES SUBMODEL

Process Modules: "Primary Balancer 1", "Primary Balancer 2" and "Audit Balancer"

The processing times in these stations change for different assembly sizes. The value of the processing times is defined by expressions, "PB1 Cycle Time", "PB2 Cycle Time" and "AB1 Cycle Time", assigned by assign modules: "Assign Assembly Characteristics 1" and "Assign Assembly Characteristics 2"

\section{FINAL SETS AND STORAGE SUBMODEL}

There are no changes incorporated here, as the variation in the conditions for these operations does not change considerably due to the new variety.

\section{DOWNTIME DATA FOR ALL RESOURCES}

Due to the addition of new resources, their downtimes (shown in the table below) will also be added to the existing process.

\begin{tabular}{|l|l|l|l|l|}
\hline Name & Type & Uptime & Downtime & Units \\
\hline T Soaper 2 Failure & Time & 1 & 0 & Hours \\
\hline T Soaper 1 Failure & Time & 1 & 0 & Hours \\
\hline Inflator 2 Failure & Time & 0.9971 & 0.0029 & Hours \\
\hline Inflator 1 Failure & Time & 0.9971 & 0.0029 & Hours \\
\hline
\end{tabular}

Table 7. Model 2: Downtime Data 


\section{CHAPTER V \\ OPERATIONS MODEL III}

\section{OVERVIEW}

Model 3 represents a set-up where changes have been made to the production line in order to accommodate both, the design and takt time needs. We do not change the run setup parameters from Model 2 because we must compare their performance under similar conditions.

\section{MODELING ASSUMPTIONS}

The following assumptions are made in the simulation model

- The existing equipment is capable of processing both, the current and new part sizes.

- We are considering changes made only to accommodate process parameters (processing time, waiting time in queue etc).

- The addition of new equipment and other changes do not affect the scrap and rework rate. However, downtimes of the new equipment are added to the current process.

- Processing Cost per second for the new variety increases at some resources due to additional investments made. 


\section{CHANGES FROM MODEL ॥}

- An audit balancer is added here to eliminate this bottleneck and meet takt time requirements.

\section{MODEL CONSTRUCTION AND APPROACH}

Model 3 has most modules similar to Model 2. The changes made to accommodate the new variety and cycle times are mentioned below.

\section{ORDER GENERATION SUBMODEL}

ReadWrite Module: Read Order Data

The file from which data is read is different here. This file contains data pertaining to the new variety as well and is named "Assembly orders3.xls".

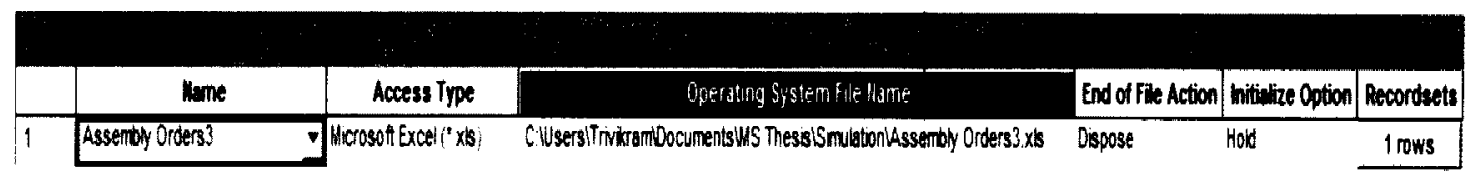

Figure 92. File Module: Read Order Data

Note that the Recordset Info does not change here except for the Recordset name as the order information is the same here as Model 2.

Assign Module: "Assign Assembly Characteristics 1" and "Assign Assembly Characteristics 2"

Here, each of the two Assign Modules, assign an additional cycle time to the new Audit Balancer station depending on the tire variety. 


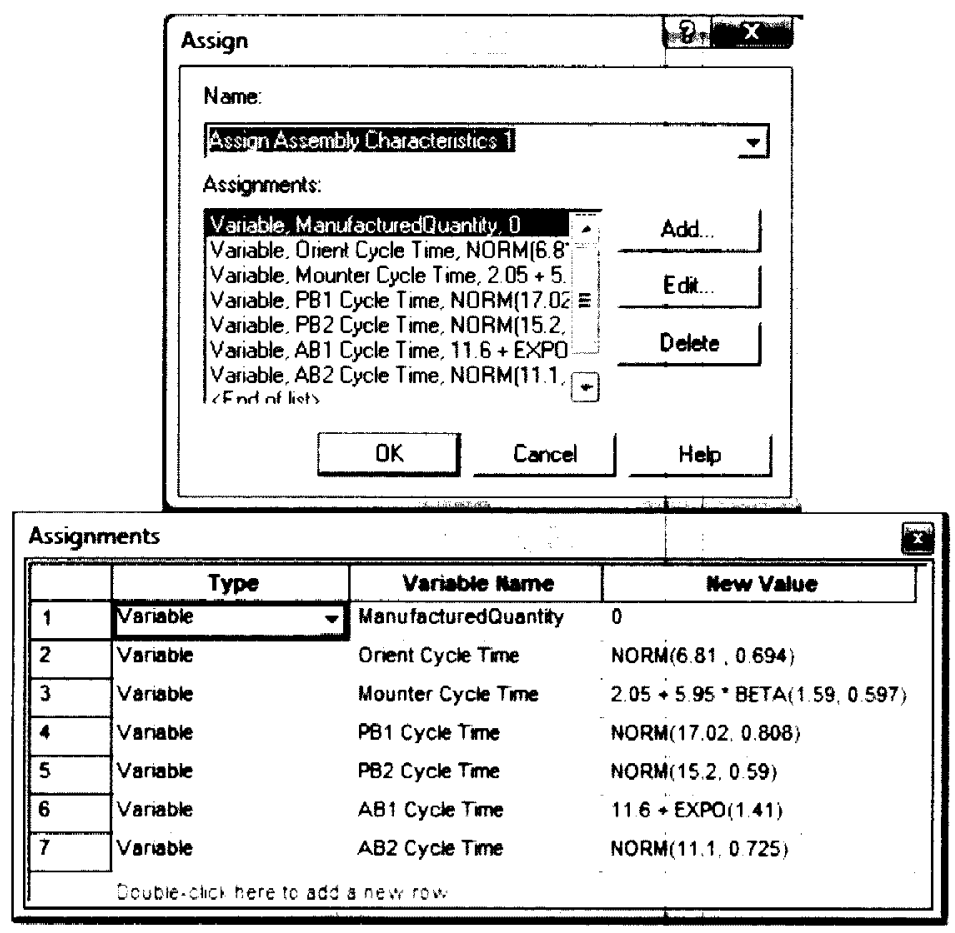

Figure 93. Assign Module: Assign Assembly Characteristics 1

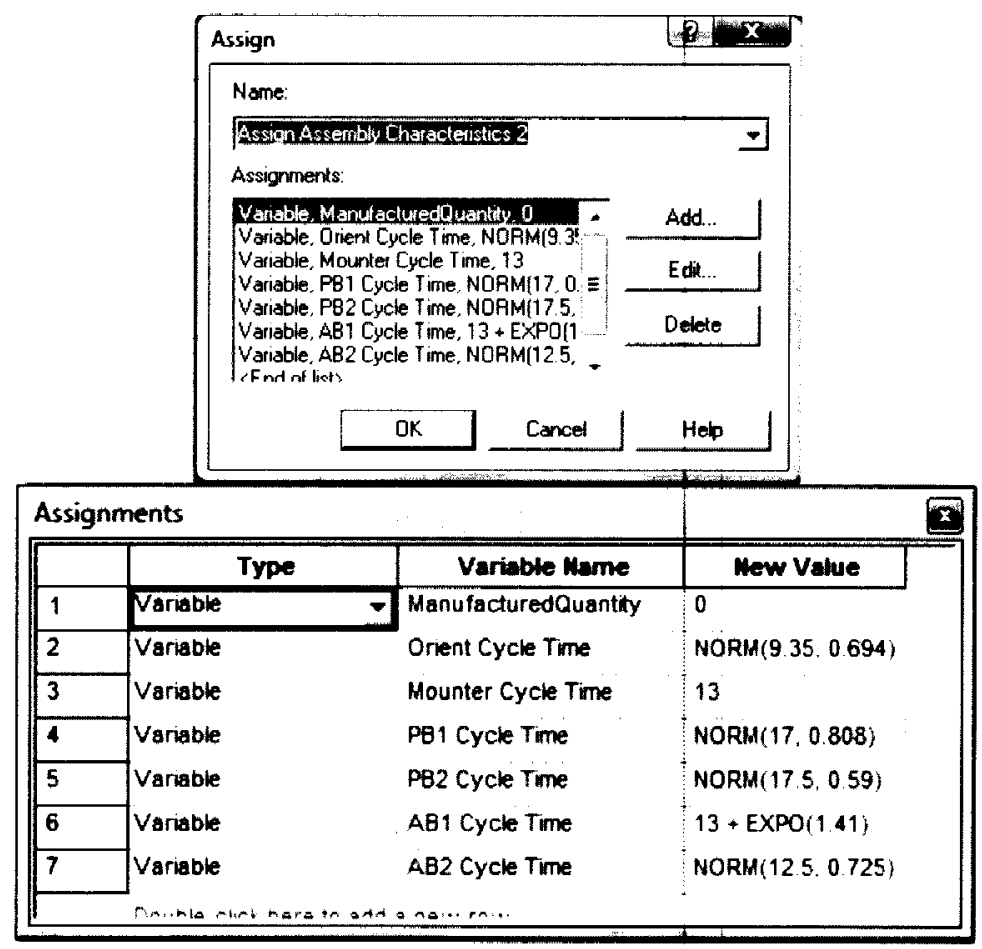

Figure 94. Assign Module: Assign Assembly Characteristics 2 


\section{TIRE LINE OPERATIONS SUBMODEL}

No additional changes were incorporated here from Model 2.

\section{WHEEL LINE OPERATIONS SUBMODEL}

No additional changes were incorporated here from Model 2.

\section{ASSEMBLY AND INFLATION SUB MODEL}

No additional changes were incorporated here from Model 2.

\section{SPARE ASSEMBLY OPERATIONS SUBMODEL}

No additional changes were incorporated here from Model 2.

\section{ROAD ASSEMBLY INSPECTION PROCESSES SUBMODEL}

Process Modules: "Audit Balancer 2"

Here an additional Audit Balancer was added as a parallel server to the existing station. Hence the existing Process module was renamed as "Audit Balancer 1" and the new station was named "Audit Balancer 2". The processing time of these two stations are assigned at the Assign Modules: "Assign Assembly Characteristics 1" and "Assign Assembly Characteristics 2" as expressions, "AB1 Cycle Time" and "AB2 Cycle Time" as per the variety being processed. 
Process Flowchart for new Road Assembly Inspection Process Submodel:

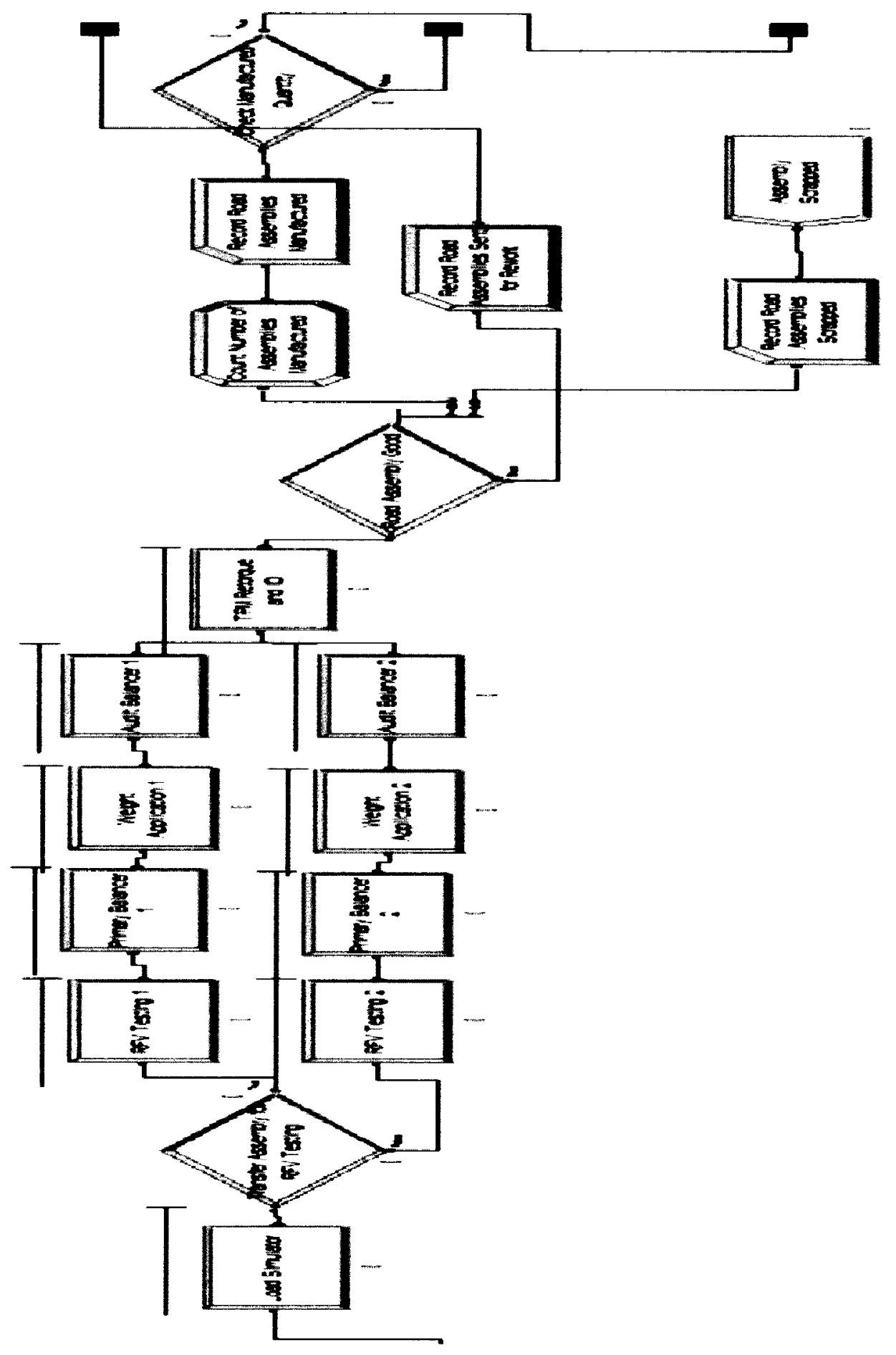

Figure 95. Road Assembly Inspection Process Submodel 
FINAL SETS AND STORAGE SUBMODEL

There are no changes incorporated into this Submodel.

DOWNTIME DATA FOR ALL RESOURCES

Due to addition of the new audit balancer (AB2) to accommodate takt time requirements of the new variety, their downtimes will also be added to the existing process.

\begin{tabular}{|c|c|c|c|c|}
\hline Name & Type & Uptime & Downtime & Units \\
\hline AB2 Failure & Time & 0.9987 & 0.0013 & Hours \\
\hline
\end{tabular}

Table 8. Model 3: Downtime Data

\section{DETERMINATION OF WARM UP PERIOD}

Total Average Utilization is used as a statistic to determine the warm up period for all three processes, by eyeballing the point in the simulation at which the process appears to become stable. The results obtained from the Arena Output Analyzer are shown in the figure below. 

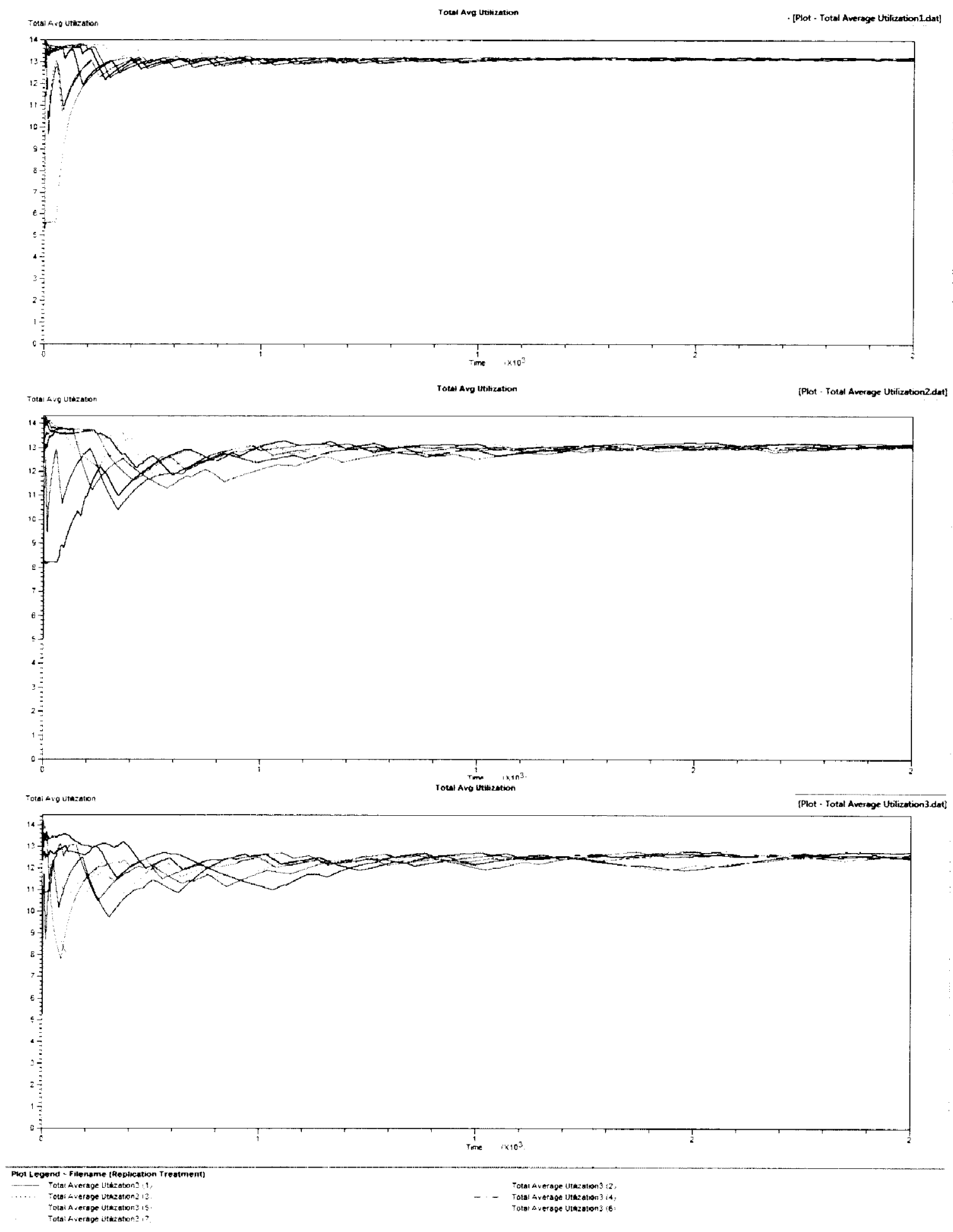

Figure 96. Total Average Utilization for all 3 models 


\section{CHAPTER VI}

\section{ANALYSIS OF RESULTS}

The 3 models are run for 10 replications with run length 200 days and a warm up period of 40 days.The results obtained for models 1,2 and are compared.

\section{COMPARISON OF RESULTS}

Production was scheduled to occur for 20 hours per day. The results are presented in the tables below:

\begin{tabular}{|c|c|c|c|}
\hline Entity & Model 1 & Model 2 & Model 3 \\
\hline Orders Processed & 543.7 & 387.80 & 461.80 \\
\hline Road Assemblies Manufactured & 763346.40 & 763023.20 & 765036.90 \\
\hline Road Assemblies Scrapped & 73747.70 & 73655.60 & 74012.00 \\
\hline Road Assemblies Sent for Rework & 14268.20 & 14311.40 & 14375.90 \\
\hline Spare Assemblies Manufactured & 191776.60 & 187403.40 & 190200.10 \\
\hline Spare Assemblies Scrapped & 18530.60 & 18106.90 & 18369.30 \\
\hline Spare Assemblies Sent for Rework & 3571.80 & 3493.10 & 3592.30 \\
\hline Total Assembly Sets Manufactured & 190961.50 & 189084.50 & 192077.40 \\
\hline Average Spare Tires in Inventory & 2425.28 & 2650.7 & 4156.74 \\
\hline
\end{tabular}

Table 9. Average Output Data for entities 


\begin{tabular}{|c|c|c|c|}
\hline Resource & Model 1 & Model 2 & Model 3 \\
\hline AB 1 & $96.15 \%$ & $98.75 \%$ & $35.98 \%$ \\
\hline AB 2 & --- & $\ldots$ & $54.56 \%$ \\
\hline Inflator 1 & $64.74 \%$ & $50.21 \%$ & $49.42 \%$ \\
\hline Inflator 2 & -- & $14.55 \%$ & $15.36 \%$ \\
\hline Labor 1 & $79.00 \%$ & $78.66 \%$ & $78.61 \%$ \\
\hline Labor 2 & $73.72 \%$ & $75.43 \%$ & $75.35 \%$ \\
\hline Labor 3 & $51.35 \%$ & $50.15 \%$ & $49.92 \%$ \\
\hline Labor 4 & $74.36 \%$ & $76.15 \%$ & $75.94 \%$ \\
\hline Labor 5 & $71.66 \%$ & $71.63 \%$ & $71.83 \%$ \\
\hline Labor 6 & $61.61 \%$ & $61.01 \%$ & $61.98 \%$ \\
\hline W Soaper & $93.44 \%$ & $93.47 \%$ & $93.39 \%$ \\
\hline Matcher & $59.38 \%$ & $59.39 \%$ & $59.42 \%$ \\
\hline Mounter & $58.90 \%$ & $72.05 \%$ & $73.16 \%$ \\
\hline Orient Station & $50.30 \%$ & $58.03 \%$ & $58.23 \%$ \\
\hline PB 1 & $47.21 \%$ & $46.00 \%$ & $45.89 \%$ \\
\hline PB 2 & $70.12 \%$ & $75.39 \%$ & $75.29 \%$ \\
\hline RFV 1 & $44.71 \%$ & $43.64 \%$ & $43.47 \%$ \\
\hline RFV 2 & $79.85 \%$ & $81.77 \%$ & $81.54 \%$ \\
\hline Simulator & $43.75 \%$ & $44.00 \%$ & $43.86 \%$ \\
\hline T Heater & $92.46 \%$ & $92.44 \%$ & $92.44 \%$ \\
\hline T Soaper 1 & $94.31 \%$ & $68.68 \%$ & $67.18 \%$ \\
\hline T Soaper 2 & --- & $25.62 \%$ & $27.11 \%$ \\
\hline
\end{tabular}

Table 10. Average Resource Utilization

\begin{tabular}{|c|r|r|r|}
\hline Entity & \multicolumn{1}{|c|}{ Model 1 } & \multicolumn{1}{c|}{ Model 2 } & \multicolumn{1}{|c|}{ Model 3 } \\
\hline Assembly Sets & 85.7415 & 813.86 & 279.10 \\
\hline Road TW Assembly Set & 211.41 & 2888.21 & 574.53 \\
\hline Tire & 7684.38 & 29168.22 & 8484.88 \\
\hline TW Assembly & 7516.96 & 29481.07 & 8339.87 \\
\hline Wheel & 7548.89 & 28879.46 & 8387.77 \\
\hline
\end{tabular}

Table 11. Process WIP 


\begin{tabular}{|c|c|c|c|}
\hline Operation & Model 1 & Model 2 & Model 3 \\
\hline Audit Balancer 1 & 51333.70 & 166288.77 & 14.2186 \\
\hline Audit Balancer 2 & --- & -- & 11.9138 \\
\hline Film Application & 8.0568 & 8.0984 & 8.0697 \\
\hline Full Set and Stock & 5165.47 & 49722.07 & 17103.04 \\
\hline Inflate 16 to 18 inch Assembly & 7.1414 & 543.75 & 533.75 \\
\hline Inflate 19 to 20 inch Assembly & --- & 7.0044 & 7.0040 \\
\hline Load Simulator & 5.9608 & 5.9921 & 5.9939 \\
\hline Load Stem & 156.25 & 170.69 & 129.29 \\
\hline Load TPM & 20.9091 & 20.8800 & 20.7353 \\
\hline Match Mark High Point with Low Point & 6.5125 & 398.68 & 417.19 \\
\hline Mount Tire on Wheel & 6.8854 & 10428.70 & 10034.89 \\
\hline Primary Balancer 1 & 17.8555 & 602.70 & 609.15 \\
\hline Primary Balancer 2 & 16.0461 & 1492.14 & 1311.99 \\
\hline RFV Testing 1 & 16.9668 & 1949.55 & 1847.57 \\
\hline RFV Testing 2 & 61.5231 & 62.0298 & 62.0949 \\
\hline Tire Heater & 77.0212 & 76.5035 & 76.3845 \\
\hline 16 to 18 inch Tire Soaper & 32.0492 & 33.8263 & 32.3055 \\
\hline 19 to 20 inch Tire Soaper & --- & 29.0425 & 29.8366 \\
\hline TPM Retorque and ID & 9.7172 & 9.7169 & 819.04 \\
\hline TPM Scan and Torque & 59.1749 & 58.8713 & 59.9031 \\
\hline Weight Application 1 & 21.3778 & 936.31 & 723.75 \\
\hline Weight Application 2 & 23.1230 & 46.0601 & 55.8564 \\
\hline Wheel Orient & 6.8122 & 18.1818 & 23.0179 \\
\hline Wheel Soaper & 21.5741 & 22.4161 & 23.4580 \\
\hline & & & \\
\hline & & \\
\hline
\end{tabular}

Table 12. Average Operation Total Times (seconds)

\begin{tabular}{|c|c|c|c|c|}
\hline $\begin{array}{c}\text { Time } \\
\text { Classification }\end{array}$ & $\begin{array}{c}\text { Manufactured } \\
\text { Entity }\end{array}$ & Model 1 & Model 2 & Model 3 \\
\hline $\begin{array}{c}\text { Value Added } \\
\text { Time }\end{array}$ & Assembly Sets & 520.38 & 532.25 & 533.07 \\
\cline { 2 - 5 } & TW Assembly & 94.9852 & 97.4659 & 97.6108 \\
\hline $\begin{array}{c}\text { Non Value Added } \\
\text { Time }\end{array}$ & Assembly Sets & 210.24 & 213.62 & 209.04 \\
\cline { 2 - 5 } & TW Assembly & 41.9922 & 42.8516 & 41.8538 \\
\hline \multirow{2}{*}{ Waiting Time } & Assembly Sets & 412865.73 & 1128518.05 & 402607.77 \\
\cline { 2 - 5 } & TW Assembly & 49948.84 & 159277.97 & 21761.62 \\
\hline
\end{tabular}

Table 13. Average Time Allocation for Manufactured Entities (seconds) 


\begin{tabular}{|c|c|}
\hline & Spare Tire Inventory \\
\hline Model 1 & 2425.28 \\
\hline Model 2 & 2650.7 \\
\hline Model 3 & 4156.74 \\
\hline
\end{tabular}

Table 14. Average Spare Tires in Inventory During Process

\section{STATISTICAL INFERENCE}

The comparison of the model output in Table 9 shows that Model 1 performs better than the other two in terms of the number of orders processed at the end of the simulation. However, when we look at the total assembly sets manufactured, Model 3 is the best performer and Model 2 is the least efficient. Also, from the average assembly sets manufactured numbers we can compute the average cycle time per assembly for the 3 Models using the formula from the model validation section.

The average cycle time values obtained are displayed below:

$$
\begin{aligned}
& \text { Model } 1=\quad 12.06526 \text { seconds } \\
& \text { Model 2= } \quad 12.18503 \text { seconds } \\
& \text { Model 3= } \quad 11.99516 \text { seconds } \\
& \text { Table 15. Average Cycle Times }
\end{aligned}
$$

. From a high-level view, the difference between the average cycle times in the three models might seem minimal, but for a facility manufacturing around 10,000 assemblies a day, these cycle times can quickly compound, resulting in significant overtime labor and high operating expense. The average cycle times show that both models 1 and 2 will not be able to meet the company's takt time 
of 12 seconds with the new variety. Model 3 only marginally meets the takt time requirements. So additional modifications might be required to model 3 to increase the positive gap between takt time and average cycle time. This would usually necessitate added investments to the company.

Results from Table 10 for average resource utilization show that with the new variety entailing changes and additions to existing equipment, equipment utilization for most machines has dropped from Model 1 to Model 3. Specially, the stations such as the audit balancer, inflator and tire soaper show a steep drop in utilization. For example, the Audit Balancer Station went from being at a high utilization of more than $96 \%$ in Model 1 , to an average utilization of around $45 \%$ in Model 3 due to the addition of anther unit to meet takt time requirements. Similar observations are made for the inflator and tire soaper (t soaper) stations.

Also, the average WIP inventory in Table 11 seems to go up significantly when changes were made only to accommodate design requirements. WIP inventory for final products (assembly sets and road tire wheel assembly sets) increased by more than ten times in Model 2 and parts WIP inventory (tire, wheel and tire wheel assembly) quadrupled in the model as compared to Model 1. This was mitigated a little with the equipment additions (audit balancer) in model 3. However, Model 1 is observed to be the one with least WIP inventory.

The total time an entity spends at an operation (includes waiting time and actual processing time) shown in Table 12 seems to be very high for some operations, specially, at the Audit Balancer and Full Set and Stock operations in Model 1. This condition worsened drastically in Model 2 for more than half of the 
operations (ex: audit balancer, full set and stock, match marking and mounting operations) when the new variety was added. However, with the addition of a new unit at the Audit Balancer Operation, waiting times almost seem to vanish at this station. However, this addition did not have a similar mitigating affect on the total times at the other stations. This validates the point that additional adjustments will be required to reduce total times and meet production targets.

When we look at the manufacturing time classifications for the final products in Table 13, we can see that, while value added and non value added times remain close to constant for all the three models, there is a severe increase in total waiting times for the entities. This can be attributed to the increase in processing times and failures due to the new equipment changes.

Also, Table 14, showing the average spare tire inventory in the system for the three models shows that, spare tire inventory maintained, steadily increases in successive models to the point where it almost doubles for Model 3. High WIP and inventory will result in large storage and operating costs.

From the above observations it is concluded that with the addition of new variety, process changes just to meet production requirements are not sufficient. Several other modifications or additions are required to equipment, layout, scheduling and other process performance parameters to improve performance. The company that facilitated this research estimates that an investment of approximately $\$ 5.34$ million would be required to go from the scenario in Model 1 to that in Model 3. With an investment of this magnitude, even though performance measures such as average cycle time improved marginally, these 
additional, but occasionally used resources result in high WIP inventory, lower resource utilization and increased waiting times and parts inventory. Another observation made was that, while Model 1 seemed to have consistent results for all ten replications, there seemed to be a lot of variability among replications in the key performance measure values shown for Models 2 and 3 . This provides proof that system variability increased significantly due to product mix and equipment changes. According to six sigma principles, this variability is the number one enemy of for industries and can result in severe product and process quality issues. So, the companies need to make these trade-offs between production, variability and cost targets and reach an optimal manufacturing scenario. 


\section{CHAPTER VII CONCLUSIONS AND SUMMARY}

An objective of this thesis was to capture the effect of product variety on key performance measures in the manufacturing environment. The facility where this research was conducted has already employed several lean strategies such as JIT manufacturing, pull inventory systems, zero setup times and flexible automation. Previous research suggests, that these strategies can have an assuaging effect on a facility's production performance when new product variety is introduced. While, for a non "lean" facility, the effect of product proliferation can be disastrous as indicated by earlier studies, our simulation models show that even with the application of some lean manufacturing principles such as one piece flow, some key production performance parameters can deteriorate with changes in product mix. The need to manufacture greater variety can force a facility to add more resources to meet production requirements and demand rate, which can reduce machine utilizations and create new bottlenecks in the process. Thus a relatively simple and lean manufacturing process can get very complicated and create unstable outputs, which is believed to be the root cause for quality problems. Thus an initiative made to increase production, market share and profits can end up creating losses for a company if some of the above 
issues and future implications are not considered before making these investments.

Also, we observed during our data collection that, as Child et al (1991) suggest, a majority of the orders received by the facilitating company were from a smaller sample of the total variants it offers. So, with the introduction of new configurations, which can have different characteristics associated with it (such as increased dimensions and weight in this case), recognizing the top 20 to 30 percent variety which has the highest impact on a company's business in terms of sales and investments, and making trade-off decisions based on this will be vital. Simulation, can act as a decisive tool in such cases giving an insight to the long-term effects of product variety before it is actually introduced into the system.

\section{FUTURE RESEARCH}

We believe, this research strongly advocates the use of simulation to assess the future impact of changing product variety instead of analyzing this effect after introducing new variants into the system. However, due to time constraints and the need to keep the model simple and more generic, some of the complexities in the manufacturing environment such as transfer time between stations, finite queue lengths and raw material availability were not included in this model. Also, the scrap and rework rates are considered to be consistent for all the three models. The variability in these metrics in the real world could also have a significant impact on the effects due to product variety. 
The use of discrete-event simulation as a proactive tool in assessing the effect of product variety can be extended to other manufacturing and nonmanufacturing industries. One observation that was made during the literature review of this thesis was that, the issues caused due to product variety and solutions provided to tackle them can be fairly industry specific. Hence, one of the potential areas for further study can be on how simulation models can be generalized further so as to accommodate more manufacturing and nonmanufacturing environments into a model and absorb changes due to variety more effectively. Also, more research can be conducted on the effect of product variety on the process with variable scrap and rework rates, presence of set-up times and including time dedicated to non-production activities such as maintenance downtimes and line stoppages. These would give a further insight to the impact of product proliferation on the industry and when combined with market analysis data can be used as a means to assess business risks and return on Investments more effectively. 


\section{REFERENCES}

Randall, Taylor, and Karl Ulrich [2001] Product variety, supply chain structure, and firm performance: analysis of the U.S. bicycle industry, Management Science, Vol. 47, No. 12, December, pp.1588-1604

Patrik Appelqvist "Matching customer demand, offering portfolio and operations system in technology-intensive industries". Doctoral dissertation series 2005/5 ISBN 951-22-7915-0

Amit Garg and Hau L Lee (1999) "MANAGING PRODUCT VARIETY: AN OPERATIONS PERSPECTIVE", Quantitative Models for Supply Chain Management by Sridhar Tayur, Ram Ganeshan, Michael Magazine, pp. 467-490

Aimao Zhang, Arlyn Melcher, Ling Li, "Mapping the relationships among product complexity, information technology, and transaction governance structure", Journal of the Academy of Business and Economics, March, 2003

Child, P., R. Diederichs, F. H. Sanders, S. Wisniowski. 1991. SMR forum-The management of complexity. Sloan Management Rev. 33(1) 73-80.

Sivadasan, S., Efstathiou, J., Calinescu, A., Schirn, J. and Fjeldsoe-Nielsen, L. (2000). "The Costs of Complexity", Manufacturing Engineer, Vol 79, No 3, pp. 109-112.

Fisher, M. L., C. Ittner. 1999. The impact of product variety on automobile assembly operations: Empirical evidence and simulation analysis. Management Sci. 45(6) 771-786.

KEKRE, S. And SRINIVASAN, K., "Broader Product Line: A Necessity to Achieve Success?" Management Science, Vol. 36, No. 10, October 1990, pp. 1216-1231.

MacDuffie, J. P., K. Sethuraman, M. L. Fisher. 1996. Product variety and manufacturing performance: Evidence from the International Automotive Assembly Plant Study. Management Sci. 42(3) 350-369

Lisa H. Harrington, "Reducing Complexity" February, 2006. Inbound Logistics:

Feature Story:

http://www.inboundlogistics.com/articles/features/0206_feature02.shtml 
Ramesh Srinivasan and Jayashankar M Swaminathan ("Managing configurable products in the computer industry: Planning and coordination issues", Sadhana, Volume 22, Number 1 / February, 1997; pp 33-43

Fisher, M., Jain, A., MacDuffie, J. (1995), "Strategies for product variety: lessons from the auto industry", in Bowman, E., Kogut, B. (Eds), Redesigning the Firm, Oxford University Press, New York, NY, pp.116-54

Swaminathan, J.M. and T.R. Nitsch, "Managing Product Variety in Automobile Industry: The Importance of the Sequencing Point," Interfaces 37, No. 4, pp. 324333, July-August 2007.

CANDACE ARAI YANO AND RAM RACHAMADUGU, "Sequencing to minimize overload in assembly lines with product options", MANAGEMENT SCIENCE, Vol. 37. No, 5. May 1991, pp. 572-586

Pil, F.K., M. Holweg, "Linking Product Variety to Order-Fulfillment Strategies," Interfaces 34, Sept.-Oct. 2004, pp. 394-403.--this one might be very relevant

Jay Jina, Arindam K. Bhattacharya and Andrew D. Walton, "Applying lean principles for high product variety and low volumes", Logistics Information Management. Volume $10 \cdot$ Number $1 \cdot 1997 \cdot 5-13$

Lee, H. L. and C. S. Tang [1997]. Modeling the costs and benefits of delayed product differentiation, Management Science, Vol. 43, No. 1, pp. 40-53.

Shang-Tae Yee: Simulation applications in the automotive industry: establishment of product offering and production leveling principles via supply chain simulation under order-to-delivery environment. Winter Simulation Conference 2002: 1260-1268

NOVAK, S. AND S. D. EPPINGER (2001), "Product Complexity and the Supply Chain", Management Science, 47, 1, 189-204.

Tynjälä, T. and Eloranta, E. (2007) 'Investigating the effect of product variants, and demand distributions on the optimal demand supply network setup', Production Planning \& Control, 18:7, $561-572$

Randall, Taylor, and Karl Ulrich [2001]. Product variety, supply chain structure, and firm performance: analysis of the U.S. bicycle industry, Management Science, Vol. 47, No. 12, December, pp.1588-1604.

Loveland, J.L., S.K. Monkman, and D.J. Morrice, "Dell Uses a New Production Scheduling Algorithm to Accommodate Increased Product Variety," Interfaces 37, No. 3, pp. 209-219, May-June 2007. 
Danese, P., P. Romano, "Finn-Power Italia Develops and Implements a Method to Cope with High Product Variety and Frequent Modifications," Interfaces 35, November-December 2005, pp. 449-459

Er, Mahendrawathi.; MacCarthy, B.(2006)., "Managing Product Variety in Multinational Corporation Supply Chains: A Simulation Study", International Journal of Manufacturing Technology and Management, Vol.17 (8), pp. 117-138. 


\section{CURRICULUM VITAE}

\section{TRIVIKRAM H RAO}

\section{EDUCATION}

M.S. in Industrial Engineering

Jan '07-Present

University of Louisville, Louisville, KY

B.S. in Mechanical Engineering

Sep ‘01-July '06

Vishveshwariah Technological University, Bangalore, India

\section{WORK EXPERIENCE:}

Caterpillar Production Systems(CPS) Division, Caterpillar Inc, Mossville, IL

Corporate Intern-Engineering

Aug '08 to Dec '08

Corporate Intern-Engineering-Assembly Technology

May '08 to Aug '08

EnovaPremier LLC, Louisville, KY

Engineering Intern

Feb '08 to May '08 
Industrial Engineering Department, University of Louisville, Louisville, KY

Graduate Research Assistant

Graduate Teaching Assistant

Hewlett Packard Inc., Bangalore, India

Sales Engineer

Dell International Services, Bangalore, India

Sales Engineer
Apr '03 to Sep '03

Aug '07 to Present

May '07 to Aug 07

Jul '06 to Dec '06

\section{HONORS \& PROFESSIONAL LICENSE:}

Graduate Teaching Assistantship-University of Louisville

Graduate Research Assistantship-University of Louisville

Six Sigma Green Belt Certification-Caterpillar Inc

National Meting Presentations:

1. Rao, T., Heragu, SS., Evans, G.,(2007-2008). "Quantifying The Costs and Benefits of Product Variety on Key Performance Measures". CELDi National Conference poster presentation, October 30, 2007, Atlanta; April 17, 2008, Chicago; October 29, 2008, Dallas.

May '07

Aug '07

Jul ‘08 